\title{
Ab initio studies on the photodissociation dynamics of the 1,1-difluoroethyl radical
}

\section{Journal Article}

Author(s):

Fritsche, Lukas; Bach, Andrea; Chen, Peter

Publication date:

2018-02-28

Permanent link:

https://doi.org/10.3929/ethz-b-000249991

Rights / license:

In Copyright - Non-Commercial Use Permitted

Originally published in:

The Journal of Chemical Physics 148(8), https://doi.org/10.1063/1.5007152 


\title{
$A b$ initio studies on the photodissociation dynamics of the 1,1- difluoroethyl radical
}

\author{
Lukas Fritsche, Andreas Bach and Peter Chen \\ Laboratorium für Organische Chemie, ETH Zurich, Wolfgang-Pauli-Strasse 10, \\ CH-8093 Zürich, Switzerland
}

\begin{abstract}
BOMD trajectory calculations at the HCTH147/6-31G** level of theory simulate the dissociation dynamics of photolytically excited 1,1-difluoroethyl radicals. EOMCCSD/AUG-cc-pVDZ calculations show that an excitation energy of $94.82 \mathrm{kcal} / \mathrm{mol}$ is necessary to initiate photodissociation reactions. In contrast to photodissociation dynamics of ethyl radicals where a large discrepancy between actual dissociation rates and rates predicted by statistical rate theories, we find reaction rates of $5.1 \cdot 10^{11} \mathrm{~s}^{-1}$ for the dissociation of an $\mathrm{H}$ atom, which is in perfect accordance to what is predicted by RRKM calculations and there is no indication of any nonstatistical effects. However, our trajectory calculations show a much larger fraction of C-C bond breakage reaction of 56\% occurring than expected by RRKM (only $16 \%$ ).
\end{abstract}

\section{INTRODUCTION}

The 1,1-difluoroethyl radical is an interesting model compound for the ethyl radical with two hydrogen atoms substituted by fluorine. Ethyl radicals play an important role in combustion processes and are important intermediates in hydrocarbon crackers. Ethene is formed from ethyl radicals through the loss of a hydrogen atom and features a key role in petrochemical industry. Therefore, the

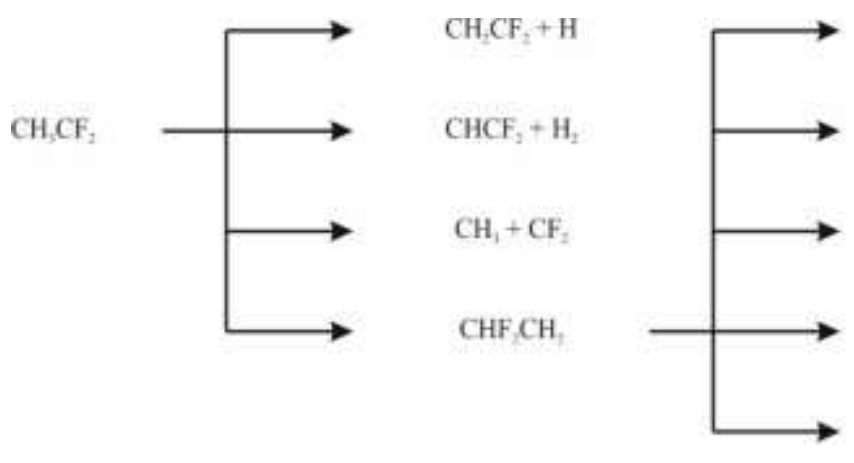

conclusion that the dissociation of ethyl radicals must possess nonstatistical dynamics.

The intention of this work is thus to compare dissociation reactions of the 1,1-difluoroethyl radical with those occurring from ethyl radicals to explore the impact of substitution with fluorine on the statistical behavior of the decomposition. We explore the dissociation of 1,1difluoroethyl radical by comparing RRKM kinetics and Born-Oppenheimer Molecular Dynamics (BOMD)

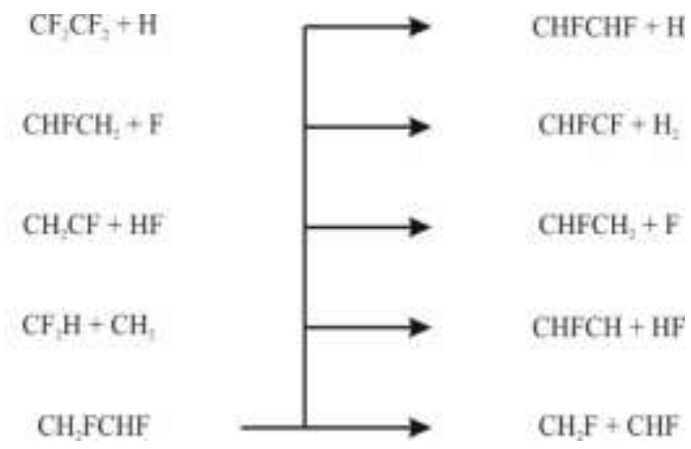

FIG. 1 Dissociation products of the 1,1-difluoroethyl radical. Due to the substitution with fluorine, much more reaction channels exist than for the dissociation of unsubstituted ethyl radicals.

kinetics of this reaction is of high interest and it is not surprising that the dynamics of this reaction has been investigated extensively in photodissociation experiments ${ }^{1-7}$ and in theory ${ }^{8-11}$.

Dissociation dynamics of the ethyl radical have been studied by Hase et al with chemical dynamics simulations. Although the dynamics of the dissociation reaction have been found to be in accord with the Rice-RamspergerKassel-Marcus (RRKM) theory ${ }^{12-15}$, the classical microcanonical rate constants have been found to be much smaller than predicted by RRKM due to anharmonicity. Inconsistancies between theoretical and experimental thermal kinetics remain for the $\mathrm{H}+\mathrm{C}_{2} \mathrm{H}_{4} \rightleftarrows \mathrm{C}_{2} \mathrm{H}_{5}$ association and dissociation reactions ${ }^{16,17}$. Furthermore, recent work in our group simulated the dissociation process with direct dynamics classical trajectory calculations resulting in a number of trajectories with a much longer lifetime than predicted by RRKM ${ }^{18,19}$. This leads to the trajectory simulations.

In this work we simulate a photodissociation process, where a photon excites the 1,1-difluoroethyl radical to an excited state, which yields the required reaction energy for the dissociation after internal conversion. Thus, we calculate the excitation energy of 1,1-difluoroethyl radical to this first excited (3s) Rydberg state. Within the RRKM approach we expect that after excitation the dissociations proceed by internal conversion to the ground state. The ground state PES covers the 1,1-difluoroethyl radical plus dissociation products and transition states. In comparison with the ethyl radical, the 1,1-difluoroethyl radical exhibits more decomposition pathways as displayed in Figure 1, including dissociation of fluorine atoms, hydrogen fluoride as well as $\mathrm{H}$ shift and $\mathrm{F}$ shift reactions.

We intend to take into account all possible reaction channels for a proper investigation of the dissociation of 1,1-difluoroethyl radicals and explore whether the dissociation to other products can compete with the 
formation of 1,1-difluoroethene and affect the kinetics of the overall decomposition. Other publications show that there are other important reaction channels in the decomposition of similarly sized hydrocarbon radicals ${ }^{20}$.

\section{COMPUTATIONAL METHODS}

We simulate the photodissociation dynamics of the 1,1difluoroethyl radical two theoretical models, the harmonic Rice-Ramsperger-Kassel-Marcus (RRKM) theory approach based on computationally derived energy surfaces and Born-Oppenheimer Molecular Dynamics (BOMD) trajectory calculations.

For the statistical modeling of photodissociation rates, we use the MultiWell software package ${ }^{21-23}$ that is based on the RRKM model. The software tool DenSum provides exact counts for sums and densities of states using the Stein-Rabinovitch extension ${ }^{24}$ of the Beyer-Swineheart algorithm ${ }^{25}$. As a data input, reaction paths need to be defined within the reaction system. The program requires inputs of relative energies of products and activation energies of reaction intermediates (wells).We consider paths leading to a well as reversible and reactions to a dissociation product as irreversible. Barrierless dissociations such as the $\mathrm{C}-\mathrm{C}$ bond cleavage are treated in a loose transition state model that is employed in the CRUNCH data analysis program ${ }^{26-28}$ Rates of the barrierless dissociations generated by the CRUNCH data analysis program serve as input to the MultiWell program package. We discuss the suitability of this method in the Results part.

To generate the required PES, we optimize all structures using a Hamprecht-Cohen-Tozer-Handy functional ${ }^{29}$ with a relatively small basis set $\left(\mathrm{HCTH} 147 / 6-31 \mathrm{G}^{* *}\right)$. Density functional theory (DFT) calculations are performed with GAUSSIAN $09^{30}$. This method should be sufficient for an accurate structure determination. Previous work on the ethyl radical ${ }^{31}$ shows that this functional reproduces energies obtained using $\operatorname{CCSD}(\mathrm{T})$ extrapolated to the complete basis set (CBS) limit, exceptionally well. In addition, the structures of some key components are optimized by the more accurate CCSD(T)/cc-pVTZ ${ }^{32}$ level of theory and show a very small deviation in terms of atomic coordinates compared to the DFT-optimized structures (see appendix). Single point calculations at the CCSD(T)/cc-pVTZ level of theory refine the energy levels of all structures in the reaction system. We use both, the GAUSSIAN 09 and the CFOUR program package ${ }^{33}$ to perform calculations at the coupled cluster level of theory. There are no differences in energies that can be assigned to the choice of the program package. Single point energies of all structures occurring in the most probable reaction channels are determined using CCSD(T)/cc-pVTZ-F12 calculations and the resulting relative energies for the relevant reaction channels are compared to the ones obtained using the smaller cc-pVTZ basis set in the coupled cluster methods. The UCCSD(T)/cc-pVTZ-F12 is implemented in the MOLPRO ${ }^{34-36}$ program package and is considered to yield reliable estimations of energies at the (CBS) limit.
We use the HCTH147/6-31G** method for a frequency analysis to derive the vibrational frequencies for the zeropotential-energiy (ZPE) corrections. To determine the excitation energy of $94.8 \mathrm{kcal} / \mathrm{mol}$, we optimize the structure of the 1,1-difluoroethyl radical in the first excited state using the equation of motion coupled cluster theory with singles and doubles excitations with an augmented correlation consistent double zeta valence basis set (EOMCCSD/AUG-cc-pVDZ).

In a Born-Oppenheimer molecular dynamics approach at the HCTH147/6-31G** level of theory we simulate 500 trajectories of the 1,1-difluoroethyl radical. We generate a microcanonical ensemble which is excited by the same excitation energy that is used in the RRKM approach and read in the resulting initial Cartesian coordinates and velocities externally using quasiclassical normal mode sampling ${ }^{18}$. The maximum number of steps for the BOMD trajectories is $20^{\prime} 000$. An interfragment gradient of $3 \cdot 10^{-5}$ to $3 \cdot 10^{-7}$ serves as additional stop criterium. We evaluate trajectories manually and assign each of them to a certain reaction path. A FORTRAN program integrates the state probabilities in time steps of $0.1 \mathrm{ps}$.

Regarding the computational costs for the BOMD trajectory calculation, we are bound to the more resource efficient DFT-methods instead of an ab initio approach. Since for similar systems, the HCTH147 functional has been shown to reproduce energies obtained by $\operatorname{CCSD}(\mathrm{T})$ extrapolated to the CBS limit very well ${ }^{31}$, it has been used for this study as well. Use of the same functional and basis set for both ways of determining the photodissociation rates allows a good comparability.

\section{RESULTS}

\section{A. Potential energy surfaces}

The high excitation energy of $94.8 \mathrm{kcal} / \mathrm{mol}$ used for the simulation of the dissociation dynamics render reaction channels other than the dissociation of a hydrogen atom with a dissociation energy of $39.8 \mathrm{kcal} / \mathrm{mol}$ possible. Figures 1-3 give an overview over the possible dissociation channels of 1,1-difluoroethyl radical. The number in brackets is an index for the reactions or rather the reaction products, where the reactant holds number (0). The fluorine substituents largely destabilize the carbon-carbon bond and make the fission of this bond (3) more likely. Furthermore, instead of the loss of a hydrogen atom, the molecule could undergo a 1,2-hydrogen shift.

Other than in the ethyl radical, where such a shift reaction just generates the starting material, in the 1,1difluoroethyl radical, the product of the shift is not the same as the starting material and opens a large variety of sequential reactions. FIG. 2 shows possible dissociation reactions of the 1,1-difluoroethyl radical after a 1,2hydrogen shift (5)-(9). Dissociation of H-radical again results in the formation of 1,1-difluoroethene, reaction products (1) and (5) are the same but different starting materials and transition states. In addition to the reaction types that are already discussed in Figure 1, one now has to take into account fluorine radical dissociations (6) and the elimination of hydrogen fluoride (7). 


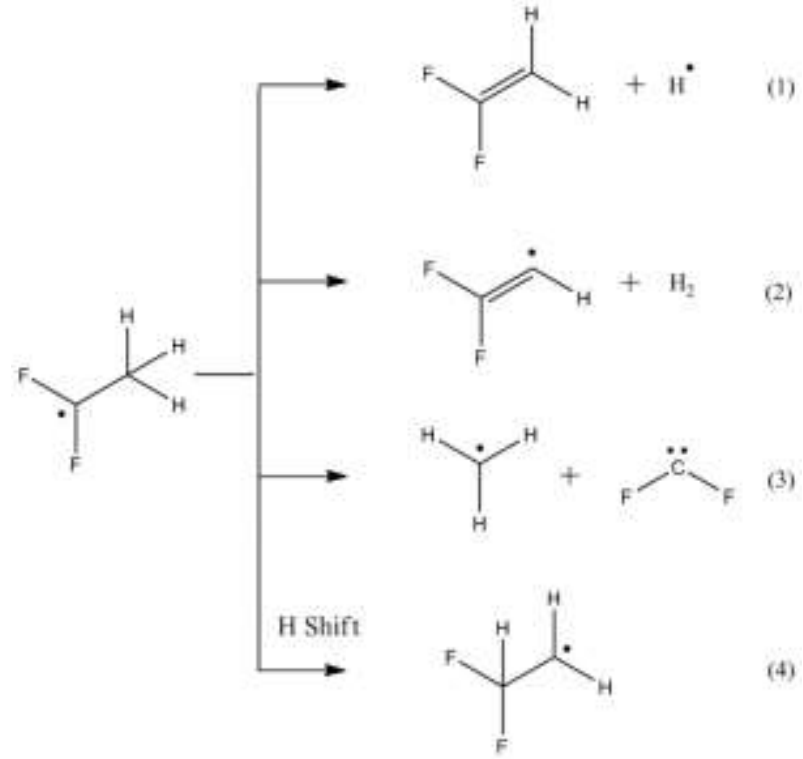

FIG. 2: Reaction channels of the photolytically excited 1,1 difluoroethyl radical including $\mathrm{H}$ radical dissociation, $\mathrm{H}_{2}$ elimination, C-C bond breakage and 1,2-H shift.

Yet another reaction channel opens with the formation of (4), the 1,2-F-shift reaction leading to the formation of 1,2-difluoroethyl radical (9) and thus yet to another bunch of possible reactions, which are drawn in Figure 3 (10)(17). The types of reactions are the same as already described so far in Figures 1 and 2.

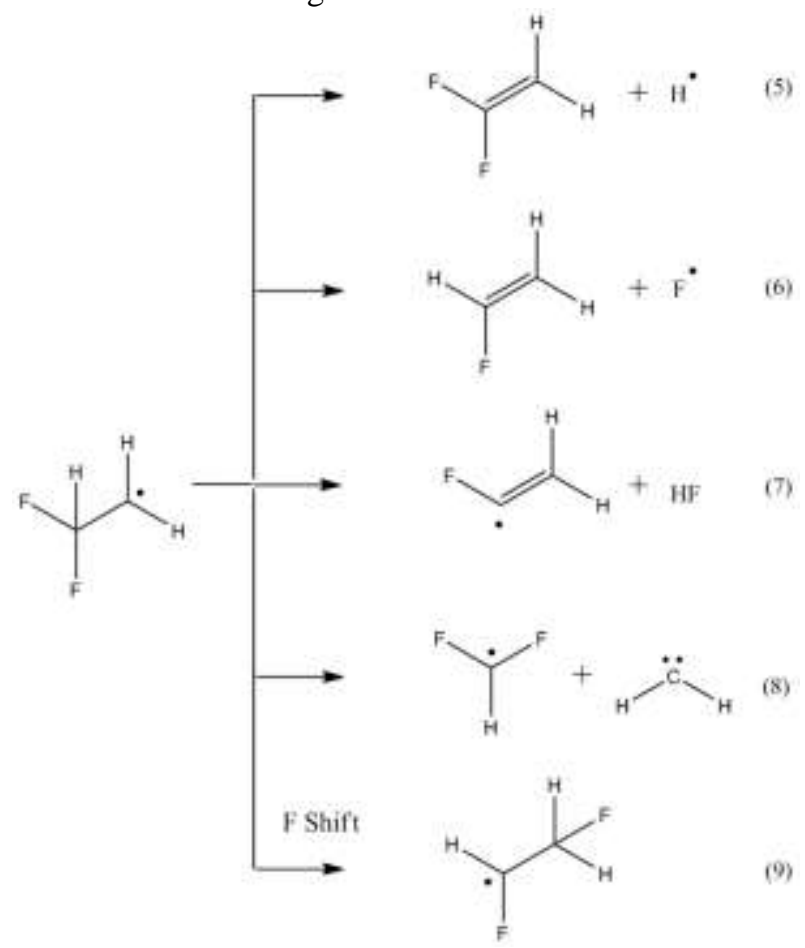

FIG. 3: Reaction channels taken into account from the 1,1-difluoroethy radical after an $\mathrm{H}$-shift reaction (4). Possible dissociation channels are the loss of a hydrogen radical (5), fluorine radical dissociation (6), elimination of hydrogen fluoride (7), C-C bond fission and 1,2-shifting of a fluorine atom.

Due to a reduction of symmetry during the fluorine shift reaction, several reactions can now lead to multiple isomers such as the $\mathrm{H}$ dissociation reaction leading to the formation of either cis- or trans-1,2-difluoroethene. The reaction product of the loss of a fluorine atom (14) is the same as reaction product (6) but again with different starting material and transition state.

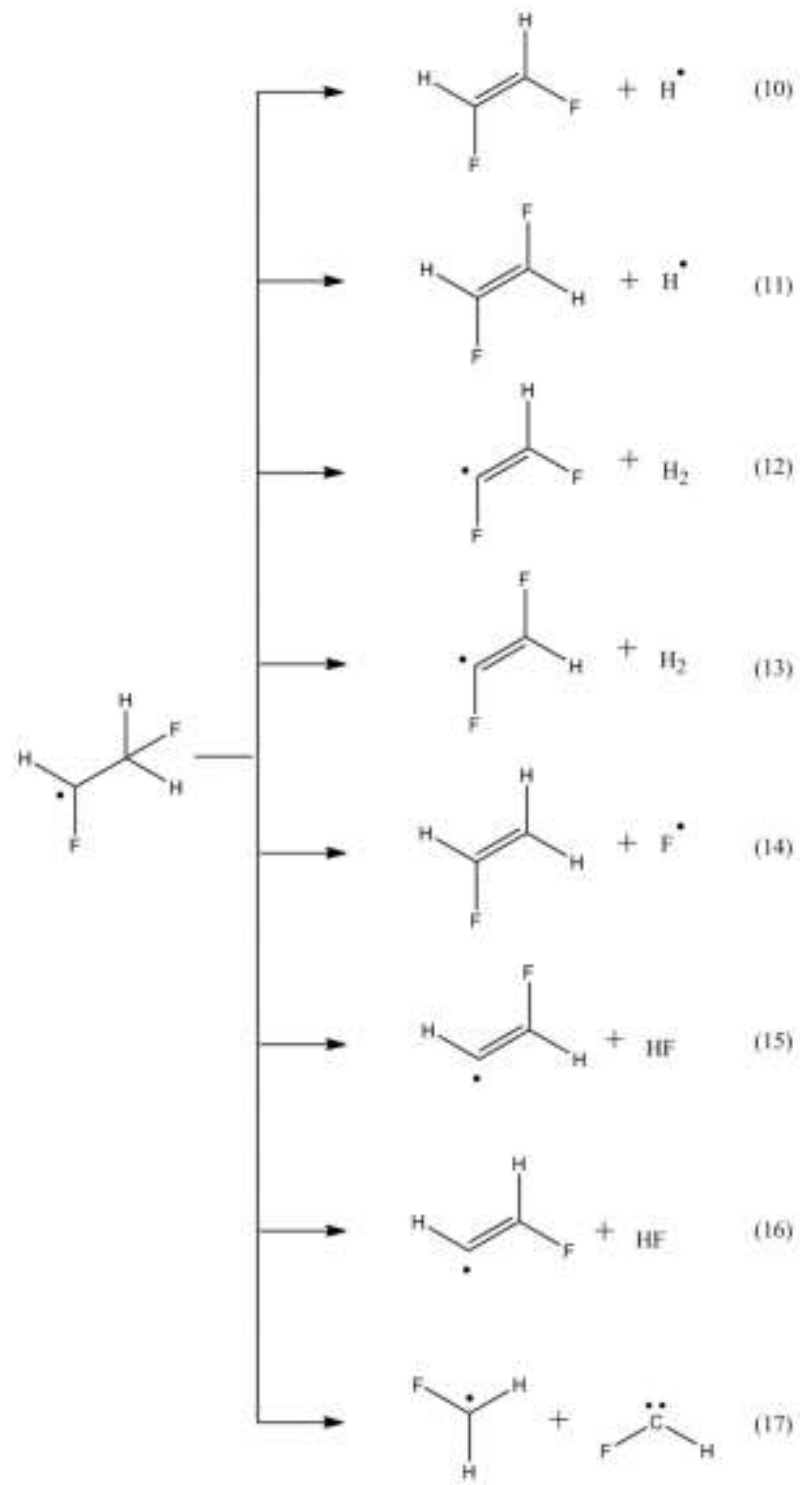

FIG. 4: Reaction channels taken into account outgoing from the 1,2difluoroethyl radical (9).

For a proper investigation on the dissociation dynamics, we must take into account all the reaction channels. A comparison between the results of both methods gives us hints whether nonstatistical effects can occur in such small molecules and how the dissociation dynamics of the ethyl radical changes due to a substitution with fluorine atoms.

As mentioned above, we model the ground state potential energy surface including many dissociation channels for the 1,1-difluoroethyl radical. Figure 4 shows a simplified overview of the energetic landscape with single point energy levels derived at the CCSD(T)/cc-pVTZ level of theory. The numbers in brackets correspond to the reactions with the same number shown in Figures 1-3. Reaction path (1) leads therefore to product(s) (1) and so on.

Calculated reaction energy results of both levels of theory indicate that the dissociation of an H-radical has the energetically lowest lying transition state which is 39.8 $\mathrm{kcal} / \mathrm{mol}$ above the 1,1-difluoroethyl radical ground state. 
The next higher lying transition state is the one of the $\mathrm{H}$ shift reaction (4). The energy difference between these two transition states amounts to $10.7 \mathrm{kcal} / \mathrm{mol}$. This leads to the assumption that the dissociation of a hydrogen radical should be by far the most favorable reaction. However, it is not easy to predict the probability of a bond breakage between the two carbon atoms (3) since this reaction has no reverse barrier according to our calculations. Therefore, this reaction could possibly occur much more frequently than predicted by just watching at transition state energies.

Linear transit simulations performed using the GAUSSIAN 09 software did not result in any transition state for the loss of $\mathrm{H}_{2}$ in one step, i.e. simultaneous breakage of two carbon-hydrogen bonds and formation of a hydrogen-hydrogen bond. Rather, we find a process corresponding to the hydrogen atom roaming mechanism for the loss of $\mathrm{H}_{2}{ }^{37-39}$ and a transition state for the abstraction of the second $\mathrm{H}$ atom by the first one can be assigned. The treatment of roaming transition states is not simple. However, the calculated activation energy of this reaction of $20.6 \mathrm{kcal} / \mathrm{mol}$ indicates that this reaction channel is of only minor importance to the overall dissociation dynamics. The same is true for the elimination of $\mathrm{H}_{2}$ from Product (9). Connecting lines between (1) and (2) as well as between (10) and (12) and (11) and (13) in Figure 5 are therefore displayed using a dotted line style.

As for the $\mathrm{C}-\mathrm{C}$ bond breakage reactions of the products (0), (4) and (9) we did not find reverse barriers for fluorine radical dissociation reactions. Reactions (6) and (14) lead to the same product lying $53.4 \mathrm{kcal} / \mathrm{mol}$ above the ground state of 1,1-difluoroethyl radical.
A summary of the energetic results and a comparison between the energies calculated at HCTH147/6-31G** and CCSD(T)/cc-pVTZ levels of theory appears in Table I for reaction products and in Table II for transition states. Product (0), the ground state of 1,1-difluoroethyl radical serves as reference for the relative energies for all products and transition states. For most of the products, differences in relative energies comparing the two computational methods are less than 3-4 kcal/mol except where fluorine atoms are involved in the dissociation reactions (6), (7), (14), (15), (16). Furthermore, the substrate (0) as well as the reaction products (1), (3) and (4), which are considered to result from the most important reaction channels are investigated using UCCSD(T)/cc-pVTZ-F12 calculations. Energies of those structures all lie in between the values obtained by the CCSD(T)/cc-pVTZ and the DFT method and are given in Table I.

Differences in transition state energies relative to product (0) are generally larger than relative energies of reaction products. Most transition state energies are underestimated by the DFT method. Transition states of the H-shift reaction (0) -> (4) lies about $3.1 \mathrm{kcal} / \mathrm{mol}$ higher and the F-shift reaction (4) $\rightarrow>(9)$ is enhanced at about 5.8 $\mathrm{kcal} / \mathrm{mol}$ using CCSD(T) instead of DFT. Largest differences occur in transition states that result in the loss of diatomic fragments such as $\mathrm{H}_{2}$-elimination or $\mathrm{HF}$ elimination. CCSD(T)-energies for all of them lie higher in energy at $6.1-9.4 \mathrm{kcal} / \mathrm{mol}$ than DFT-energies. However, a closer investigation on the transition states of the $\mathrm{H}$ dissociation reaction (0) -> (1) and the $\mathrm{H}$-shift reaction (0) -> (4), determined at the UCCSD(T)/cc-pVTZ-F12 level of theory show, that their energies again lie in between the

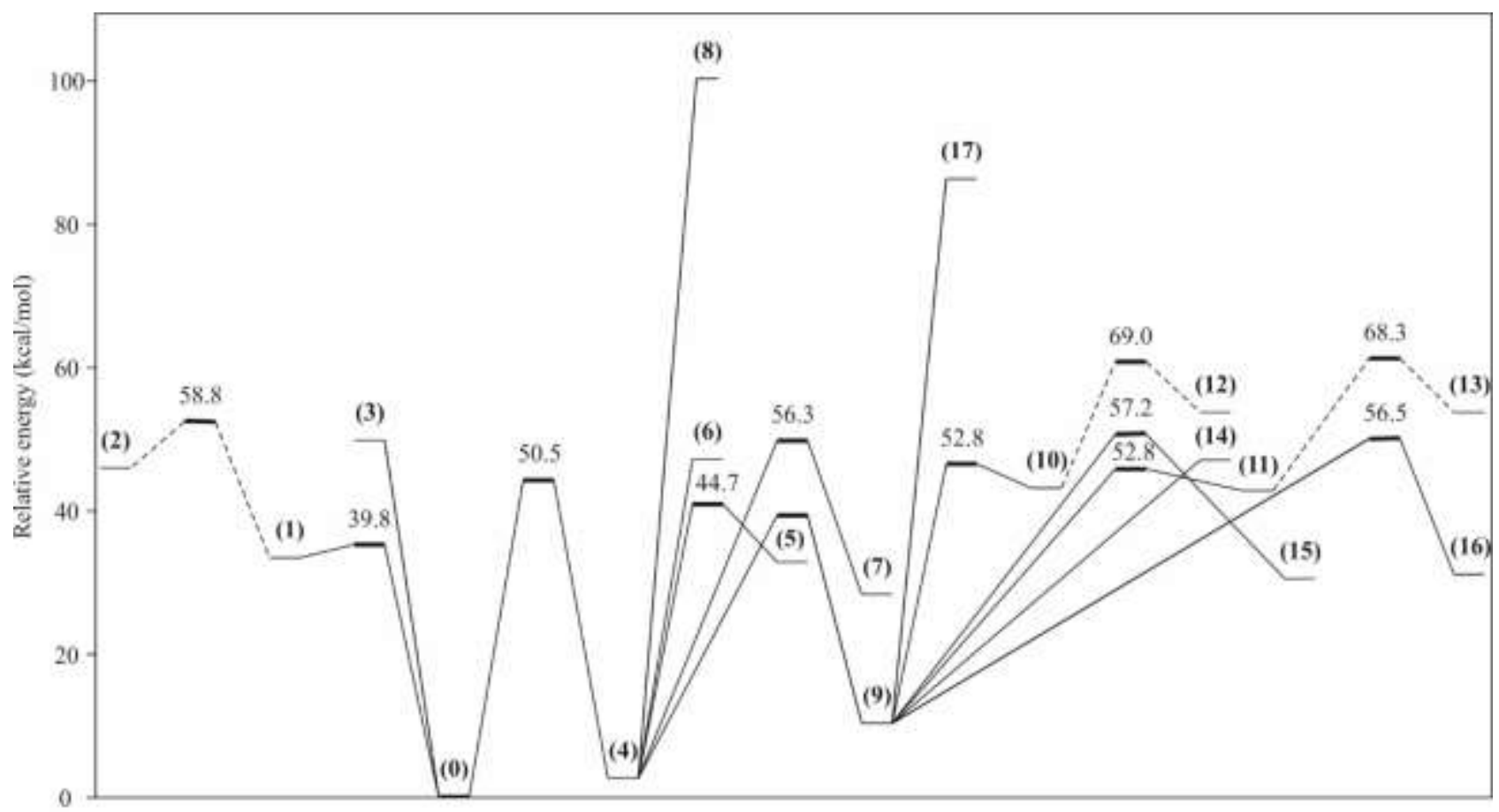

Reaction coordinate

FIG. 5: Simplified energy surface of the dissociation reaction system of 1,1-difluoroethyl radical labeled as (0). Numbers in brackets indicate the corresponding reaction pathway. Transition state energies have a slightly broader line. The products of all processes are labeled in brackets and relative energies of transition states are given in $\mathrm{kcal} / \mathrm{mol}$. For the $\mathrm{H}_{2}$-elimination reactions it is not clear which path on the energy surface is taken, therefore the connecting lines are displayed as dashed lines. 
CCSD(T)/cc-pVTZ and the DFT-energies. The exact values are given in Table II.

In addition to the energies of structures given in Tables I \& II and Figure 4, we calculate the transition state energies of rotational transition states of product (1), (4) and (9) as well as the other rotamer (enantiomer) of product (9). Calculations show that the two rotamers of (9) have very similar energies of $11.7 \mathrm{kcal} / \mathrm{mol}$ respectively. In addition to a rotation around the $\mathrm{C}-\mathrm{C}$ bond, the one rotamer of (9) can also undergo an $\mathrm{H}$-shift reaction to form the other enantiomer. We calculated the corresponding transition states and found them to be much too high in energy (58.9 $\mathrm{kcal} / \mathrm{mol}$ and $63.4 \mathrm{kcal} / \mathrm{mol}$ respectively) to have significant contributions to the overall reaction dynamics.

TABLE I. Energies of all relevant reaction products in $\mathrm{kcal} / \mathrm{mol}$ calculated at the HCTH147/6-31G** and the CCSD(T)/cc-pVTZ level of theory.

\begin{tabular}{lccc}
\hline \hline $\begin{array}{c}\text { Reaction } \\
\text { Product(s) }\end{array}$ & $\begin{array}{c}\text { Relative Energy } \\
(\text { HCTH147/6- } \\
\left.31 G^{* *}\right) \\
(\mathrm{kcal} / \mathrm{mol})\end{array}$ & $\begin{array}{c}\text { Relative } \\
\text { Energy } \\
(\mathrm{CCSD}(\mathrm{T}) / \mathrm{cc}- \\
\mathrm{pVTZ}) \\
(\mathrm{kcal} / \mathrm{mol})\end{array}$ & $\begin{array}{c}\text { Relative Energy } \\
(\mathrm{CCSD} \text { (T)/cc- } \\
\mathrm{pVZT-F12}) \\
(\mathrm{kcal} / \mathrm{mol})\end{array}$ \\
\hline$(0)$ & 0 & 0 & 0 \\
$(1)$ & 39.4 & 38.2 & 38.9 \\
$(2)$ & 49.1 & 51.4 & - \\
$(3)$ & 59.6 & 56.4 & 58.2 \\
$(4)$ & 6.7 & 2.9 & 2.9 \\
$(5)$ & 39.4 & 38.2 & - \\
$(6)$ & 64.5 & 53.4 & - \\
$(7)$ & 39.6 & 32.3 & - \\
$(8)$ & 120.2 & 114.4 & - \\
$(9)$ & 13.8 & 11.7 & - \\
$(10)$ & 50.8 & 48.5 & - \\
$(11)$ & 50.8 & 48.8 & - \\
$(12)$ & 56.3 & 59.7 & - \\
$(13)$ & 56.4 & 59.7 & - \\
$(14)$ & 64.5 & 53.4 & - \\
$(15)$ & 44.4 & 35.7 & \\
$(16)$ & 44.4 & 35.0 & - \\
$(17)$ & 100.9 & 97.4 & \\
\hline \hline
\end{tabular}

TABLE II. Energies of transition states relative to reactant $(0)$ calculated at the HCTH147/6-31G** and the CCSD(T)/cc-pVTZ level of theory in $\mathrm{kcal} / \mathrm{mol}$.

\begin{tabular}{|c|c|c|c|}
\hline $\begin{array}{l}\text { Transition } \\
\text { state }\end{array}$ & $\begin{array}{c}\text { Relative energy } \\
\text { (HCTH147/6- } \\
\left.31 \mathrm{G}^{* *}\right) \\
(\mathrm{kcal} / \mathrm{mol})\end{array}$ & $\begin{array}{c}\text { Relative energy } \\
\text { (CCSD }(\mathrm{T}) / \mathrm{cc}- \\
\text { pVTZ) } \\
(\mathrm{kcal} / \mathrm{mol})\end{array}$ & $\begin{array}{c}\text { Relative energy } \\
(\mathrm{CCSD}(\mathrm{T}) / \mathrm{cc}- \\
\text { pVTZ-F12) } \\
(\mathrm{kcal} / \mathrm{mol})\end{array}$ \\
\hline$(0) \rightarrow(1)$ & 42.2 & 39.8 & 40.0 \\
\hline$(0) \rightarrow(2)$ & 52.6 & 58.8 & - \\
\hline$(0) \rightarrow(4)$ & 47.4 & 50.4 & 49.8 \\
\hline$(4) \rightarrow(5)$ & 46.5 & 44.7 & - \\
\hline$(4) \rightarrow(7)$ & 46.9 & 56.3 & - \\
\hline$(4) \rightarrow(9)$ & 37.5 & 43.3 & - \\
\hline$(9) \rightarrow(10)$ & 55.2 & 52.8 & - \\
\hline$(9) \rightarrow(11)$ & 55.3 & 52.8 & - \\
\hline$(9) \rightarrow(12)$ & 62.4 & 69.0 & - \\
\hline$(9) \rightarrow(13)$ & 61.9 & 68.2 & - \\
\hline$(9) \rightarrow(15)$ & 48.1 & 56.5 & - \\
\hline$(9) \rightarrow(16)$ & 48.9 & 57.2 & - \\
\hline
\end{tabular}

Thus, it is to be expected that only a minor fraction of the 1,1-difluoroethyl radicals undergoes reactions other than (0) -> (1), (0) -> (3) and (0) -> (4). Any other reaction (except $(0)->(2)$ ) can only occur after the formation of product (4) via H-shift.

\section{B. Statistically derived rate constants and branching ratios - the prior distribution}

We calculate the energy input for photodissociation reactions using the EOMCCSD/AUG-cc-pVDZ method as being the energy required for the excitation to the first excited state of the 1,1-difluoroethyl radical, which has $3 \mathrm{~s}$ Rydberg character. The adiabatic excitation energy amounts to $94.8 \mathrm{kcal} / \mathrm{mol}$. In the simplified PES given in Table I, all the reaction channels except $\mathrm{C}-\mathrm{C}$ bond breakage reactions (8) and (17) should be accessible with such a high energy input. The input energy as well as relative energies and activation energies from the ground state PES derived by both methods, DFT and $\operatorname{CCSD}(\mathrm{T})$, serve as inputs to model the RRKM dissociation dynamics of the 1,1difluoroethyl radical.

The roaming mechanism of $\mathrm{H}_{2}$ loss is not simulated, because the RRKM treatment of such reactions is not accurate and the reaction channel is of minor importance to the overall reaction dynamics. Furthermore, in the spirit that the statistical treatment produces a prior distribution against which the BOMD-derived product distribution may be compared, one might argue that "special" transition states should not be handled explicitly in the RRKM calculation. Therefore, the fluorine atom dissociation channel was also not simulated.

Since the C-C bond breakage channel does not show a saddle point on the PES, such reactions are treated as loose transition states. This treatment assumes a transition state at the centrifugal barrier and identical vibrational frequencies and internal rotational constants for the reaction products and the transition state. It is questionable, whether the use of this approach is appropriate to model this reaction channel accurately. On the other hand, the statistical calculations, essentially phase space results, correspond to Levine's prior distribution in surprisal theory, which define the expected distribution of products with no "other" effects. They provide a baseline against which the product distribution taken from the BOMD trajectory calculations, done with numerical energies and gradients, and no assumptions about symmetry or model (analytical) potential functions, may be assessed for new chemical information.

Figure 5 shows the fractions of reactant and products as a function of time and allows a comparison of the results based on ground state PESs derived based on the two different methods. For both methods, only the $\mathrm{H}$ dissociation channel and the $\mathrm{C}-\mathrm{C}$ bond breakage channel are drawn because the fractions of all the other reaction products are less than $2 \%$. Although for some processes, the relative energies on the ground state PES show relatively large variations between different computational methods, the reaction dynamics and especially the branching ratios of both methods look quite similar. The decay of 1,1-difluoroethyl radical and the formation of dissociation products is somewhat slower in the model based on DFT-energies than for $\operatorname{CCSD}(\mathrm{T})$-energies. 


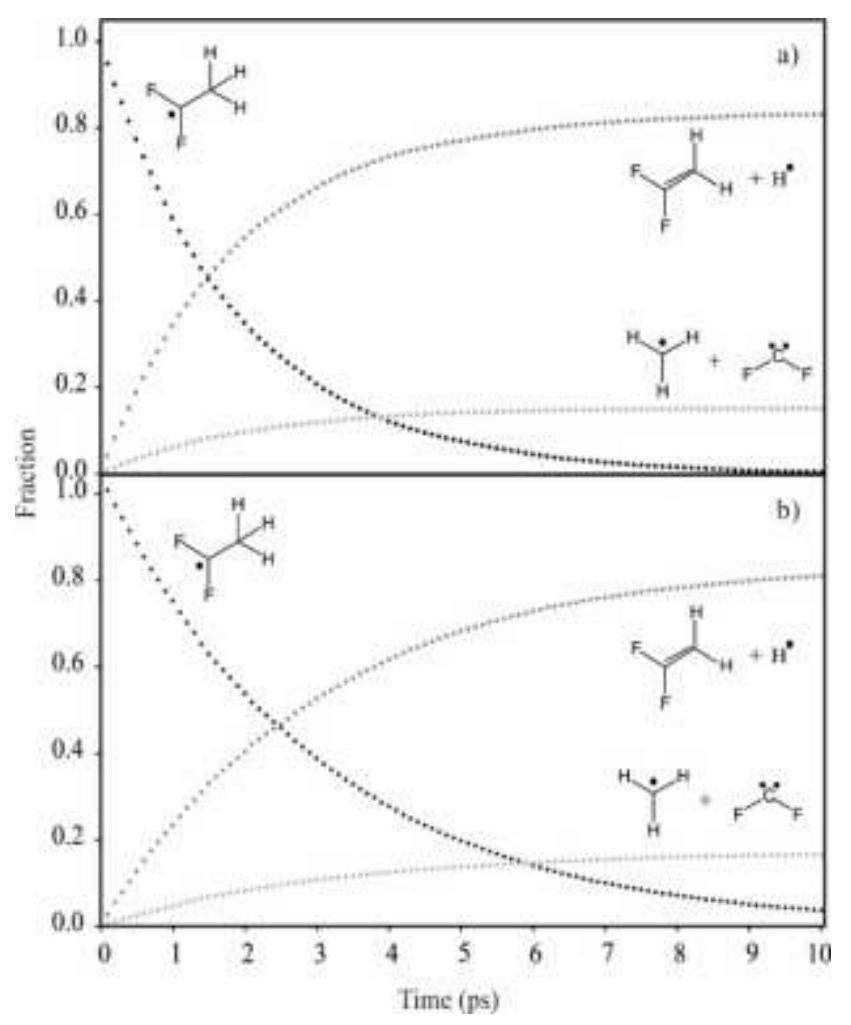

FIG. 6: Fractions of the 1,1-difluoroethyl radical and the main dissociation products as a function of time according a statistically treated photodissociation. a) Reaction dynamics is calculated based on CCSD(T)energies. b) Reaction dynamics is calculated based on DFT-energies.

The branching ratios in both models are very similar. The fraction of CCSD(T)-energy based $\mathrm{H}$ dissociation products (1) is slightly higher and amounts to $83.2 \%$. With the same model $15.2 \%$ C-C bond breakage products (3) are formed after $10 \mathrm{ps}$. The modeling based on DFT-energies yields a fraction of $\mathrm{H}$ dissociation products (1) that amounts to $77.6 \%$ and a fraction of C-C bond breakage products that is $15.9 \%$ after $10 \mathrm{ps}$. After $10 \mathrm{ps}$, the 1,1-difluoroethyl radical is not fully decomposed and about $4 \%$ of reactant (0) remains undissociated in the DFT based model. Regarding the results described above and the circumstance that energies for all the relevant channels obtained by CCSD(T)-F12 calculations lie in between the energy values yielded by $\operatorname{CCSD}(\mathrm{T})$ and DFT, we think that the following assumptions are justified:

- Reaction channels other than H-dissociation and C$\mathrm{C}$ bond breakage are of minor relevance to the overall reaction dynamics

- Branching ratios and reaction rates calculated at the CCSD(T)/cc-pVTZ and HCTH147/6-31G** level of theory can serve as upper and lower bounds of the value derived with the most accurate computational methods in a statistical RRKM approach.

- The HCTH147 functional reproduces energies derived by $\operatorname{CCSD}(\mathrm{T})-\mathrm{F} 12$ very well. For the most relevant transition states, the largest deviation is less than $2.5 \mathrm{kcal} / \mathrm{mol}$.

An overview of the results for the dissociation rate constants based on both methods as well as branching ratios are given in the next section in Tables III \& IV.

\section{Rate constants and branching ratios derived by BOMD-trajectories}

We calculate 500 trajectories of the dissociation of 1,1difluoroethyl radical. The excitation energy is the same as for the RRKM approach and amounts to $94.8 \mathrm{kcal} / \mathrm{mol}$. Manual evaluation of the trajectories provides branching ratios for the dissociation products using the abovementioned BOMD method. Table III gives an overview over the product fractions calculated using the different theoretical approaches.

As already the RRKM-derived branching ratios indicate, the 1,1-difluoroethyl radical decomposes mainly in $\mathrm{H}$-radical dissociation and $\mathrm{C}-\mathrm{C}$ bond breaking reactions. In this case, the branching ratio between $\mathrm{H}$ dissociation and $\mathrm{C}-\mathrm{C}$ bond cleavage amounts to 4.88 and 5.47 respectively for DFT and $\operatorname{CCSD}(\mathrm{T})$ derived electronic surfaces. However, in contrast to what RRKM predicts, the BOMDapproach indicates that the $\mathrm{C}-\mathrm{C}$ bond breakage is favored over the $\mathrm{H}$ dissociation. $\mathrm{C}-\mathrm{C}$ bond cleavage occurs in $56 \%$ of all trajectories and $\mathrm{H}$ dissociation in only $38.4 \%$, leading to a branching ratio of only 0.68 . This trend is the opposite of what is shown by the statistically derived branching ratios. In $3.8 \%$ of all trajectories, we found that the $\mathrm{H}$-shift reaction from reactant $(0)$ to product (4) occurs. This is only slightly more than calculated by the RRKM model. In very few trajectories we observe (4) to react further to other products such as (7), (9), (11), (14), and (15). Six out of the 500 trajectories resulted in computational error due to convergence problems and are sorted out.

TABLE III. Fractions of products formed out of the reactant after $10 \mathrm{ps}$ calculated statistically using energies at the HCTH147/6-31G** and $\operatorname{CCSD}(\mathrm{T}) / \mathrm{cc}-\mathrm{pVTZ}$ level of theory as well as with MD at the HCTH147/6$\underline{31 \mathrm{G}^{* *} \text { level. }}$

\begin{tabular}{lccc}
\hline $\begin{array}{c}\text { Reaction } \\
\text { product }\end{array}$ & $\begin{array}{c}\text { RRKM at } \\
\text { HCTH147/6- } \\
31 \mathrm{G}^{* *}\left(\mathrm{~s}^{-1}\right)\end{array}$ & $\begin{array}{c}\text { RRKM at } \\
\text { CCSD(T)/cc- } \\
\mathrm{pVTZ}\left(\mathrm{s}^{-1}\right)\end{array}$ & $\begin{array}{c}\text { MD at } \\
\text { HCTH147/6- } \\
31 \mathrm{G}^{* *}\left(\mathrm{~s}^{-1}\right)\end{array}$ \\
\hline$(0)$ & 0.0354 & 0.0046 & 0.012 \\
$(1)$ & 0.7763 & 0.8319 & 0.378 \\
$(2)$ & - a) & - a) & 0.002 \\
$(3)$ & 0.1591 & 0.1519 & 0.564 \\
$(4)$ & 0.0012 & 0 & 0.014 \\
$(5)$ & - b) & - b) & 0.004 \\
$(6)$ & 0.0160 & 0.0113 & 0 \\
$(7)$ & 0.0068 & 0.0003 & 0.014 \\
$(8)$ & - a) & - a) & 0 \\
$(9)$ & 0.0001 & 0 & 0.002 \\
$(10)$ & 0.0006 & 0 & 0 \\
$(11)$ & 0.0004 & 0 & 0.002 \\
$(12)$ & - a) & - a) & 0 \\
$(13)$ & - a) & - a) & 0 \\
$(14)$ & - a) & - a) & 0.002 \\
$(15)$ & 0.0027 & 0 & 0.006 \\
$(16)$ & 0.0013 & 0 & 0 \\
$(17)$ & - a) & - a) & 0 \\
\hline \hline
\end{tabular}

a) $\mathrm{H}_{2}$-elimination as well as $\mathrm{F}$ dissociation have not been taken into account in the RRKM calculations. b) (1) and (5) are the same product but originating from a different reactant. MultiWell gives the fraction of products only, not taking into account the reaction pathway.

Figure 6 shows the results for rate constants for the two major reaction channels. We selected trajectories leading to the dissociation of H-radicals and bond breaking between the two carbon atoms in the 1,1-difluoroethyl radical, and integrate the state probability in steps of $0.1 \mathrm{ps}$. The 
resulting cumulative distributions of each reaction channel are drawn against time and fitted exponentially. We find that a single exponential describes the decomposition well enough. Calculated reaction rates amount to $5.1 \cdot 10^{11} \mathrm{~s}^{-1}$ for the dissociation of an H-radical and $5.9 \cdot 10^{11} \mathrm{~s}^{-1}$ for the C-C bond cleavage. This is in good accordance with literature values of $\mathrm{C}-\mathrm{H}$ bond fission of $10^{11}-10^{12} \mathrm{~s}^{-1}$ at $100-120$ $\mathrm{kcal} / \mathrm{mol}$ total excitation energy ${ }^{4,12}$. The fractions of dissociation reactions other than $\mathrm{H}$ dissociations and $\mathrm{C}-\mathrm{C}$ bond cleavage are too small to make statistics and calculate the rate constants.

Table IV gives an overview over all the rate constants that are calculated in this work. For the $\mathrm{H}$ dissociation reaction, the two RRKM rate constants as well as the BOMD rate constant are in good agreement with each other. For the $\mathrm{C}-\mathrm{C}$ bond breaking reactions we find that, no matter on which of the levels of theory the PES was modeled, RRKM-reaction rates are very similar. The rate constant we calculated using molecular dynamics is larger by a factor of 10 . This also explains the difference in branching ratios between RRKM statistical method and the MD method since a larger rate constant leads to an enhanced fraction of $\mathrm{C}-\mathrm{C}$ bond cleavage products.

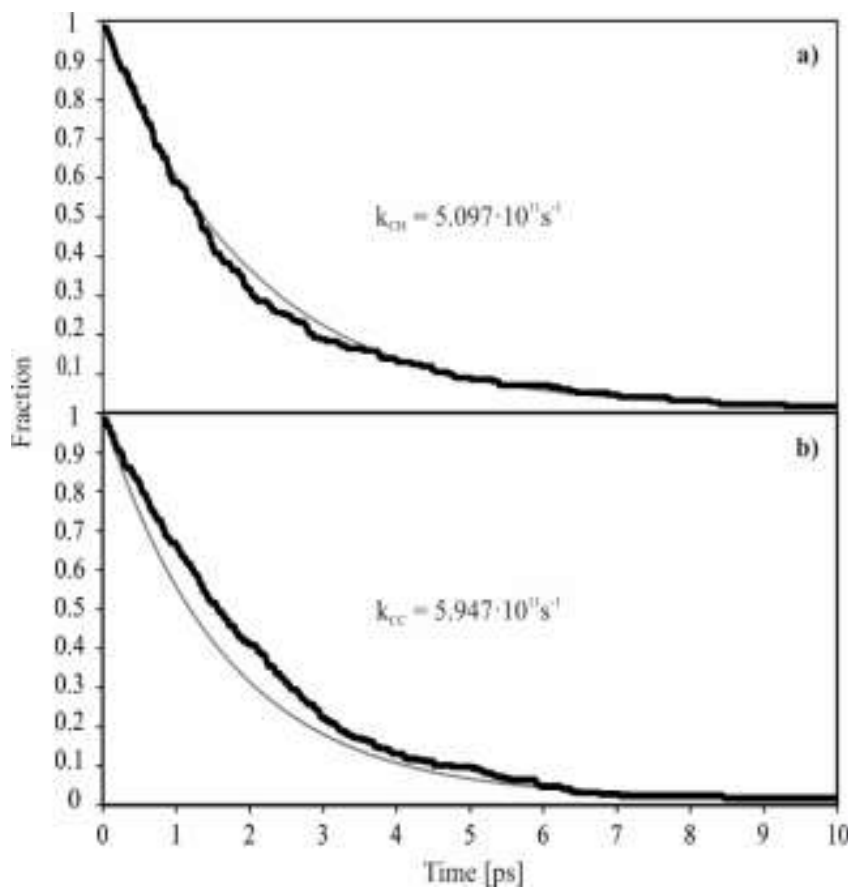

FIG. 7. a) Decay of the 1,1-difluoroethyl radical in a loss of H-radical. b) Decay of the 1,1-difluoroethyl radical due to carbon bond cleavage. The gray lines show exponential fits through the data points and the reaction rates $\mathrm{k}_{\mathrm{CH}}$ and $\mathrm{k}_{\mathrm{CC}}$ as multipliers of the time in the exponent is given in the middle of the figures.

TABLE IV. Reaction rates calculated using statistical methods (RRKM) at different levels of theory as well as reaction rates derived from trajectories at the HCTH147/6-31G** level of theory.

\begin{tabular}{cccc}
\hline \hline $\begin{array}{c}\text { Reaction } \\
\text { channel }\end{array}$ & $\begin{array}{c}\text { RRKM at } \\
\text { HCTH147/6- } \\
31 G^{* *}\left(\mathrm{~s}^{-1}\right)\end{array}$ & $\begin{array}{c}\text { RRKM at } \\
\text { CCSD(T)/cc- } \\
\mathrm{pVTZ}\left(\mathrm{s}^{-1}\right)\end{array}$ & $\begin{array}{c}\text { MD at } \\
\mathrm{HCTH} 147 / 6- \\
31 \mathrm{G}^{* *}\left(\mathrm{~s}^{-1}\right)\end{array}$ \\
\hline$(0) \rightarrow(1)$ & $2.66 \cdot 10^{11}$ & $4.32 \cdot 10^{11}$ & $5.10 \cdot 10^{11}$ \\
$(0) \rightarrow(2)$ & - a) & - a) & - \\
$(0) \rightarrow(3)$ & $5.73 \cdot 10^{10}$ & $8.14 \cdot 10^{10}$ & $5.95 \cdot 10^{11}$ \\
$(0) \rightarrow(4)$ & $1.30 \cdot 10^{10}$ & $6.85 \cdot 10^{09}$ & - \\
$(4) \rightarrow(5)$ & $9.08 \cdot 10^{10}$ & $8.30 \cdot 10^{10}$ & - \\
$(4) \rightarrow(6)$ & $2.07 \cdot 10^{11}$ & $7.59 \cdot 10^{11}$ & - \\
$(4) \rightarrow(7)$ & $1.24 \cdot 10^{11}$ & $1.02 \cdot 10^{10}$ & - \\
\hline \hline
\end{tabular}

\begin{tabular}{lccc}
\hline \hline$(4) \rightarrow(8)$ & - a) & - a) & - \\
$(4) \rightarrow(9)$ & $2.05 \cdot 10^{11}$ & $4.65 \cdot 10^{10}$ & - \\
$(9) \rightarrow(10)$ & $8.59 \cdot 10^{10}$ & $1.18 \cdot 10^{11}$ & - \\
$(9) \rightarrow(11)$ & $9.80 \cdot 10^{10}$ & $1.36 \cdot 10^{11}$ & - \\
$(9) \rightarrow(12)$ & - a) & - a) & - \\
$(9) \rightarrow(13)$ & - a) & - a) & - \\
$(9) \rightarrow(14)$ & $9.24 \cdot 10^{11}$ & $2.72 \cdot 10^{12}$ & - \\
$(9) \rightarrow(15)$ & $4.75 \cdot 10^{11}$ & $5.66 \cdot 10^{10}$ & - \\
$(9) \rightarrow(16)$ & $3.07 \cdot 10^{11}$ & $3.67 \cdot 10^{10}$ & - \\
$(9) \rightarrow(17)$ & - a) & - a) & - \\
\hline
\end{tabular}

a) Sequential $\mathrm{H}_{2}$-elimination as well as $\mathrm{F}$ dissociation have not been taken into account in the RRKM calculations.

\section{DISCUSSION}

The aim of this study was to study the photodissociation dynamics of the 1,1-difluoroethyl radical and to compare the results to our previous work on the ethyl radical. For a direct comparison, we therefore used the same methods and basis sets here for the determination of the PES. However, molecules containing fluorine substituents usually exhibit large polarization effects. For a good description of such molecules, it is important to use appropriate basis sets for our calculations and computations at the CBS limit should give the most reliable results. To check the influence of the basis set we perform single point calculations with larger basis sets and compare the resulting relative energies. A list of relative energies derived at HCTH147/6-31++G** and $\mathrm{CCSD}(\mathrm{T}) / \mathrm{AUG}$-cc-pVTZ as well as a comparison to the methods with non-augmented basis sets is given in the appendix. Furthermore, we compare the relative energies for the most relevant reaction channels to single point calculations at the CCSD(T)/cc-pVTZ-F12 level of theory, as shown in Tables I \& II. We find that for coupled cluster methods, the introduction of an augmented basis set does not change the relative energies much. On this level of theory, deviations of relative energies are mostly within the range of $\pm 2 \mathrm{kcal} / \mathrm{mol}$. For the DFT methods, the difference in relative energies is a bit larger and for some reaction channels as high as $10 \mathrm{kcal} / \mathrm{mol}$. However, reaction channels where large differences in relative energies occur are those where fluorine is involved in the reaction. Regarding the reaction scheme in Figure 1, such reactions only occur after an 1,2-H shift in the starting material and are therefore of minor importance. Furthermore, the energies calculated using CCSD(T)/cc-pVTZ-F12, at least for the relevant structures, all lie in between the energies obtained by CCSD(T)/cc-pVTZ and DFT (nonaugmented). HCTH147/6-31G** thus reproduces CCSD(T)/cc-pVTZ-F12 even better than it reproduces $\operatorname{CCSD}(\mathrm{T}) / \mathrm{cc}-\mathrm{pVTZ}$. The rate constants that would be obtained by RRKM using CCSD(T)-F12 are expected therefore to lie between the values presented in Table IV. Furthermore, since the rate constants for the different potential energy surfaces differ only slightly in the RRKM approach, the HCTH147 functional seems to be appropriate to use for the BOMD trajectory calculations.

One must be careful with the comparison of the reaction rates and branching ratios between the different approaches discussed above. In RRKM modeled results, the decomposition is taking places on a fixed time scale and branching ratios are taken after $10 \mathrm{ps}$ where the reaction is 
not totally run to completion as seen in Figure $6 \mathrm{~b}$ ). For the BOMD method, there is no time limit given and all trajectories (other than the 6 trajectories terminating due to a computational error) end up in one of the products. Nevertheless, it is seen that after 10 ps only a small fraction of surviving stating materials remains, which minimizes the error and in our opinion makes a comparison reasonable.

Statistical theories of chemical reactions treat photodissociation dynamics as thermal reactions of microcanonical ensembles, and assume a fast internal energy conversion to the ground state with redistribution of energy within the electronic ground state, which is much faster than the dissociation rate. Recent work questions the validity of this assumption in the dissociation dynamics of small alkyl radicals. Bach and Hostettler performed quasiclassical trajectory calculations on the same level of theory as used in this work to investigate the dissociation dynamics of the ethyl radical ${ }^{18,19,31}$. As mentioned in the introduction, they found a fraction of ethyl radicals decaying much slower than expected, with rates of about $10^{7} \mathrm{~s}^{-1}$. Statistical rate theories such as RRKM would predict dissociation rates that are roughly four orders of magnitude larger, on the order of $10^{11} \mathrm{~s}^{-1}$. A possible explanation of that result is a trapping of part of the population in highly excited torsional vibrational states. The weak coupling of these torsional excitations to other modes causes a bottleneck for the dissociation of hydrogen atoms. Steinbauer et al. support the finding of a channel of $\mathrm{H}$-atoms formed with an unusually slow decay rate on the order of $10^{7} \mathrm{~s}^{-1}$ in their velocity map imaging experiment ${ }^{40}$. They suggest that interactions with a valence state play a role in the photodissociation and might explain the occurrence of a fraction of long-lived ethyl radicals. However, in this work, for the 1,1-difluoroethyl radical, we find no indications of a long living fraction of the reactant. In fact, the reaction rates for $\mathrm{H}$ dissociation obtained by trajectory calculations agree shockingly well with the value predicted by RRKM. A single exponential fit describes the $\mathrm{H}$ atom dissociation well and there is no evidence for nonstatistical behaviour in the photodissociation dynamics of the 1,1-difluoroethyl radical.

There are several works that focus on the dissociation dynamics of other small hydrocarbon radicals such as the 2-propyl radical or the tert-butyl radical. In a photofragment translational spectroscopy experiment, Negru et al. ${ }^{20}$ found a branching ratio between loss of $\mathrm{H}$ atom and methyl radical from tert-butyl radicals of 1.1. As in our work, this was lower than expected for statistical dissociation on the ground state surface since the loss of $\mathrm{H}$ atoms should be favored due to a lower energy barrier. This and other indicators led to the assumption that, especially the methyl dissociation, but also the loss of $\mathrm{H}$ atoms must occur on an excited state surface causing a faster $\mathrm{C}-\mathrm{C}$ bond cleavage. Noller and Fischer found that for 2-propyl radicals, the loss of $\mathrm{H}$ atoms is the most probable dissociation process proceeding with reaction rates on the order of $10^{7} \mathrm{~s}^{-141}$. For the 1-propyl radical, in contrast, they predicted the $\mathrm{C}-\mathrm{C}$ bond cleavage and formation of methyl radical and ethane to be the most favorable dissociation reaction. Thus, there are other examples where the branching ratio between $\mathrm{H}$ dissociation and $\mathrm{C}-\mathrm{C}$ bond cleavage lie on the $\mathrm{C}-\mathrm{C}$ cleavage side.
In principle, one could attempt to ameliorate the discrepancy between the RRKM predicted reaction rate for the $\mathrm{C}-\mathrm{C}$ bond cleavage channel, and the results of the BOMD simulation, by adding effects due to anharmonicity, or by implementing a variational transition state model for the description of the $\mathrm{C}-\mathrm{C}$ bond cleavage channel, but the aim of the RRKM calculation was to provide the comparison against which the BOMD simulation can identify those places where a simple statistical treatment is inadequate. Accordingly, the discrepancy provides the motivation to explore additional models for that part of the potential surface involved in the $\mathrm{C}-\mathrm{C}$ bond cleavage.

Beside $\mathrm{H}$ dissociation and $\mathrm{C}-\mathrm{C}$ bond cleavage, we find other photodissociation processes occurring, but only to a small extent. In both theoretical approaches, RRKM as well as BOMD trajectory calculations, less than $7 \%$ of alternative products are formed. The fraction of trajectories resulting in one of the alternative products is not sufficient to derive rate constants, whereas RRKM calculations predict reaction rates in the order of $10^{10}$ to $10^{12} \mathrm{~s}^{-1}$ for these reactions. We consider them to be of minor importance to the overall dissociation dynamics.

\section{CONCLUSIONS}

We calculated reaction rates and branching ratios of several dissociation processes in the 1,1-difluoroethyl radical after photolytic excitation using RRKM theory as well as trajectory calculations. H dissociation yielding 1,1difluoroethene and $\mathrm{C}-\mathrm{C}$ bond cleavage leading to formation of methyl radicals and $\mathrm{CF}_{2}$ emerge to be the most important processes both with reaction rates in the order of $10^{11} \mathrm{~s}^{-1}$, which agrees very well with statistically derived dissociation rates of photolytically activated alkyl radicals. Trajectory calculations show a single exponential decay of the reactant towards both reaction channels and do not give any indication for nonstatistical effects for the $\mathrm{H}$ dissociation. The branching ratio between $\mathrm{H}$ dissociation and C-C bond is surprisingly low and amounts to 0.68 according to our trajectory calculations. RRKM computations provide much larger branching ratios. We assign the discrepancy to an underestimation of the C-C bond breakage rate constant using RRKM due to the lack of reverse barrier for the cleavage process and the use of non-scaled vibrational frequencies for the density of states computation.

\section{SUPPLEMENTARY MATERIAL}

See supplementary material for the geometries and absolute energies of all studied structures as well as the excited states of the difluoroethyl radicals and calculations including larger basis sets.

\section{ACKNOWLEDGEMENTS}

We gratefully acknowledge support of this work by the Schweiz. Nationalfonds and ETH Zürich. 
1. G. Amaral, K. Xu and J. Zhang, The Journal of Chemical Physics 114 (12), 5164-5169 (2001).

2. J. L. Brum, S. Deshmukh and B. Koplitz, The Journal of Chemical Physics 93 (10), 7504-7505 (1990).

3. J. L. Brum, S. Deshmukh and B. Koplitz, The Journal of Chemical Physics 95 (3), 2200-2202 (1991).

4. T. Gilbert, T. L. Grebner, I. Fischer and P. Chen, The Journal of Chemical Physics 110 (12), 5485-5488 (1999).

5. G. W. Johnston, S. Satyapal, R. Bersohn and B. Katz, The Journal of Chemical Physics 92 (1), 206-212 (1990).

6. Z. Min, R. Quandt and R. Bersohn, Chemical Physics Letters 296 (3), 372-376 (1998).

7. R. Quandt, X. Wang, Z. Min, H. L. Kim and R. Bersohn, The Journal of Physical Chemistry A 102 (30), 6063-6067 (1998).

8. E. M. Evleth, H. Z. Cao, E. Kassab and A. Sevin, Chemical Physics Letters 109 (1), 45-49 (1984).

9. S. Matsika and D. R. Yarkony, The Journal of Chemical Physics 117 (15), 6907-6910 (2002).

10. A. Sevin, H. T. Yu and E. M. Evleth, Journal of Molecular Structure: THEOCHEM 104 (1), 163-178 (1983).

11. A. S. Zyubin, A. M. Mebel and S. H. Lin, Chemical Physics Letters 323 (5), 441-447 (2000).

12. W. L. Hase, G. Mrowka, R. J. Brudzynski and C. S. Sloane, The Journal of Chemical Physics 69 (8), 3548-3562 (1978).

13. W. L. Hase, R. J. Wolf and C. S. Sloane, The Journal of Chemical Physics 71 (7), 2911-2928 (1979).

14. W. L. Hase and D. G. Buckowski, Journal of Computational Chemistry 3 (3), 335-343 (1982).

15. W. L. Hase, D. G. Buckowski and K. N. Swamy, The Journal of Physical Chemistry 87 (15), 2754-2763 (1983).

16. W. L. Hase and H. B. Schlegel, The Journal of Physical Chemistry 86 (20), 3901-3904 (1982).

17. W. L. Hase, H. B. Schlegel, V. Balbyshev and M. Page, The Journal of Physical Chemistry 100 (13), 5354-5361 (1996).

18. A. Bach, J. M. Hostettler and P. Chen, The Journal of Chemical Physics 123 (2), 021101 (2005).

19. J. M. Hostettler, A. Bach and P. Chen, The Journal of Chemical Physics 130 (3), 034303 (2009).

20. B. Negru, G. M. P. Just, D. Park and D. M. Neumark, Physical Chemistry Chemical Physics 13 (18), 81808185 (2011).

21. J. R. Barker, International Journal of Chemical Kinetics 33 (4), 232-245 (2001).

22. J. R. Barker, International Journal of Chemical Kinetics 41 (12), 748-763 (2009).

23. J. R. Barker, T. L. Nguyen, J. F. Stanton, C. Aieta, M. Ceotto, F. Gabas, T. H. D. Kumar, C. G. L. Li, L. L. Lohr, A. Maranzana, N. F. Ortiz, J. M. Preses, J. M. Simmier, J. A. Sonk and P. J. Stimac, (University of Michigan, Ann Arbor, MI, 2011).

24. S. E. Stein and B. S. Rabinovitch, The Journal of Chemical Physics 58 (6), 2438-2445 (1973).

25. T. Beyer and D. F. Swinehart, Commun. ACM 16 (6), 379 (1973).
26. M. E. Weber, J. L. Elkind and P. B. Armentrout, The Journal of Chemical Physics 84 (3), 1521-1529 (1986).

27. K. M. Ervin and P. B. Armentrout, The Journal of Chemical Physics 83 (1), 166-189 (1985).

28. P. B. Armentrout and K. M. Ervin, (2002).

29. A. D. Boese, J. M. L. Martin and N. C. Handy, The Journal of Chemical Physics 119 (6), 3005-3014 (2003).

30. M. J. Frisch, G. W. Trucks, H. B. Schlegel, G. E. Scuseria, M. A. Robb, J. R. Cheeseman, G. Scalmani, B. Barone, B. Mennucci, G. A. Petersson, H. Nakatsuii, M. Caricato, X. Li, H. P. Hratchian, A. F. Izmaylov, J. Bloino, G. Zheng, J. L. Sonnenberg, M. Hada, M. Ehara, K. Toyota, R. Fukuda, J. Gasegawa, M. Ishida, T. Nakajima, Y. Honda, O. Kitao, H. Nakai, T. Vreven, J. J. A. Montgomery, J. E. Peralta, F. B. Ogliaro, M., J. J. Heyd, E. Brothers, K. N. Kudin, V. N. Staroverov, R. Kobayashi, J. Normand, K. Raghayachari, A. Rendell, J. C. Burant, S. S. Ivengar, J. Tomasi, M. Cossi, N. Rega, J. M. Millam, M. K. Klene, J. E., J. B. Cross, V. Bakken, C. Adamo, J. Jaramillo, R. Gomperts, R. E. Stratmann, O. Yazyev, A. J. Austin, R. Cammi, C. Pomelli, J. W. Ochterski, R. L. Martin, K. Morokuma, V. G. Zakrzewski, G. A. Voth, P. Salvador, J. J. Dannenberg, S. Dapprich, A. D. Daniels, O. Farkas, J. B. Foresman, J. V. Ortiz, J. Cioslowski and D. J. Fox, (2009), Vol. Revision A.1 (Gaussian, Inc., Wallingford CT, 2009).

31. A. Bach, J. M. Hostettler and P. Chen, The Journal of Chemical Physics 125 (2), 024304 (2006).

32. J. D. Watts, J. Gauss and R. J. Bartlett, The Journal of Chemical Physics 98 (11), 8718-8733 (1993).

33. J. F. Stanton, J. Gauss, M. E. Harding, P. G. Szalay, w. c. f. and A. A. Auer.

34. H.-J. K. Werner, P. J.; Knizia, G.; Manby, F. R. ; Schütz, M.; Celani, P.; Györffy, W.; Kats, D.; Korona, T.; Lindh, R.; Mitrushenkov, A.; Rauhut, G.; Shamasundar, K. R.; Adler, T. B.; Amos, R. D.; Bernhardsson, A.; Berning, A.; Cooper, D. L.; Deegan, M. J. O.; Dobbyn, A. J.; Eckert, F.; Goll, E.; Hampel, C.; Hesselmann, A.; Hetzer, G.; Hrenar, T.; Jansen, G.; Köppl, C.; Liu, Y.; Lloyd, A. W.; Mata, R. A.; May, A. J.;McNichols, S. J.; Meyer, W.; Mura, M. E.; Nicklass, A.; O'Neill, D. P.; Palmieri, P.; Peng, D.; Pflüger, K.; Pitzer, R.; Reiher, M.; Shiozaki, T.; Stoll, H.; Stone, A. J.; Tarroni, R.; Thorsteinsson, T. and Wang, M. , (2015).

35. H.-J. Werner, P. J. Knowles, G. Knizia, F. R. Manby and M. Schütz, Wiley Interdisciplinary Reviews: Computational Molecular Science 2 (2), 242-253 (2012).

36. G. A. Knizia, T. B.; Werner, H.-J., The Journal of Chemical Physics 130 (5), 054104 (2009).

37. A. M. Mebel, K. Morokuma and M. C. Lin, The Journal of Chemical Physics 103 (9), 3440-3449 (1995).

38. G.-S. Kim, T. L. Nguyen, A. M. Mebel, S. H. Lin and M. T. Nguyen, The Journal of Physical Chemistry A 107 (11), 1788-1796 (2003). 
39. D. Townsend, S. A. Lahankar, S. K. Lee, S. D. Chambreau, A. G. Suits, X. Zhang, J. Rheinecker, L. B. Harding and J. M. Bowman, Science 306 (5699), 1158-1161 (2004).

40. M. Steinbauer, J. Giegerich, K. H. Fischer and I. Fischer, The Journal of Chemical Physics 137 (1), 014303 (2012).

41. B. Noller and I. Fischer, The Journal of Chemical Physics 126 (14), 144302 (2007). 


\section{Supporting Information}

\section{A) Geometries}

\section{A.1) Coordinates and vibrational frequencies}

Coordinates and harmonical vibrational frequencies of all products and transition states are calculated at the HCTH147/6-31G** level of theory using structure optimization and frequency analysis. Results are given in the tables below.

\begin{tabular}{llllll}
\hline \hline \multicolumn{2}{l}{ 1, 1-difluoroethyl radical $(0)$} & & \multicolumn{2}{l}{ Harmonic frequencies $\left[\mathrm{cm}^{-1}\right]$} \\
\hline Atom & \multicolumn{2}{l}{ Coordinates $[\AA]$} & & 201.6530 & 1238.6110 \\
& $\mathrm{X}$ & $\mathrm{y}$ & $\mathrm{z}$ & 201.6530 & 1257.8930 \\
$\mathrm{C}$ & 0.064775 & -1.491382 & 0.000000 & 365.7350 & 1391.5440 \\
$\mathrm{C}$ & -0.305036 & -0.046595 & 0.000000 & 447.1720 & 1457.6220 \\
$\mathrm{~F}$ & 0.063236 & 0.633817 & 1.103608 & 520.4530 & 2982.6700 \\
$\mathrm{~F}$ & 0.063236 & 0.633817 & -1.103608 & 845.3050 & 3095.3630 \\
$\mathrm{H}$ & 1.159100 & 1.623219 & 0.000000 & 967.7050 & 3142.2910 \\
$\mathrm{H}$ & -0.341229 & -1.980192 & 0.890179 & 1074.6560 & \\
$\mathrm{H}$ & -0.341229 & -1.980192 & -0.890179 & & \\
\hline \hline
\end{tabular}

\begin{tabular}{llllll}
\hline \hline \multicolumn{2}{l}{ 1, 1 -difluoroethene $(1,5)$} & & & \\
\hline Atom & \multicolumn{2}{l}{ Coordinates $[\AA]$} & & \multicolumn{2}{l}{ Harmonic frequencies $\left[\mathrm{cm}^{-1}\right]$} \\
& $\mathrm{X}$ & $\mathrm{y}$ & $\mathrm{z}$ & 429.2210 & 1319.2920 \\
$\mathrm{C}$ & 0.144146 & -0.000006 & 0.000000 & 536.5260 & 1387.2540 \\
$\mathrm{C}$ & 1.472265 & -0.000032 & 0.000000 & 614.3850 & 1761.4350 \\
$\mathrm{~F}$ & -0.617147 & 1.088106 & 0.000000 & 701.8540 & 3191.1730 \\
$\mathrm{~F}$ & -0.617199 & -1.088077 & 0.000000 & 758.1630 & 3296.0190 \\
$\mathrm{H}$ & 2.011070 & -0.938671 & 0.000000 & 929.7630 & \\
$\mathrm{H}$ & 2.011124 & 0.938570 & 0.000000 & 941.6700 & \\
\hline
\end{tabular}

\begin{tabular}{|c|c|c|c|c|c|}
\hline \multicolumn{6}{|c|}{ 1, 1 -difluoroethenyl radical (2) } \\
\hline \multirow[t]{2}{*}{ Atom } & \multicolumn{3}{|c|}{ Coordinates $[\AA]$} & \multicolumn{2}{|c|}{ Harmonic frequencies $\left[\mathrm{cm}^{-1}\right]$} \\
\hline & $\mathrm{x}$ & $\mathrm{y}$ & $\mathrm{z}$ & 407.6070 & 1227.4250 \\
\hline $\mathrm{C}$ & 0.116047 & -0.135198 & 0.000000 & 456.9340 & 1745.4720 \\
\hline $\mathrm{C}$ & 1.023423 & -1.082687 & 0.000000 & 529.9590 & 3333.3170 \\
\hline $\mathrm{F}$ & -1.196368 & -0.345169 & 0.000000 & 604.3990 & \\
\hline $\mathrm{F}$ & 0.365647 & 1.178505 & 0.000000 & 726.9610 & \\
\hline $\mathrm{H}$ & 2.092343 & -1.207977 & 0.000000 & 948.4480 & \\
\hline
\end{tabular}

\begin{tabular}{llllll}
\hline \hline \multicolumn{2}{l}{ methyl radical (3) } & \multicolumn{3}{l}{ Harmonic frequencies $\left[\mathrm{cm}^{-1}\right]$} \\
\hline Atom & \multicolumn{2}{l}{ Cartesian coordinates $[\AA]$} & & 456.4170 & 3291.7140 \\
& $\mathrm{x}$ & $\mathrm{y}$ & $\mathrm{z}$ & 1389.3950 & \\
$\mathrm{C}$ & 0.000000 & 0.000000 & -0.000002 & 1389.5100 & \\
$\mathrm{H}$ & 0.000000 & -0.938872 & 0.542075 & 3106.1320 \\
$\mathrm{H}$ & 0.000000 & 0.938872 & 0.542075 & 3291.9290 \\
$\mathrm{H}$ & 0.000000 & 0.000000 & -1.084124 & 3 \\
\hline \hline
\end{tabular}

\begin{tabular}{|c|c|c|c|c|}
\hline \multicolumn{5}{|l|}{$\mathrm{CF}_{2}(3)$} \\
\hline \multirow[t]{2}{*}{ Atom } & \multicolumn{3}{|c|}{ Cartesian coordinates $[\AA]$} & Harmonic frequencies $\left[\mathrm{cm}^{-1}\right]$ \\
\hline & $\mathrm{x}$ & $\mathrm{y}$ & $\mathrm{z}$ & 635.7100 \\
\hline $\mathrm{C}$ & 0.000000 & 0.000000 & 0.618588 & \\
\hline $\mathrm{F}$ & 0.000000 & 1.042460 & -0.195360 & 1097.7420 \\
\hline $\mathrm{F}$ & 0.000000 & -1.042460 & -0.195360 & \\
\hline
\end{tabular}

\begin{tabular}{|c|c|c|c|c|c|}
\hline \multicolumn{6}{|c|}{ 1, 1-difluoroethyl radical (4) } \\
\hline \multirow[t]{2}{*}{ Atom } & \multicolumn{3}{|c|}{ Coordinates $[\AA]$} & \multicolumn{2}{|c|}{ Harmonic frequencies $\left[\mathrm{cm}^{-1}\right]$} \\
\hline & $\mathrm{x}$ & $\mathrm{y}$ & $\mathrm{z}$ & 82.6800 & 1134.0530 \\
\hline $\mathrm{C}$ & 0.000001 & 0.065544 & 0.355018 & 382.7000 & 1344.1610 \\
\hline $\mathrm{C}$ & 0.000019 & 1.472231 & -0.105107 & 425.2490 & 1366.5930 \\
\hline $\mathrm{F}$ & 0.939401 & 2.007988 & -0.191833 & 485.7260 & 1430.2300 \\
\hline $\mathrm{F}$ & -0.939349 & 2.008012 & -0.191833 & 631.0670 & 2938.3100 \\
\hline $\mathrm{H}$ & -0.000001 & -0.039650 & 1.457257 & 895.2310 & 3160.6120 \\
\hline $\mathrm{H}$ & -1.116637 & -0.591108 & -0.107402 & 966.2700 & 3280.6920 \\
\hline
\end{tabular}




\begin{tabular}{|c|c|c|c|c|c|}
\hline $\mathrm{H}$ & 1.116621 & -0.591136 & -0.107402 & \multicolumn{2}{|l|}{1124.4000} \\
\hline \multicolumn{6}{|c|}{ monofluoroethene $(6,14)$} \\
\hline \multirow[t]{2}{*}{ Atom } & \multicolumn{3}{|c|}{ Coordinates $[\AA]$} & \multicolumn{2}{|c|}{ Harmonic frequencies $\left[\mathrm{cm}^{-1}\right]$} \\
\hline & $\mathrm{x}$ & $\mathrm{y}$ & $\mathrm{z}$ & 476.7830 & 1398.6330 \\
\hline $\mathrm{C}$ & -0.123009 & -0.445685 & 0.000000 & 719.1230 & 1702.0350 \\
\hline $\mathrm{C}$ & -1.276815 & 0.215379 & 0.000000 & 827.2590 & 3153.9630 \\
\hline $\mathrm{F}$ & 1.071946 & 0.175687 & 0.000000 & 928.9940 & 3171.7050 \\
\hline $\mathrm{H}$ & -0.018114 & -1.530409 & 0.000000 & 947.6680 & 3261.7750 \\
\hline $\mathrm{H}$ & -1.312507 & 1.300710 & 0.000000 & 1168.7290 & \\
\hline $\mathrm{H}$ & -2.209044 & -0.339941 & 0.000000 & 1317.5690 & \\
\hline
\end{tabular}

\begin{tabular}{llllll}
\hline \hline \multicolumn{2}{l}{ monofluoroethenyl radical $(7)$} & & & \\
\hline \multicolumn{2}{c}{ Atom } & \multicolumn{2}{l}{ Coordinates $[\AA]$} & & \multicolumn{2}{l}{ Harmonic frequencies $\left[\mathrm{cm}^{-1}\right]$} \\
& $\mathrm{x}$ & $\mathrm{y}$ & $\mathrm{z}$ & 438.6710 & 1697.2710 \\
$\mathrm{C}$ & -1.304834 & -0.154761 & 0.000000 & 604.2570 & 3108.6340 \\
$\mathrm{C}$ & -0.113341 & 0.419699 & 0.000000 & 774.0210 & 3239.4180 \\
$\mathrm{~F}$ & 1.087328 & -0.125889 & 0.000000 & 928.3020 & \\
$\mathrm{H}$ & -1.412357 & -1.240972 & 0.000000 & 1149.1200 & \\
$\mathrm{H}$ & -2.198782 & 0.459519 & 0.000000 & 1374.8140 & \\
\hline \hline
\end{tabular}

\begin{tabular}{llllll}
\hline \hline \multicolumn{2}{l}{ difluoromethyl radical $(8)$} & & & \\
\hline Atom & \multicolumn{2}{l}{ Cartesian coordinates $[\AA]$} & & \multicolumn{2}{l}{ Harmonic frequencies $\left[\mathrm{cm}^{-1}\right]$} \\
& $\mathrm{X}$ & $\mathrm{y}$ & $\mathrm{z}$ & 528.498 & 3053.954 \\
$\mathrm{C}$ & 0.000281 & 0.502847 & -0.077484 & 1003.524 & \\
$\mathrm{~F}$ & 1.129382 & -0.193182 & 0.015222 & 1160.207 & \\
$\mathrm{~F}$ & -1.123323 & -0.202293 & 0.013138 & 1176.803 & \\
$\mathrm{H}$ & -0.117563 & 1.467762 & 0.387974 & 1335.292 \\
\hline \hline
\end{tabular}

\begin{tabular}{|c|c|c|c|c|}
\hline \multicolumn{5}{|c|}{$\mathrm{CH}_{2}(8)$} \\
\hline \multirow[t]{2}{*}{ Atom } & \multicolumn{3}{|c|}{ Cartesian coordinates $[\AA \stackrel{\mathrm{A}}{ }]$} & Harmonic frequencies $\left[\mathrm{cm}^{-1}\right]$ \\
\hline & $\mathrm{x}$ & $\mathrm{y}$ & $\mathrm{z}$ & 1416.2310 \\
\hline $\mathrm{C}$ & 0.000000 & 0.000000 & 0.096472 & \\
\hline $\mathrm{H}$ & 0.000000 & -0.859136 & -0.574337 & 2809.9560 \\
\hline $\mathrm{H}$ & 0.000000 & 0.859136 & -0.574337 & \\
\hline
\end{tabular}

\begin{tabular}{llllll}
\hline \hline \multicolumn{7}{l}{ 1, 2-difluoroethyl radical $(9$, rotamer a) } \\
\hline Atom & \multicolumn{4}{l}{ Coordinates $[\AA]$} & \multicolumn{3}{l}{ Harmonic } & \\
& $\mathrm{x}$ & $\mathrm{y}$ & $\mathrm{z}$ & 122.6600 & 1245.5630 \\
$\mathrm{C}$ & 0.645584 & 0.564267 & 0.327427 & 300.3550 & 1350.2790 \\
$\mathrm{C}$ & -0.662584 & 0.509770 & -0.338873 & 445.4950 & 1423.1500 \\
$\mathrm{~F}$ & 1.526072 & -0.444604 & -0.125150 & 574.6810 & 1461.3470 \\
$\mathrm{~F}$ & -1.557692 & -0.381959 & 0.123342 & 900.0060 & 3012.0590 \\
$\mathrm{H}$ & 0.522912 & 0.440020 & 1.412405 & 933.9540 & 3069.7010 \\
$\mathrm{H}$ & -0.843158 & 0.817455 & -1.367406 & 1100.0120 & 3171.5120 \\
$\mathrm{H}$ & 1.118723 & 1.535600 & 0.125365 & 1210.2600 & \\
\hline \hline
\end{tabular}

\begin{tabular}{|c|c|c|c|c|c|}
\hline \multicolumn{6}{|c|}{ 1, 2-difluoroethyl radical $(9$, rotamer b) } \\
\hline \multirow[t]{2}{*}{ Atom } & \multicolumn{3}{|c|}{ Coordinates $[\AA]$} & \multicolumn{2}{|c|}{ Harmonic frequencies $\left[\mathrm{cm}^{-1}\right]$} \\
\hline & $\mathrm{x}$ & $\mathrm{y}$ & $\mathrm{z}$ & 122.6540 & 1245.5650 \\
\hline $\mathrm{C}$ & -0.645579 & 0.564262 & 0.327429 & 300.3530 & 1350.2780 \\
\hline $\mathrm{C}$ & 0.662586 & 0.509766 & -0.338874 & 445.4910 & 1423.1520 \\
\hline $\mathrm{F}$ & 1.557695 & -0.381958 & 0.123341 & 574.6670 & 1461.3460 \\
\hline $\mathrm{F}$ & -1.526081 & -0.444598 & -0.125151 & 900.0070 & 3012.0610 \\
\hline $\mathrm{H}$ & -1.118717 & 1.535601 & 0.125387 & 933.9510 & 3069.7050 \\
\hline $\mathrm{H}$ & 0.843171 & 0.817466 & -1.367400 & 1100.0110 & 3171.5140 \\
\hline $\mathrm{H}$ & -0.522899 & 0.439992 & 1.412403 & 1210.2670 & \\
\hline
\end{tabular}

\begin{tabular}{llllll}
\hline \hline \multicolumn{2}{l}{ cis-1, 2-difluoroethene $(10)$} & & & \\
\hline Atom & \multicolumn{2}{l}{ Coordinates $[\AA]$} & & \multicolumn{2}{l}{ Harmonic frequencies $\left[\mathrm{cm}^{-1}\right]$} \\
& $\mathrm{x}$ & $\mathrm{y}$ & $\mathrm{z}$ & 223.4390 & 1276.1670 \\
$\mathrm{C}$ & -0.667131 & 0.638631 & 0.000000 & 487.2040 & 1388.8460 \\
\hline \hline
\end{tabular}




\begin{tabular}{llllll}
\hline \hline $\mathrm{C}$ & 0.667100 & 0.638659 & 0.000000 & 759.9070 & 1750.2960 \\
$\mathrm{~F}$ & -1.399700 & -0.486075 & 0.000000 & 767.0530 & 3181.0820 \\
$\mathrm{~F}$ & 1.399734 & -0.486055 & 0.000000 & 802.8550 & 3205.8400 \\
$\mathrm{H}$ & -1.246636 & 1.558423 & 0.000000 & 1015.4920 & \\
$\mathrm{H}$ & 1.246347 & 1.558635 & 0.000000 & 1145.9330 & \\
\hline \hline
\end{tabular}

\begin{tabular}{|c|c|c|c|c|c|}
\hline \multicolumn{6}{|c|}{ trans-1, 2-difluoroethene (11) } \\
\hline \multirow[t]{2}{*}{ Atom } & \multicolumn{3}{|c|}{ Coordinates $[\AA ̊ a]$} & \multicolumn{2}{|c|}{ Harmonic frequencies $\left[\mathrm{cm}^{-1}\right]$} \\
\hline & $\mathrm{x}$ & $\mathrm{y}$ & $\mathrm{z}$ & 310.4010 & 1284.6000 \\
\hline $\mathrm{C}$ & -0.529010 & 0.406333 & 0.000000 & 333.8880 & 1287.0570 \\
\hline $\mathrm{C}$ & 0.529006 & -0.406307 & 0.000000 & 547.2710 & 1733.8460 \\
\hline $\mathrm{F}$ & -1.777237 & -0.097637 & 0.000000 & 762.4350 & 3191.6450 \\
\hline $\mathrm{F}$ & 1.777243 & 0.097619 & 0.000000 & 892.9320 & 3199.2830 \\
\hline $\mathrm{H}$ & -0.476809 & 1.492237 & 0.000000 & 1153.4810 & \\
\hline $\mathrm{H}$ & 0.476747 & -1.492209 & 0.000000 & 1181.0060 & \\
\hline
\end{tabular}

\begin{tabular}{llllll}
\hline \hline \multicolumn{2}{c}{ cis-1, 2-difluoroethenyl radical (12) } & & \\
\hline Atom & \multicolumn{2}{l}{ Coordinates $[\AA]$} & & \multicolumn{3}{l}{ Harmonic frequencies $\left[\mathrm{cm}^{-1}\right]$} \\
& $\mathrm{x}$ & $\mathrm{y}$ & $\mathrm{z}$ & 202.1390 & 1338.3130 \\
$\mathrm{C}$ & 0.670900 & 0.635163 & 0.000000 & 370.5250 & 1742.9420 \\
$\mathrm{C}$ & -0.655833 & 0.615056 & 0.000000 & 733.9520 & 3219.1510 \\
$\mathrm{~F}$ & -1.505868 & -0.385501 & 0.000000 & 766.2480 & \\
$\mathrm{~F}$ & 1.430999 & -0.487127 & 0.000000 & 1005.6120 & \\
$\mathrm{H}$ & 1.231952 & 1.563672 & 0.000000 & 1126.3170 & \\
\hline \hline
\end{tabular}

\begin{tabular}{|c|c|c|c|c|c|}
\hline \multirow[t]{2}{*}{ Atom } & \multicolumn{3}{|c|}{ Coordinates $[\AA]$} & \multicolumn{2}{|c|}{ Harmonic Frequencies $\left[\mathrm{cm}^{-1}\right]$} \\
\hline & $\mathrm{x}$ & $\mathrm{y}$ & $\mathrm{z}$ & 292.4800 & 1280.1020 \\
\hline $\mathrm{C}$ & 0.543054 & -0.400568 & 0.000000 & 298.2310 & 1729.5080 \\
\hline $\mathrm{C}$ & -0.545275 & 0.360228 & 0.000000 & 537.2310 & 3133.8690 \\
\hline $\mathrm{F}$ & -1.801608 & -0.032757 & 0.000000 & 663.5400 & \\
\hline $\mathrm{F}$ & 1.775252 & 0.137366 & 0.000000 & 1120.1970 & \\
\hline $\mathrm{H}$ & 0.523283 & -1.491655 & 0.000000 & 1202.7490 & \\
\hline
\end{tabular}

\begin{tabular}{|c|c|c|c|c|c|}
\hline \multicolumn{6}{|c|}{ cis-monofluoroethenyl radical (15) } \\
\hline \multirow[t]{2}{*}{ Atom } & \multicolumn{3}{|c|}{ Coordinates $[\AA]$} & \multicolumn{2}{|c|}{ Harmonic Frequencies $\left[\mathrm{cm}^{-1}\right]$} \\
\hline & $\mathrm{x}$ & $\mathrm{y}$ & $\mathrm{z}$ & 418.4200 & 1655.7290 \\
\hline $\mathrm{C}$ & 0.154435 & -0.431294 & 0.000000 & 594.9340 & 3153.5240 \\
\hline $\mathrm{C}$ & 1.326097 & 0.158855 & 0.000000 & 780.8870 & 3298.7560 \\
\hline $\mathrm{F}$ & -1.028591 & 0.192055 & 0.000000 & 865.5510 & \\
\hline $\mathrm{H}$ & 0.002528 & -1.520754 & 0.000000 & 1044.8500 & \\
\hline $\mathrm{H}$ & 1.758905 & 1.144229 & 0.000000 & 1291.8340 & \\
\hline
\end{tabular}

\begin{tabular}{llllll}
\hline \hline \multicolumn{2}{l}{ trans-monofluoroethenyl radical (16) } \\
\hline Atom & \multicolumn{2}{l}{ Coordinates $[\AA]$} & \multicolumn{3}{l}{ Harmonic frequencies $\left[\mathrm{cm}^{-1}\right]$} \\
& $\mathrm{x}$ & $\mathrm{y}$ & $\mathrm{z}$ & 465.6490 & 1670.4490 \\
$\mathrm{C}$ & 0.168257 & 0.409568 & 0.000000 & 597.7410 & 3085.6590 \\
$\mathrm{C}$ & 1.293644 & -0.268106 & 0.000000 & 733.8410 & 3295.5210 \\
$\mathrm{~F}$ & 0.102531 & 1.502928 & 0.000000 & 782.6830 & \\
$\mathrm{H}$ & -1.053638 & -0.165915 & 0.000000 & 1108.8690 & \\
$\mathrm{H}$ & 2.352876 & -0.059644 & 0.000000 & 1277.9110 & \\
\hline \hline
\end{tabular}

\begin{tabular}{llllll}
\hline \hline \multicolumn{3}{l}{ monofluoromethyl radical (17) } & & & \\
\hline Atom & \multicolumn{2}{l}{ Cartesian coordinates $[\AA]$} & & \multicolumn{2}{l}{ Harmonic frequencies $\left[\mathrm{cm}^{-1}\right]$} \\
& $\mathrm{x}$ & $\mathrm{y}$ & $\mathrm{z}$ & 604.832 & 3241.707 \\
$\mathrm{C}$ & -0.057495 & 0.740239 & 0.000000 & 1165.278 & \\
$\mathrm{~F}$ & 0.009897 & -0.599338 & 0.000000 & 1189.745 & \\
$\mathrm{H}$ & 0.249006 & 1.242080 & 0.910316 & 1470.524 & \\
$\mathrm{H}$ & 0.249006 & 1.242080 & -0.910316 & 3092.143 & \\
\hline \hline
\end{tabular}




\begin{tabular}{lllll}
\hline Atom & \multicolumn{2}{l}{ Cartesion coordinates $[\AA$ A $]$} & Harmonic frequencies $\left[\mathrm{cm}^{-1}\right]$ \\
& $\mathrm{x}$ & $\mathrm{y}$ & $\mathrm{z}$ & 1195.7000 \\
$\mathrm{C}$ & -0.771095 & -0.099250 & 0.000000 & \\
$\mathrm{~F}$ & 0.546697 & 0.013255 & 0.000000 & 1422.1510 \\
$\mathrm{H}$ & -1.124428 & 0.931893 & 0.000000 & \\
\hline \hline
\end{tabular}

\begin{tabular}{lllll}
\hline \hline \multicolumn{4}{l}{ hydrogen molecule $(1,5,10,11)$} & \\
\hline \multicolumn{4}{c}{ Atom } & \multicolumn{2}{l}{ Cartesian coordinates $[\AA]$} & Harmonic frequencies $\left[\mathrm{cm}^{-1}\right]$ \\
& $\mathrm{x}$ & $\mathrm{y}$ & $\mathrm{z}$ & 4437.7181 \\
$\mathrm{H}$ & 0.000000 & 0.000000 & 0.371830 & \\
$\mathrm{H}$ & 0.000000 & 0.000000 & -0.371830 & \\
\hline \hline
\end{tabular}

\begin{tabular}{lllll}
\hline \hline \multicolumn{4}{l}{ hydrogenfluoride $(7,15,16)$} & \\
\hline \multicolumn{4}{l}{ Atom } & \multicolumn{2}{l}{ Cartesian coordinates $[\stackrel{\circ}{\mathrm{A}}]$} & Harmonic frequencies $\left[\mathrm{cm}^{-1}\right]$ \\
& $\mathrm{x}$ & $\mathrm{y}$ & $\mathrm{z}$ & 4059.2144 \\
$\mathrm{~F}$ & 0.000000 & 0.000000 & 0.046558 & \\
$\mathrm{H}$ & 0.000000 & 0.000000 & -0.877664 & \\
\hline \hline
\end{tabular}

\begin{tabular}{|c|c|c|c|c|c|}
\hline \multicolumn{6}{|c|}{ TS H dissociation $(0->1)$} \\
\hline \multirow[t]{2}{*}{ Atom } & \multicolumn{3}{|c|}{ Cartesian coordinates $[\AA]$} & \multicolumn{2}{|c|}{ Harmonic frequencies $\left[\mathrm{cm}^{-1}\right]$} \\
\hline & $\mathrm{x}$ & $\mathrm{y}$ & $\mathrm{z}$ & 146.1860 & 945.8130 \\
\hline $\mathrm{C}$ & -0.166696 & -1.433836 & 0.000000 & 170.4130 & 1330.2970 \\
\hline $\mathrm{C}$ & -0.051168 & -0.105041 & 0.000000 & 428.5610 & 1387.1380 \\
\hline $\mathrm{F}$ & 0.026516 & 0.647733 & -1.087722 & 537.9260 & 1726.1810 \\
\hline $\mathrm{F}$ & 0.026516 & 0.647733 & 1.087722 & 608.7150 & 3195.4640 \\
\hline $\mathrm{H}$ & 2.104031 & -2.166858 & 0.000000 & 729.3480 & 3302.2330 \\
\hline $\mathrm{H}$ & -0.254837 & -1.965352 & 0.938308 & 778.9480 & -331.4080 \\
\hline $\mathrm{H}$ & -0.254837 & -1.965352 & -0.938308 & 929.7310 & \\
\hline
\end{tabular}

\begin{tabular}{|c|c|c|c|c|c|}
\hline \multicolumn{6}{|c|}{ TS H shift $(0->4)$} \\
\hline \multirow[t]{2}{*}{ Atom } & \multicolumn{3}{|c|}{ Cartesian coordinates $[\AA]$} & \multicolumn{2}{|c|}{ Harmonic frequencies $\left[\mathrm{cm}^{-1}\right]$} \\
\hline & $\mathrm{x}$ & $\mathrm{y}$ & $\mathrm{z}$ & 188.3260 & 1291.7720 \\
\hline $\mathrm{C}$ & -0.081888 & 1.509437 & 0.000000 & 385.9940 & 1299.2830 \\
\hline $\mathrm{C}$ & 0.225474 & 0.072867 & 0.000000 & 458.0590 & 1396.3950 \\
\hline $\mathrm{F}$ & -0.059235 & -0.630995 & 1.119228 & 599.1370 & 2102.3860 \\
\hline $\mathrm{F}$ & -0.059235 & -0.630995 & -1.119228 & 679.7800 & 3150.3010 \\
\hline $\mathrm{H}$ & 1.165984 & 0.979458 & 0.000000 & 898.9900 & 3285.6260 \\
\hline $\mathrm{H}$ & -0.321189 & 1.984970 & -0.945018 & 909.7390 & -2005.5340 \\
\hline $\mathrm{H}$ & -0.321189 & 1.984970 & 0.945018 & 1177.8320 & \\
\hline
\end{tabular}

\begin{tabular}{|c|c|c|c|c|c|}
\hline \multicolumn{6}{|c|}{ TS $\mathrm{H}_{2}$ elimination $(1->2)$} \\
\hline \multirow[t]{2}{*}{ Atom } & \multicolumn{3}{|c|}{ Cartesian coordinates $[\AA]$} & \multicolumn{2}{|c|}{ Harmonic frequencies $\left[\mathrm{cm}^{-1}\right]$} \\
\hline & $\mathrm{x}$ & $\mathrm{y}$ & $\mathrm{z}$ & 166.9630 & 926.6660 \\
\hline $\mathrm{C}$ & -1.132236 & -0.864639 & 0.000002 & 228.7840 & 1047.1030 \\
\hline $\mathrm{C}$ & -0.062655 & -0.092228 & 0.000001 & 481.0140 & 1254.0940 \\
\hline $\mathrm{F}$ & -0.079084 & 1.234975 & 0.000001 & 532.3930 & 1727.3050 \\
\hline $\mathrm{F}$ & 1.198718 & -0.529987 & -0.000001 & 537.6520 & 2508.3500 \\
\hline $\mathrm{H}$ & -1.215537 & -1.941185 & 0.000003 & 619.9270 & 3283.9780 \\
\hline $\mathrm{H}$ & -2.455145 & -0.164820 & -0.000008 & 835.5400 & -712.2100 \\
\hline $\mathrm{H}$ & -3.208061 & 0.209593 & -0.000015 & 862.8850 & \\
\hline
\end{tabular}

\begin{tabular}{|c|c|c|c|c|c|}
\hline \multicolumn{6}{|c|}{ TS H dissociation (4 -> 5) } \\
\hline \multirow[t]{2}{*}{ Atom } & \multicolumn{3}{|c|}{ Cartesian coordinates $[\AA ⿻]$} & \multicolumn{2}{|c|}{ Harmonic frequencies $\left[\mathrm{cm}^{-1}\right]$} \\
\hline & $\mathrm{x}$ & $\mathrm{y}$ & $\mathrm{z}$ & 374.1250 & 948.6620 \\
\hline $\mathrm{C}$ & 0.047453 & 0.125201 & 0.000000 & 448.3170 & 1331.2800 \\
\hline $\mathrm{C}$ & -0.070408 & 1.481684 & 0.000000 & 455.3550 & 1381.6090 \\
\hline $\mathrm{F}$ & -0.043309 & -0.619447 & 1.092969 & 544.4830 & 1605.9790 \\
\hline $\mathrm{F}$ & -0.043309 & -0.619447 & -1.092969 & 634.4400 & 3180.0270 \\
\hline $\mathrm{H}$ & -0.058804 & 2.012674 & -0.944129 & 650.0840 & 3296.6590 \\
\hline $\mathrm{H}$ & -0.058804 & 2.012674 & 0.944129 & 749.1510 & -773.0580 \\
\hline $\mathrm{H}$ & 2.023751 & 0.196008 & 0.000000 & 908.1290 & \\
\hline
\end{tabular}




\begin{tabular}{llllll}
\hline \hline \multicolumn{2}{l}{ TS HF elimination $(4->7)$} & \multicolumn{3}{l}{ Harmonic } \\
\hline Atom & \multicolumn{2}{l}{ Cartesian coordinates $[\AA]$ encies $\left[\mathrm{cm}^{-1}\right]$} \\
& $\mathrm{x}$ & $\mathrm{y}$ & $\mathrm{z}$ & 114.2500 & 1229.0440 \\
$\mathrm{C}$ & -0.363055 & 0.100333 & -0.197209 & 220.7130 & 1377.5310 \\
$\mathrm{C}$ & -0.860036 & 1.323304 & 0.061982 & 489.2670 & 1593.0900 \\
$\mathrm{~F}$ & 1.871803 & -0.067832 & 0.052993 & 607.4380 & 2347.7150 \\
$\mathrm{~F}$ & -1.022484 & -1.021680 & 0.053590 & 757.7550 & 3153.6740 \\
$\mathrm{H}$ & -1.903995 & 1.466116 & 0.331219 & 850.3960 & 3267.9620 \\
$\mathrm{H}$ & -0.218924 & 2.186585 & -0.077488 & 936.0180 & -428.0960 \\
$\mathrm{H}$ & 0.675627 & -0.065423 & -0.652794 & 1156.6530 & \\
\hline \hline
\end{tabular}

\begin{tabular}{|c|c|c|c|c|c|}
\hline \multicolumn{6}{|c|}{ TS F shift (4 -> 9) } \\
\hline \multirow[t]{2}{*}{ Atom } & \multicolumn{3}{|c|}{ Cartesian coordinates $[\AA]$} & \multicolumn{2}{|c|}{ Harmonic frequencies $\left[\mathrm{cm}^{-1}\right]$} \\
\hline & $\mathrm{x}$ & $\mathrm{y}$ & $\mathrm{z}$ & 185.8060 & 1295.2650 \\
\hline $\mathrm{C}$ & 0.447696 & 0.258001 & 0.468617 & 361.2030 & 1405.1800 \\
\hline $\mathrm{C}$ & -0.378381 & 1.130968 & -0.180929 & 471.8920 & 1605.3560 \\
\hline $\mathrm{F}$ & -1.386166 & -0.634877 & -0.033242 & 665.9120 & 3176.4390 \\
\hline $\mathrm{F}$ & 1.390887 & -0.406705 & -0.184224 & 794.1130 & 3204.1390 \\
\hline $\mathrm{H}$ & -0.293042 & 1.280094 & -1.251782 & 869.5480 & 3289.4870 \\
\hline $\mathrm{H}$ & -1.072507 & 1.739473 & 0.385451 & 942.0150 & -322.1570 \\
\hline $\mathrm{H}$ & 0.451231 & 0.076956 & 1.540325 & 1200.7200 & \\
\hline
\end{tabular}

\begin{tabular}{llllll}
\hline \hline \multicolumn{2}{l}{ TS H dissociation $(9->10)$} & \multicolumn{3}{l}{ Harmonic frequencies $\left[\mathrm{cm}^{-1}\right]$} \\
\hline Atom & \multicolumn{2}{l}{ Cartesian coordinates $[\AA]$} & & 218.1510 & 1155.3940 \\
& $\mathrm{x}$ & $\mathrm{y}$ & $\mathrm{z}$ & 251.8050 & 1270.7010 \\
$\mathrm{C}$ & -0.670551 & -0.608490 & -0.078919 & 321.8460 & 1393.2360 \\
$\mathrm{C}$ & 0.676678 & -0.625971 & -0.108823 & 504.1010 & 1680.4810 \\
$\mathrm{~F}$ & -1.257771 & -1.494698 & -0.303812 & 755.7460 & 3188.0620 \\
$\mathrm{~F}$ & 1.411819 & 0.477698 & 0.057879 & 764.3820 & 3209.2450 \\
$\mathrm{H}$ & -1.365001 & 0.533094 & -0.014489 & 845.1970 & -500.6190 \\
$\mathrm{H}$ & 1.244078 & -1.548835 & -0.195575 & 1014.3150 & \\
$\mathrm{H}$ & -0.941823 & -1.312294 & 1.916868 & & \\
\hline \hline
\end{tabular}

\begin{tabular}{|c|c|c|c|c|c|}
\hline \multicolumn{6}{|c|}{ TS H dissociation (9 -> 11) } \\
\hline \multirow[t]{2}{*}{ Atom } & \multicolumn{3}{|c|}{ Cartesian coordinates $[\AA ̊]$} & \multicolumn{2}{|c|}{ Harmonic frequencies $\left[\mathrm{cm}^{-1}\right]$} \\
\hline & $\mathrm{x}$ & $\mathrm{y}$ & $\mathrm{z}$ & 250.9590 & 1191.7250 \\
\hline $\mathrm{C}$ & -0.528592 & -0.376833 & 0.126844 & 292.4190 & 1271.4390 \\
\hline $\mathrm{C}$ & -1.764173 & 0.135741 & 0.018528 & 339.2890 & 1288.5430 \\
\hline $\mathrm{F}$ & 0.541100 & 0.406904 & -0.109326 & 352.6540 & 1669.0220 \\
\hline $\mathrm{F}$ & -0.475877 & -1.365734 & 0.574239 & 545.8340 & 3195.4630 \\
\hline $\mathrm{H}$ & 0.490032 & 1.425455 & -0.485600 & 764.9990 & 3200.3730 \\
\hline $\mathrm{H}$ & 1.780123 & -0.075840 & 0.055091 & 895.8270 & -483.2980 \\
\hline $\mathrm{H}$ & -0.463752 & -1.546964 & -1.684994 & 1156.5170 & \\
\hline
\end{tabular}

\begin{tabular}{|c|c|c|c|c|c|}
\hline \multicolumn{6}{|c|}{$\mathrm{TS} \mathrm{H}_{2}$ elimination $(10->12)$} \\
\hline \multirow[t]{2}{*}{ Atom } & \multicolumn{3}{|c|}{ Cartesian coordinates $[\AA ̊ 丿]$} & \multicolumn{2}{|c|}{ Harmonic frequencies $\left[\mathrm{cm}^{-1}\right]$} \\
\hline & $\mathrm{x}$ & $\mathrm{y}$ & $\mathrm{z}$ & 232.9670 & 1125.8570 \\
\hline $\mathrm{C}$ & 0.533598 & -0.315221 & -0.000001 & 240.5880 & 1193.8210 \\
\hline $\mathrm{C}$ & -0.552016 & 0.454941 & 0.000001 & 315.2230 & 1278.2920 \\
\hline $\mathrm{F}$ & -1.783501 & -0.083015 & 0.000000 & 327.9660 & 1709.7790 \\
\hline $\mathrm{F}$ & 1.779545 & 0.143077 & 0.000000 & 545.7460 & 1964.5380 \\
\hline $\mathrm{H}$ & -0.532185 & 1.544900 & 0.000001 & 732.6970 & 3149.2040 \\
\hline $\mathrm{H}$ & 0.432552 & -1.727695 & 0.000000 & 971.3470 & -940.7750 \\
\hline $\mathrm{H}$ & 0.393501 & -2.613051 & 0.000003 & 1100.9410 & \\
\hline
\end{tabular}

\begin{tabular}{llllll}
\hline \hline \multicolumn{2}{l}{$\mathrm{TS} \mathrm{H}_{2}$ elimination $(10->13)$} & & \multicolumn{3}{l}{ Harmonic frequencies $\left[\mathrm{cm}^{-1}\right]$} \\
\hline Atom & \multicolumn{2}{l}{ Cartesian coordinates $[\AA]$} & & 204.1200 & 1120.8690 \\
& $\mathrm{x}$ & $\mathrm{y}$ & $\mathrm{z}$ & 210.3970 & 1180.9570 \\
$\mathrm{C}$ & 0.671275 & -0.505172 & 0.000000 & 264.6390 & 1339.3550 \\
$\mathrm{C}$ & -0.652631 & -0.639193 & 0.000000 & 414.2640 & 1723.0930 \\
$\mathrm{~F}$ & -1.503988 & 0.407705 & 0.000000 & 721.1870 & 1965.5070 \\
$\mathrm{~F}$ & -1.130632 & -1.614316 & 0.000000 & 773.4760 & 3204.8360 \\
$\mathrm{H}$ & 1.371194 & 0.618179 & 0.000000 & & -938.7340 \\
$\mathrm{H}$ & 1.458751 & -1.681336 & 0.000000 & 927.8140 & \\
\hline \hline
\end{tabular}




\begin{tabular}{|c|c|c|c|c|c|}
\hline $\mathrm{H}$ & 1.953178 & -2.417416 & 0.000001 & \multicolumn{2}{|l|}{995.8440} \\
\hline \multicolumn{6}{|c|}{ TS HF elimination $(9->15)$} \\
\hline \multirow[t]{2}{*}{ Atom } & \multicolumn{3}{|c|}{ Cartesian coordinates $[\AA]$} & \multicolumn{2}{|c|}{ Harmonic frequencies $\left[\mathrm{cm}^{-1}\right]$} \\
\hline & $\mathrm{x}$ & $\mathrm{y}$ & $\mathrm{z}$ & 98.3310 & 1232.5480 \\
\hline $\mathrm{C}$ & -0.199837 & -0.685300 & 0.096858 & 229.4360 & 1300.5840 \\
\hline $\mathrm{C}$ & 0.704617 & 0.301920 & 0.114636 & 388.1020 & 1606.4260 \\
\hline $\mathrm{F}$ & -2.281970 & 0.198447 & -0.071124 & 547.3230 & 1874.5590 \\
\hline $\mathrm{F}$ & 2.008786 & 0.082971 & -0.089014 & 769.3660 & 3182.0070 \\
\hline $\mathrm{H}$ & -0.043127 & -1.684002 & -0.301768 & 871.3010 & 3209.5080 \\
\hline $\mathrm{H}$ & 0.478081 & 1.342621 & 0.341834 & 948.2410 & -572.4910 \\
\hline $\mathrm{H}$ & -1.295525 & -0.398759 & 0.460452 & 1149.3040 & \\
\hline
\end{tabular}

\begin{tabular}{llllll}
\hline \hline \multicolumn{2}{l}{ TS HF elimination $(9->16)$} & \multicolumn{3}{l}{ Harmonic } & frequencies $\left[\mathrm{cm}^{-1}\right.$ ] \\
\hline Atom & \multicolumn{2}{l}{ Cartesian coordinates $[\AA]$} & & 88.2780 & 1253.1590 \\
& $\mathrm{x}$ & $\mathrm{y}$ & $\mathrm{z}$ & 271.1380 & 1300.4010 \\
$\mathrm{C}$ & -0.168135 & 1.017858 & -0.112729 & 502.5590 & 1622.8960 \\
$\mathrm{C}$ & 1.056818 & 0.520444 & 0.102711 & 551.1140 & 1995.4030 \\
$\mathrm{~F}$ & -1.938830 & -0.387545 & 0.046054 & 722.1030 & 3132.2210 \\
$\mathrm{~F}$ & 1.352591 & -0.769695 & -0.037622 & 897.7450 & 3221.1300 \\
$\mathrm{H}$ & 1.935540 & 1.127557 & 0.333408 & 926.4250 & -541.6520 \\
$\mathrm{H}$ & -0.435363 & 2.034633 & 0.158952 & 1144.0380 & \\
$\mathrm{H}$ & -1.030451 & 0.336536 & -0.532034 & & \\
\hline \hline
\end{tabular}

\begin{tabular}{|c|c|c|c|c|c|}
\hline \multicolumn{6}{|c|}{ TS rotation $(0->0)$} \\
\hline \multirow[t]{2}{*}{ Atom } & \multicolumn{3}{|c|}{ Cartesian coordinates $[\AA]$} & \multicolumn{2}{|c|}{ Harmonic frequencies $\left[\mathrm{cm}^{-1}\right]$} \\
\hline & $\mathrm{x}$ & $\mathrm{y}$ & $\mathrm{Z}$ & 389.5440 & 1378.8240 \\
\hline $\mathrm{C}$ & 1.504660 & 0.000003 & 0.063885 & 474.6280 & 1447.5380 \\
\hline $\mathrm{C}$ & 0.047140 & 0.000000 & -0.296963 & 518.2740 & 1467.8600 \\
\hline $\mathrm{F}$ & -0.639483 & -1.102840 & 0.061151 & 847.6230 & 3019.5100 \\
\hline $\mathrm{F}$ & -0.639489 & 1.102837 & 0.061151 & 929.5760 & 3097.4480 \\
\hline $\mathrm{H}$ & 1.747516 & 0.892939 & 0.650584 & 1014.8210 & 3120.5020 \\
\hline $\mathrm{H}$ & 1.747520 & -0.892933 & 0.650583 & 1233.8570 & -211.5930 \\
\hline $\mathrm{H}$ & 2.137711 & 0.000004 & -0.831424 & 1258.1110 & \\
\hline
\end{tabular}

\begin{tabular}{llllll}
\hline \hline \multicolumn{2}{l}{ TS rotation $(4->4)$} & \multicolumn{3}{l}{ Harmonic frequencies $\left[\mathrm{cm}^{-1}\right.$ ] } \\
\hline Atom & \multicolumn{2}{l}{ Cartesian coordinates $[\AA]$} & & 340.9570 & 1340.5220 \\
& $\mathrm{x}$ & $\mathrm{y}$ & $\mathrm{z}$ & 458.2910 & 1377.3660 \\
$\mathrm{C}$ & -0.078980 & 0.000007 & 0.372719 & 545.9990 & 1448.5870 \\
$\mathrm{C}$ & -1.472665 & 0.000116 & -0.115819 & 551.1080 & 3033.6460 \\
$\mathrm{~F}$ & 0.595092 & 1.106496 & -0.103772 & 878.3180 & 3155.9080 \\
$\mathrm{~F}$ & 0.594919 & -1.106588 & -0.103772 & 1019.2260 & 3276.4840 \\
$\mathrm{H}$ & -1.651121 & 0.000111 & -1.186767 & 1109.2010 & -106.3530 \\
$\mathrm{H}$ & -2.312197 & 0.000147 & 0.571042 & 1136.2990 & \\
$\mathrm{H}$ & 0.005720 & 0.000001 & 1.469267 & & \\
\hline \hline
\end{tabular}

\begin{tabular}{llllll}
\hline \hline \multicolumn{2}{l}{ TS H-shift a $(9->9)$} & \multicolumn{3}{l}{ Harmonic frequencies $\left[\mathrm{cm}^{-1}\right.$ ] } \\
\hline Atom & \multicolumn{2}{l}{ Cartesian coordinates [̊̊] } & & 257.6600 & 1216.8860 \\
& $\mathrm{x}$ & $\mathrm{y}$ & $\mathrm{z}$ & 364.5500 & 1385.5620 \\
$\mathrm{C}$ & -0.685929 & 0.617619 & 0.167368 & 436.9580 & 1431.7150 \\
$\mathrm{C}$ & 0.734992 & 0.636955 & -0.156469 & 693.0170 & 2054.1920 \\
$\mathrm{~F}$ & 1.427129 & -0.513360 & 0.057571 & 845.5970 & 3151.8540 \\
$\mathrm{~F}$ & -1.472029 & -0.481267 & -0.072910 & 1003.4340 & 3163.1490 \\
$\mathrm{H}$ & 1.217682 & 1.291631 & -0.891773 & 1052.9000 & -1873.4240 \\
$\mathrm{H}$ & 0.242616 & 0.952562 & 1.047772 & 1211.9480 & \\
$\mathrm{H}$ & -1.198087 & 1.567398 & 0.003385 & & \\
\hline \hline
\end{tabular}

\begin{tabular}{|c|c|c|c|c|c|}
\hline \multicolumn{6}{|c|}{ TS H-shift b (9 -> 9) } \\
\hline \multirow[t]{2}{*}{ Atom } & \multicolumn{3}{|c|}{ Cartesian coordinates $[\AA]$} & \multicolumn{2}{|c|}{ Harmonic frequencies $\left[\mathrm{cm}^{-1}\right]$} \\
\hline & $\mathrm{x}$ & $\mathrm{y}$ & $\mathrm{Z}$ & 174.7900 & 1278.3860 \\
\hline $\mathrm{C}$ & -0.621302 & -0.349175 & -0.366067 & 353.1380 & 1313.3940 \\
\hline $\mathrm{C}$ & 0.621310 & -0.348959 & 0.366264 & 602.3170 & 1425.0050 \\
\hline $\mathrm{F}$ & 1.748437 & 0.279344 & -0.107598 & 735.5860 & 2078.1260 \\
\hline
\end{tabular}




\begin{tabular}{llllll}
\hline \hline $\mathrm{F}$ & -1.748441 & 0.279407 & 0.107439 & 788.2320 & 3046.0700 \\
$\mathrm{H}$ & 0.573929 & -0.372915 & 1.454899 & 950.2510 & 3132.3710 \\
$\mathrm{H}$ & -0.000004 & -1.473658 & 0.000436 & 1086.0110 & -1963.0860 \\
$\mathrm{H}$ & -0.573932 & -0.373816 & -1.454685 & 1194.8060 & \\
\hline \hline
\end{tabular}

\begin{tabular}{llllll}
\hline \hline \multicolumn{2}{l}{ TS rotation a $(9->9)$} & \multicolumn{3}{l}{ Harmonic frequencies $\left[\mathrm{cm}^{-1}\right]$} \\
\hline Atom & \multicolumn{2}{l}{ Cartesian coordinates $[\AA]$} & & 310.1730 & 1305.8530 \\
& $\mathrm{x}$ & $\mathrm{y}$ & $\mathrm{z}$ & 356.3740 & 1419.0430 \\
$\mathrm{C}$ & -0.572846 & 0.526394 & -0.124160 & 498.4930 & 1477.2440 \\
$\mathrm{C}$ & 0.572830 & -0.421203 & -0.237202 & 960.6940 & 2946.2000 \\
$\mathrm{~F}$ & -1.739562 & -0.183936 & 0.122010 & 1059.6300 & 2977.6360 \\
$\mathrm{~F}$ & 1.774529 & 0.071606 & 0.129377 & 1065.7400 & 3173.6890 \\
$\mathrm{H}$ & -0.724545 & 1.119797 & -1.043672 & 1177.7710 & -126.6200 \\
$\mathrm{H}$ & 0.451520 & -1.493478 & -0.092670 & 1201.5900 & \\
$\mathrm{H}$ & -0.385939 & 1.238724 & 0.700156 & & \\
\hline \hline
\end{tabular}

\begin{tabular}{|c|c|c|c|c|c|}
\hline \multicolumn{6}{|c|}{ TS rotation b (9 -> 9) } \\
\hline \multirow[t]{2}{*}{ Atom } & \multicolumn{3}{|c|}{ Cartesian coordinates $[\AA]$} & \multicolumn{2}{|c|}{ Harmonic frequencies $\left[\mathrm{cm}^{-1}\right]$} \\
\hline & $\mathrm{x}$ & $\mathrm{y}$ & $\mathrm{z}$ & 238.9350 & 1387.9810 \\
\hline $\mathrm{C}$ & 0.765036 & -0.701391 & 0.017566 & 422.6100 & 1389.7170 \\
\hline $\mathrm{C}$ & -0.734037 & -0.693479 & 0.031186 & 657.9530 & 1482.2460 \\
\hline $\mathrm{F}$ & 1.264206 & 0.585163 & -0.016734 & 907.1630 & 2928.5500 \\
\hline $\mathrm{F}$ & -1.336032 & 0.506797 & 0.003346 & 971.5650 & 2951.1240 \\
\hline $\mathrm{H}$ & 1.144834 & -1.261026 & -0.858648 & 1100.1770 & 3153.3980 \\
\hline $\mathrm{H}$ & -1.327861 & -1.506999 & -0.384246 & 1193.3760 & -217.1270 \\
\hline $\mathrm{H}$ & 1.167918 & -1.207922 & 0.914790 & 1216.5540 & \\
\hline
\end{tabular}

\section{A.2) Images of reaction products and transition states}

The images below show the structures of all products and transition states including a labeling of atoms within the structures that make the data for bond lengths, angles and dihedral angles readable.

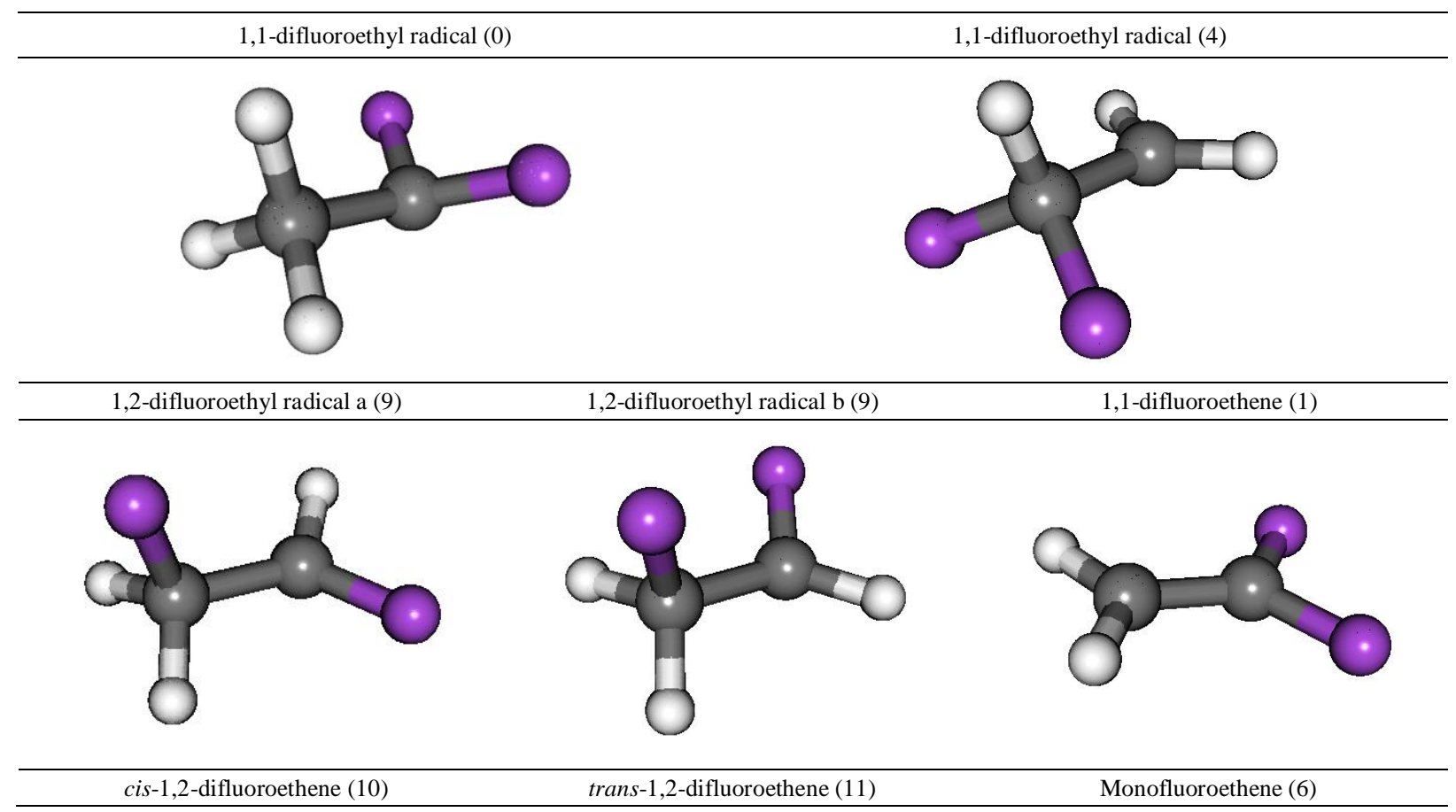



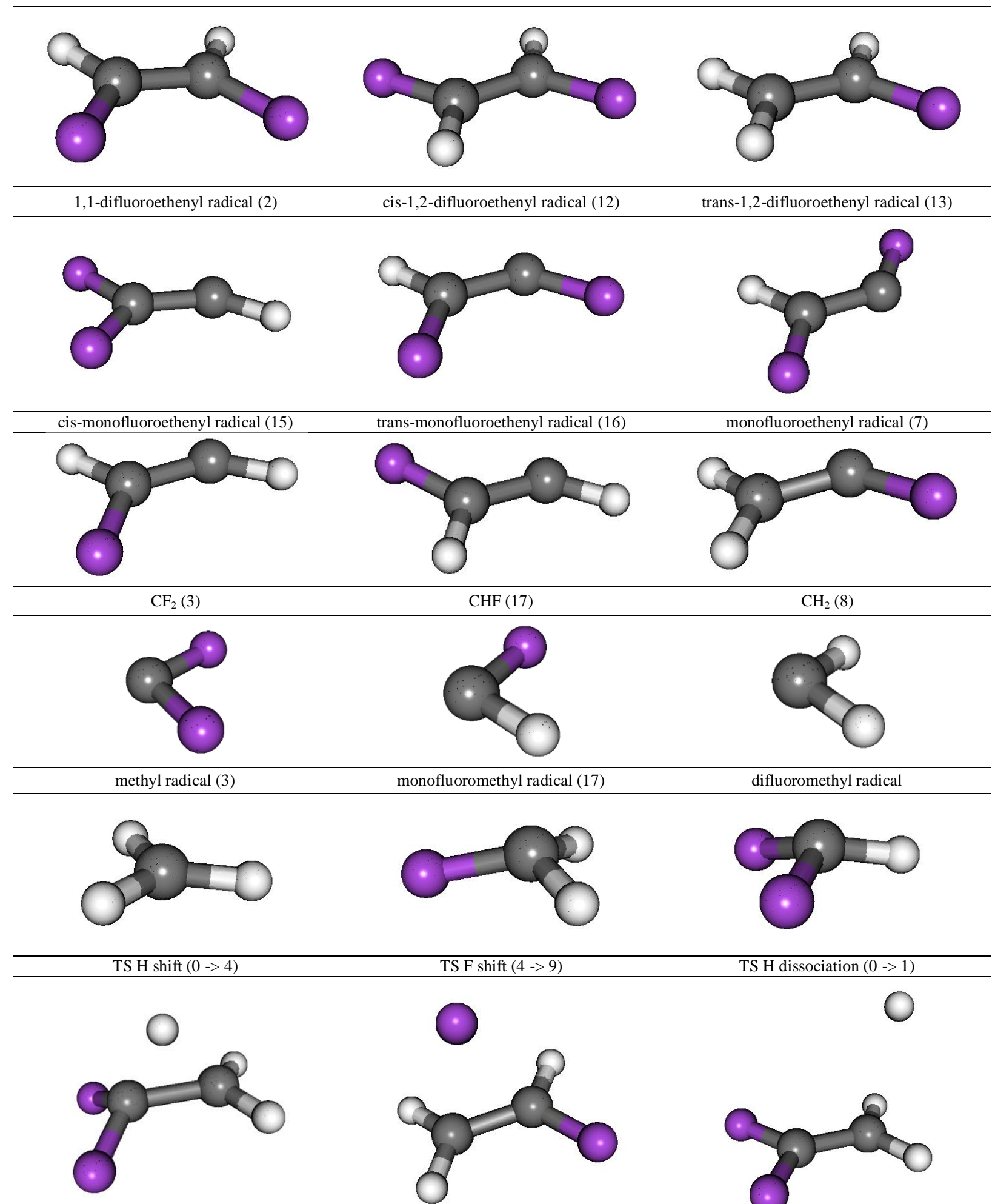

\section{TS H dissociation (4 -> 5)}

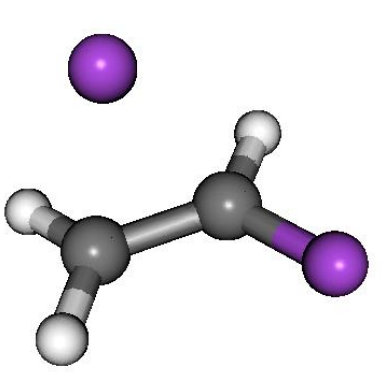

TS H dissociation (9 -> 10)

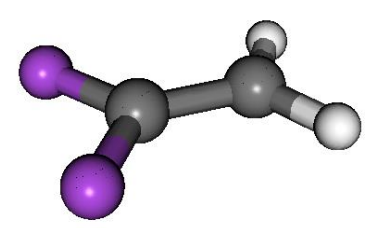

O

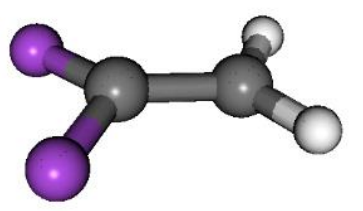

0

TS H dissociation (9 -> 11)
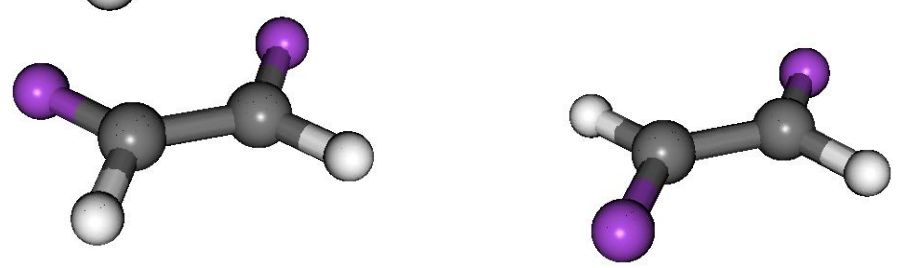

$\mathrm{TS} \mathrm{H}_{2}$ elimination (9 -> 13)

$\mathrm{TS} \mathrm{H}_{2}$ elimination (9 -> 12) 


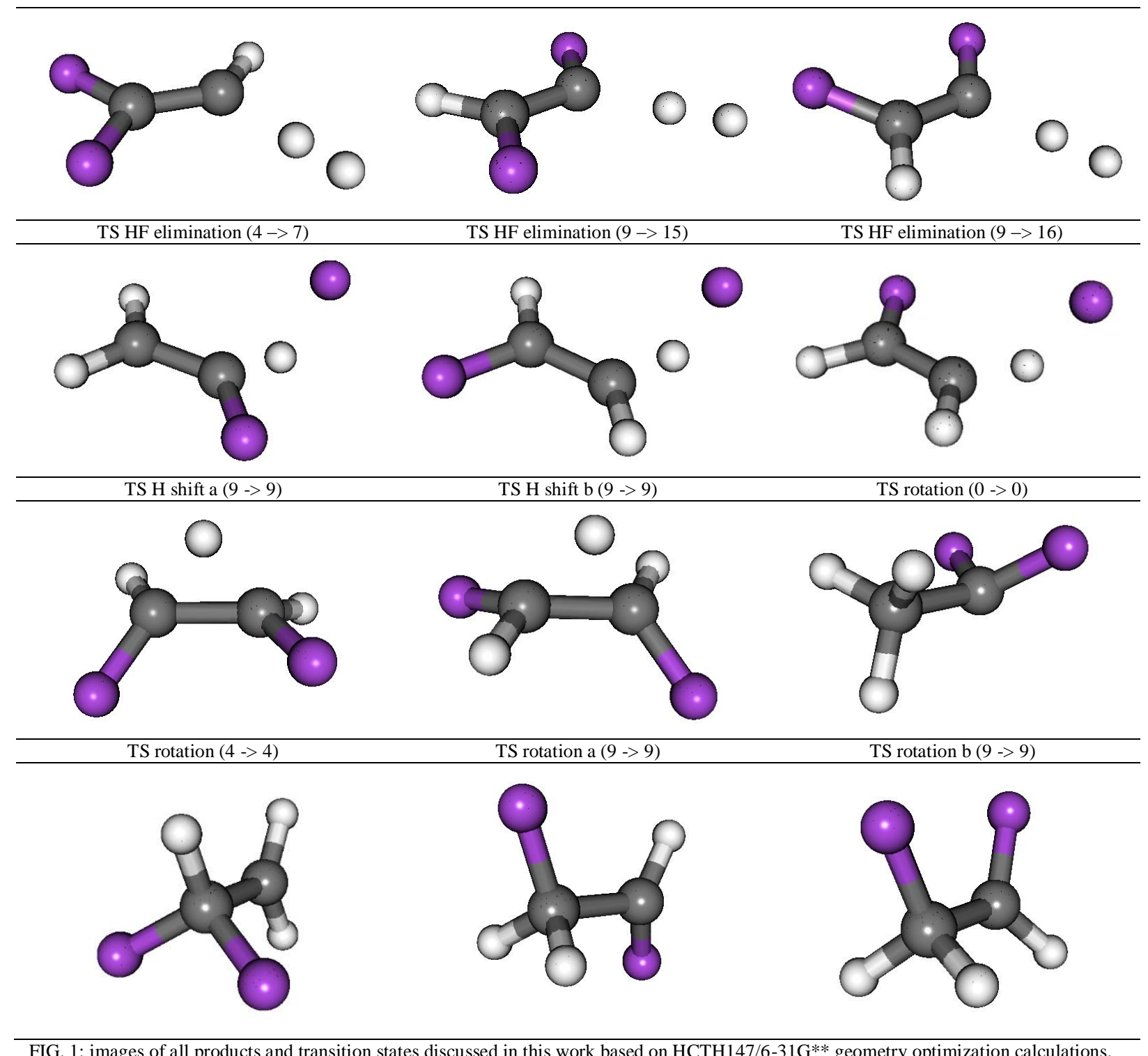

FIG. 1: images of all products and transition states discussed in this work based on HCTH147/6-31G** geometry optimization calculations.

\section{A.3) Bond lengths:}

Bond lenths between selected atoms within all structures are listed in the tables below. The atom labeling refers to the images in Fig.1.

\begin{tabular}{lccccccccc}
\hline \hline Product & $\mathrm{C}_{\mathrm{a}}-\mathrm{C}_{\mathrm{b}}$ & $\mathrm{C}_{\mathrm{a}}-\mathrm{F}_{\mathrm{b}}$ & $\mathrm{C}_{\mathrm{b}}-\mathrm{F}_{\mathrm{a}}$ & $\mathrm{C}_{\mathrm{b}}-\mathrm{F}_{\mathrm{b}}$ & $\mathrm{C}_{\mathrm{a}}-\mathrm{H}_{\mathrm{a}}$ & $\mathrm{C}_{\mathrm{a}}-\mathrm{H}_{\mathrm{b}}$ & $\mathrm{C}_{\mathrm{a}}-\mathrm{H}_{\mathrm{c}}$ & $\mathrm{C}_{\mathrm{b}}-\mathrm{H}_{\mathrm{b}}$ & $\mathrm{C}_{\mathrm{b}}-\mathrm{H}_{\mathrm{c}}$ \\
\hline 1,1-difluoroethyl radical (0) & 1.49 & & 1.35 & 1.35 & 1.10 & 1.09 & 1.09 & & \\
1,1-difluoroethyl radical (4) & 1.48 & 1.38 & & 1.37 & 1.11 & & & 1.08 & 1.08 \\
1,2-difluoroethyl radical a (9) & 1.47 & 1.35 & & 1.41 & 1.10 & 1.10 & & & 1.09 \\
1,2-difluoroethyl radical b (9) & 1.47 & 1.41 & & 1.35 & 1.10 & 1.10 & & 1.09 \\
\hline \hline
\end{tabular}

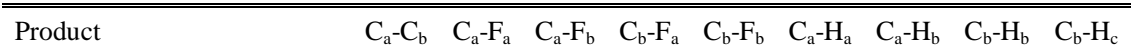

\begin{tabular}{|c|c|c|c|c|c|c|c|c|}
\hline 1,1-difluoroethene (1) & 1.33 & & 1.33 & 1.33 & 1.08 & 1.08 & & \\
\hline cis-1,2-difluoroethene (10) & 1.33 & 1.34 & & 1.34 & 1.09 & & 1.09 & \\
\hline trans-1,2-difluoroethene (11) & 1.33 & 1.35 & & 1.35 & 1.05 & & 1.09 & \\
\hline Monofluoroethene $(6,14)$ & 1.35 & & 1.33 & & 1.09 & 1.09 & & 1.09 \\
\hline
\end{tabular}




\begin{tabular}{lccccccccc}
\hline \hline Product & $\mathrm{C}_{\mathrm{a}}-\mathrm{C}_{\mathrm{b}}$ & $\mathrm{C}_{\mathrm{a}}-\mathrm{F}_{\mathrm{a}}$ & $\mathrm{C}_{\mathrm{a}}-\mathrm{F}_{\mathrm{b}}$ & $\mathrm{C}_{\mathrm{b}}-\mathrm{F}_{\mathrm{a}}$ & $\mathrm{C}_{\mathrm{b}}-\mathrm{F}_{\mathrm{b}}$ & $\mathrm{C}_{\mathrm{a}}-\mathrm{H}_{\mathrm{a}}$ & $\mathrm{C}_{\mathrm{a}}-\mathrm{H}_{\mathrm{b}}$ & $\mathrm{C}_{\mathrm{b}}-\mathrm{H}_{\mathrm{a}}$ & $\mathrm{C}_{\mathrm{b}}-\mathrm{H}_{\mathrm{b}}$ \\
\hline 1,1-difluoroethylene radical (2) & 1.31 & 1.34 & 1.33 & & & & & 1.08 & \\
trans-1,2-difluoroethylene radical (12) & 1.33 & 1.36 & & 1.31 & 1.08 & & & \\
cis-1,2-difluoroethylene radical (13) & 1.33 & 1.34 & & 1.32 & 1.09 & & \\
cis-monofluoroethylene radical (15) & 1.31 & 1.34 & & & 1.10 & & 1.08 \\
trans-monofluoroethylene radical (16) & 1.31 & 1.35 & & & 1.10 & & 1.08 \\
monofluoroethylene radical (7) & 1.32 & & & & & & & & \\
\hline \hline
\end{tabular}

\begin{tabular}{lccccc}
\hline \hline Product & $\mathrm{C}_{\mathrm{a}}-\mathrm{F}_{\mathrm{a}}$ & $\mathrm{C}_{\mathrm{a}}-\mathrm{F}_{\mathrm{b}}$ & $\mathrm{C}_{\mathrm{a}}-\mathrm{H}_{\mathrm{a}}$ & $\mathrm{C}_{\mathrm{a}}-\mathrm{H}_{\mathrm{b}}$ & $\mathrm{C}_{\mathrm{a}}-\mathrm{H}_{\mathrm{c}}$ \\
\hline $\mathrm{CF}_{2}(3)$ & 1.32 & 1.32 & & & \\
$\mathrm{CHF}(17)$ & 1.32 & & 1.14 & & \\
$\mathrm{CH}_{2}(8)$ & & & 1.13 & 1.13 & \\
Methyl radical (3) & & & 1.08 & 1.08 & 1.08 \\
Monofluoromethyl radical (17) & 1.34 & & 1.08 & 1.08 & \\
Difluoromethyl radical (8) & 1.33 & 1.33 & 1.08 & & \\
\hline \hline
\end{tabular}

\begin{tabular}{lll}
\hline \hline Product & H-F & H-H \\
\hline hydrogen fluoride & 0.92 & \\
hydrogen molecule & & 0.74 \\
\hline \hline
\end{tabular}

\begin{tabular}{|c|c|c|c|c|c|c|c|c|c|c|c|c|}
\hline Transition state & $\mathrm{C}_{\mathrm{a}}-\mathrm{C}_{\mathrm{b}}$ & $\mathrm{C}_{\mathrm{a}}-\mathrm{F}_{\mathrm{a}}$ & $\mathrm{C}_{\mathrm{a}}-\mathrm{F}_{\mathrm{b}}$ & $\mathrm{C}_{\mathrm{b}}-\mathrm{F}_{\mathrm{a}}$ & $\mathrm{C}_{\mathrm{b}}-\mathrm{F}_{\mathrm{b}}$ & $\mathrm{C}_{\mathrm{a}}-\mathrm{H}_{\mathrm{a}}$ & $\mathrm{C}_{\mathrm{a}}-\mathrm{H}_{\mathrm{b}}$ & $\mathrm{C}_{\mathrm{a}}-\mathrm{H}_{\mathrm{c}}$ & $\mathrm{C}_{\mathrm{b}}-\mathrm{H}_{\mathrm{a}}$ & $\mathrm{C}_{\mathrm{b}}-\mathrm{H}_{\mathrm{b}}$ & $\mathrm{C}_{\mathrm{b}}-\mathrm{H}_{\mathrm{c}}$ & $\mathrm{H}_{\mathrm{a}}-\mathrm{H}_{\mathrm{b}}$ \\
\hline TS H shift $(0$-> 4) & 1.47 & 1.35 & 1.35 & & & 1.31 & & & & 1.08 & 1.08 & \\
\hline TS F shift (4 -> 9) & 1.37 & 2.04 & & & 1.33 & 1.08 & 1.09 & & & & 1.08 & \\
\hline TS H dissociation $(0->1)$ & 1.33 & 1.33 & 1.33 & & & & & & 2.39 & 1.08 & 1.08 & \\
\hline TS H dissociation (4 -> 5) & 1.36 & 1.33 & 1.33 & & & 1.98 & & & & 1.08 & 1.08 & \\
\hline TS H dissociation $(9 \rightarrow 10)$ & 1.35 & 1.34 & & & 1.34 & 2.13 & 1.09 & & & & 1.09 & \\
\hline TS H dissociation (9 -> 11) & 1.35 & 1.34 & & & 1.34 & 2.16 & 1.09 & & & & 1.09 & \\
\hline TS H2 elimination ( 1 -> 2) & 1.32 & & & 1.34 & 1.33 & & 1.50 & 1.08 & & & & 0.84 \\
\hline TS H2 elimination (9 -> 13) & 1.33 & 1.33 & & & 1.34 & & 1.42 & & & & 1.09 & 0.89 \\
\hline TS H2 elimination (9 -> 12) & 1.33 & 1.32 & & & 1.35 & & 1.42 & & & & 1.09 & 0.89 \\
\hline TS HF elimination (4 -> 7) & 1.35 & 2.26 & 1.33 & & & 1.15 & & & & 1.09 & 1.08 & \\
\hline TS HF elimination (9 -> 15) & 1.34 & 2.27 & & & 1.34 & 1.09 & 1.19 & & & & 1.09 & \\
\hline TS HF elimination (9 -> 16) & 1.34 & 2.27 & & & 1.33 & 1.09 & 1.18 & & & & 1.09 & \\
\hline TS H shift a (9 -> 9) & 1.46 & 1.37 & & & 1.36 & 1.09 & 1.32 & & & & 1.10 & \\
\hline TS H shift b (9 -> 9) & 1.44 & 1.37 & & & 1.37 & 1.09 & & & & 1.34 & 1.09 & \\
\hline TS rotation $(0$-> 0$)$ & 1.50 & & & 1.35 & 1.35 & 1.10 & 1.10 & 1.10 & & & & \\
\hline TS rotation (4 -> 4) & 1.48 & 1.38 & 1.38 & & & 1.10 & & & & 1.08 & 1.09 & \\
\hline TS rotation a $(9->9)$ & 1.49 & 1.39 & & & 1.35 & 1.10 & 1.11 & & & & 1.09 & \\
\hline TS rotation $b(9->9)$ & 1.50 & 1.38 & & & 1.34 & 1.11 & 1.11 & & & & 1.09 & \\
\hline
\end{tabular}

\section{A.4) Angles}


Angles between selected atoms within all structures are listed in the tables below. The atom labeling refers to the images in Fig.1.

\begin{tabular}{|c|c|c|c|c|c|c|c|c|c|c|}
\hline Product & $\mathrm{F}_{\mathrm{a}}-\mathrm{C}_{\mathrm{a}}-\mathrm{F}_{\mathrm{b}}$ & $\mathrm{F}_{\mathrm{a}}-\mathrm{C}_{\mathrm{b}}-\mathrm{F}_{\mathrm{b}}$ & $\mathrm{C}_{\mathrm{a}}-\mathrm{C}_{\mathrm{b}}-\mathrm{F}_{\mathrm{a}}$ & $\mathrm{C}_{\mathrm{b}}-\mathrm{C}_{\mathrm{a}}-\mathrm{F}_{\mathrm{a}}$ & $\mathrm{C}_{\mathrm{a}}-\mathrm{C}_{\mathrm{b}}-\mathrm{H}_{\mathrm{a}}$ & $\mathrm{C}_{\mathrm{a}}-\mathrm{C}_{\mathrm{b}}-\mathrm{H}_{\mathrm{b}}$ & $\mathrm{C}_{\mathrm{a}}-\mathrm{C}_{\mathrm{b}}-\mathrm{H}_{\mathrm{c}}$ & $\mathrm{C}_{\mathrm{b}}-\mathrm{C}_{\mathrm{a}}-\mathrm{H}_{\mathrm{a}}$ & $\mathrm{C}_{\mathrm{b}}-\mathrm{C}_{\mathrm{a}}-\mathrm{H}_{\mathrm{b}}$ & $\mathrm{C}_{\mathrm{b}}-\mathrm{C}_{\mathrm{a}}-\mathrm{H}_{\mathrm{c}}$ \\
\hline 1,1-difluoroethyl radical (0) & & $109.94^{\circ}$ & $114.92^{\circ}$ & & & & & $111.23^{\circ}$ & $109.93^{\circ}$ & $109.93^{\circ}$ \\
\hline 1,1-difluoroethyl radical (4) & $108.11^{\circ}$ & & $110.44^{\circ}$ & & $119.62^{\circ}$ & $119.62^{\circ}$ & & $113.56^{\circ}$ & & \\
\hline 1,2-difluoroethyl radical a (9) & & $117.47^{\circ}$ & & $112.52^{\circ}$ & & & $124.45^{\circ}$ & $110.13^{\circ}$ & $109.43^{\circ}$ & \\
\hline 1,2-difluoroethyl radical b (9) & & $117.47^{\circ}$ & & $112.52^{\circ}$ & & & $124.45 \S$ & $109.43^{\circ}$ & $110.13^{\circ}$ & \\
\hline
\end{tabular}

\begin{tabular}{|c|c|c|c|c|c|c|c|c|}
\hline Product & $\mathrm{F}_{\mathrm{a}}-\mathrm{C}_{\mathrm{a}}-\mathrm{F}_{\mathrm{b}}$ & $\mathrm{C}_{\mathrm{a}}-\mathrm{C}_{\mathrm{b}}-\mathrm{F}_{\mathrm{a}}$ & $\mathrm{C}_{\mathrm{a}}-\mathrm{C}_{\mathrm{b}}-\mathrm{F}_{\mathrm{b}}$ & $\mathrm{C}_{\mathrm{b}}-\mathrm{C}_{\mathrm{a}}-\mathrm{F}_{\mathrm{a}}$ & $\mathrm{C}_{\mathrm{a}}-\mathrm{C}_{\mathrm{b}}-\mathrm{H}_{\mathrm{b}}$ & $\mathrm{C}_{\mathrm{a}}-\mathrm{C}_{\mathrm{b}}-\mathrm{H}_{\mathrm{c}}$ & $\mathrm{C}_{\mathrm{b}}-\mathrm{C}_{\mathrm{a}}-\mathrm{H}_{\mathrm{a}}$ & $\mathrm{C}_{\mathrm{b}}-\mathrm{C}_{\mathrm{a}}-\mathrm{H}_{\mathrm{b}}$ \\
\hline 1,1-difluoroethene (1) & $110.04^{\circ}$ & $124.98^{\circ}$ & & & & & $119.86^{\circ}$ & $119.86^{\circ}$ \\
\hline cis-1,2-difluoroethene (10) & & & $123.08^{\circ}$ & $123.08^{\circ}$ & $122.20^{\circ}$ & & $122.21^{\circ}$ & \\
\hline trans-1,2-difluoroethene (11) & & & $120.49^{\circ}$ & $120.49^{\circ}$ & $124.77^{\circ}$ & & $124.77^{\circ}$ & \\
\hline Monofluoroethene $(6,14)$ & & $122.72^{\circ}$ & & & & $125.33^{\circ}$ & $121.36^{\circ}$ & $119.41^{\circ}$ \\
\hline
\end{tabular}

\begin{tabular}{|c|c|c|c|c|c|c|c|c|c|}
\hline Structure & $\mathrm{F}_{\mathrm{a}}-\mathrm{C}_{\mathrm{a}}-\mathrm{F}_{\mathrm{b}}$ & $\mathrm{C}_{\mathrm{a}}-\mathrm{C}_{\mathrm{b}}-\mathrm{F}_{\mathrm{a}}$ & $\mathrm{C}_{\mathrm{a}}-\mathrm{C}_{\mathrm{b}}-\mathrm{F}_{\mathrm{b}}$ & $\mathrm{C}_{\mathrm{b}}-\mathrm{C}_{\mathrm{a}}-\mathrm{F}_{\mathrm{a}}$ & $\mathrm{C}_{\mathrm{a}}-\mathrm{C}_{\mathrm{b}}-\mathrm{H}_{\mathrm{a}}$ & $\mathrm{C}_{\mathrm{a}}-\mathrm{C}_{\mathrm{b}}-\mathrm{H}_{\mathrm{b}}$ & $\mathrm{C}_{\mathrm{a}}-\mathrm{H}_{\mathrm{a}}-\mathrm{F}_{\mathrm{a}}$ & $\mathrm{C}_{\mathrm{b}}-\mathrm{C}_{\mathrm{a}}-\mathrm{H}_{\mathrm{a}}$ & $\mathrm{C}_{\mathrm{b}}-\mathrm{C}_{\mathrm{a}}-\mathrm{H}_{\mathrm{b}}$ \\
\hline 1,1-difluoroethylene radical (2) & $109.85^{\circ}$ & & & $125.48^{\circ}$ & $140.45^{\circ}$ & & & & \\
\hline trans-1,2-difluoroethylene radical (12) & & & $131.22^{\circ}$ & $123.24^{\circ}$ & & & & $122.01^{\circ}$ & \\
\hline cis-1,2-difluoroethylene radical (13) & & & $127.67^{\circ}$ & & $123.92^{\circ}$ & & & $121.46^{\circ}$ & \\
\hline cis-monofluoroethylene radical (15) & & & & $125.48^{\circ}$ & & $140.45^{\circ}$ & & $124.67^{\circ}$ & \\
\hline trans-monofluoroethylene radical (16) & & & & $123.73^{\circ}$ & & $137.81^{\circ}$ & $111.78^{\circ}$ & & \\
\hline monofluoroethylene radical (7) & & $129.82^{\circ}$ & & & & & & $121.39^{\circ}$ & $119.76^{\circ}$ \\
\hline
\end{tabular}

\begin{tabular}{|c|c|c|c|c|c|}
\hline Structure & $\mathrm{H}_{\mathrm{a}}-\mathrm{C}_{\mathrm{a}}-\mathrm{H}_{\mathrm{b}}$ & $\mathrm{H}_{\mathrm{a}}-\mathrm{C}_{\mathrm{a}}-\mathrm{H}_{\mathrm{c}}$ & $\mathrm{H}_{\mathrm{a}}-\mathrm{C}_{\mathrm{a}}-\mathrm{F}_{\mathrm{a}}$ & $\mathrm{H}_{\mathrm{a}}-\mathrm{C}_{\mathrm{a}}-\mathrm{F}_{\mathrm{b}}$ & $\mathrm{F}_{\mathrm{a}}-\mathrm{C}_{\mathrm{a}}-\mathrm{F}_{\mathrm{b}}$ \\
\hline $\mathrm{CF}_{2}(3)$ & & & $104.03^{\circ}$ & & \\
\hline CHF (17) & $101.32^{\circ}$ & & & & \\
\hline $\mathrm{CH}_{2}(8)$ & $98.92^{\circ}$ & & & & \\
\hline Methyl radical (3) & $120.00^{\circ}$ & $120.00^{\circ}$ & & & \\
\hline Monofluoromethyl radical (17) & $114.28^{\circ}$ & & & $116.63^{\circ}$ & \\
\hline Difluoromethyl radical (8) & & & $110.67^{\circ}$ & & $115.80^{\circ}$ \\
\hline
\end{tabular}

\begin{tabular}{|c|c|c|c|c|c|c|c|c|c|c|c|c|c|}
\hline Transition state & $\begin{array}{c}\mathrm{H}_{\mathrm{a}^{-}-\mathrm{C}_{\mathrm{a}^{-}}} \\
\mathrm{H}_{\mathrm{b}}\end{array}$ & $\begin{array}{c}\mathrm{F}_{\mathrm{a}}-\mathrm{C}_{\mathrm{a}-}- \\
\mathrm{F}_{\mathrm{b}}\end{array}$ & $\begin{array}{c}\mathrm{C}_{\mathrm{a}^{-}}-\mathrm{C}_{\mathrm{b}^{-}} \\
\mathrm{F}_{\mathrm{a}}\end{array}$ & $\begin{array}{c}\mathrm{C}_{\mathrm{a}}-\mathrm{C}_{\mathrm{b}^{-}} \\
\mathrm{F}_{\mathrm{b}}\end{array}$ & $\begin{array}{c}\mathrm{C}_{\mathrm{b}-\mathrm{C}_{\mathrm{a}^{-}}} \\
\mathrm{F}_{\mathrm{a}}\end{array}$ & $\begin{array}{c}\mathrm{C}_{\mathrm{b}-\mathrm{C}_{\mathrm{a}^{-}}} \\
\mathrm{F}_{\mathrm{b}}\end{array}$ & $\begin{array}{c}\mathrm{C}_{\mathrm{a}}-\mathrm{C}_{\mathrm{b}^{-}} \\
\mathrm{H}_{\mathrm{a}}\end{array}$ & $\begin{array}{c}\mathrm{C}_{\mathrm{a}}-\mathrm{C}_{\mathrm{b}^{-}} \\
\mathrm{H}_{\mathrm{b}}\end{array}$ & $\begin{array}{c}\mathrm{C}_{\mathrm{a}}-\mathrm{C}_{\mathrm{b}^{-}} \\
\mathrm{H}_{\mathrm{c}}\end{array}$ & $\begin{array}{c}\mathrm{C}_{\mathrm{b}^{-}}-\mathrm{C}_{\mathrm{a}^{-}} \\
\mathrm{H}_{\mathrm{a}}\end{array}$ & $\begin{array}{c}\mathrm{C}_{\mathrm{b}}-\mathrm{C}_{\mathrm{a}}- \\
\mathrm{H}_{\mathrm{b}}\end{array}$ & $\begin{array}{c}\mathrm{C}_{\mathrm{b}}-\mathrm{C}_{\mathrm{a}}- \\
\mathrm{H}_{\mathrm{c}}\end{array}$ & $\begin{array}{c}\mathrm{H}_{\mathrm{a}}-\mathrm{C}_{\mathrm{a}^{-}} \\
\mathrm{F}_{\mathrm{a}}\end{array}$ \\
\hline TS H shift $(0->4)$ & & $\begin{array}{c}111.7 \\
\circ\end{array}$ & $117.7^{\circ}$ & & & & & $118.4^{\circ}$ & $118.4^{\circ}$ & & & & $120.9^{\circ}$ \\
\hline TS F shift (4 -> 9) & & & & $121.1^{\circ}$ & $73.2^{\circ}$ & & & & $125.3^{\circ}$ & $120.7^{\circ}$ & $119.9^{\circ}$ & & \\
\hline $\begin{array}{l}\text { TS H dissociation }(0- \\
>1)\end{array}$ & & $\begin{array}{c}110.3 \\
\circ\end{array}$ & & & $124.8^{\circ}$ & & $102.9^{\circ}$ & $119.8^{\circ}$ & $119.8^{\circ}$ & & & & \\
\hline $\begin{array}{l}\text { TS H dissociation (4 - } \\
>5 \text { ) }\end{array}$ & & $\begin{array}{c}111.1 \\
\circ\end{array}$ & & & $123.6^{\circ}$ & & & $119.2^{\circ}$ & $119.2^{\circ}$ & $92.9^{\circ}$ & & & \\
\hline $\begin{array}{l}\text { TS H dissociation (9- } \\
>10)\end{array}$ & & & & $122.4^{\circ}$ & $122.1^{\circ}$ & & & & $122.3^{\circ}$ & $98.3^{\circ}$ & $121.7^{\circ}$ & & \\
\hline $\begin{array}{l}\text { TS H dissociation (9- } \\
>11)\end{array}$ & & & & $120.2^{\circ}$ & $119.7^{\circ}$ & & & & $124.7^{\circ}$ & $98.3^{\circ}$ & $124.3^{\circ}$ & & \\
\hline $\begin{array}{l}\text { TS H2 elimination (1 } \\
->2)\end{array}$ & $178.6^{\circ}$ & $\begin{array}{c}109.9 \\
\circ\end{array}$ & $125.0^{\circ}$ & & & & & & & & $116.3^{\circ}$ & $130.3^{\circ}$ & \\
\hline $\begin{array}{l}\text { TS H2 elimination ( } 9 \\
->13)\end{array}$ & $178.4^{\circ}$ & & & $121.1^{\circ}$ & $124.5^{\circ}$ & & & & $124.3^{\circ}$ & & $121.3^{\circ}$ & & \\
\hline $\begin{array}{l}\text { TS H2 elimination ( } 9 \\
->12)\end{array}$ & $179.9^{\circ}$ & & & $123.3^{\circ}$ & $127.7^{\circ}$ & & & & $121.9^{\circ}$ & & $118.0^{\circ}$ & & \\
\hline $\begin{array}{l}\text { TS HF elimination (4 } \\
->7)\end{array}$ & & $\begin{array}{c}114.1 \\
\circ\end{array}$ & & & & $\begin{array}{c}123.32 \\
\circ\end{array}$ & & $\begin{array}{c}121 \\
5^{\circ}\end{array}$ & $118.7^{\circ}$ & $122.9^{\circ}$ & & & \\
\hline
\end{tabular}




\begin{tabular}{|c|c|c|c|c|c|c|c|c|c|c|c|}
\hline $\begin{array}{l}\text { TS HF elimination (9 } \\
->15)\end{array}$ & & & $122.4^{\circ}$ & $109.5^{\circ}$ & & & & $124.5^{\circ}$ & $125.8^{\circ}$ & $116.1^{\circ}$ & \\
\hline $\begin{array}{l}\text { TS HF elimination (9 } \\
->16)\end{array}$ & & & $123.1^{\circ}$ & $118.2^{\circ}$ & & & & $124.3^{\circ}$ & $122.2^{\circ}$ & $120.8^{\circ}$ & \\
\hline TS H shift a $(9->9)$ & & & $116.8^{\circ}$ & $122.0^{\circ}$ & & & & $125.9^{\circ}$ & $114.4^{\circ}$ & $57.3^{\circ}$ & \\
\hline TS H shift b (9 -> 9) & & & $122.1^{\circ}$ & $122.1^{\circ}$ & & & & $118.0^{\circ}$ & $118.0^{\circ}$ & $57.3^{\circ}$ & \\
\hline $\mathrm{TS}$ rotation $(0->0)$ & $\begin{array}{c}109.9 \\
\circ\end{array}$ & $115.5^{\circ}$ & & & & & & & $110.1^{\circ}$ & $111.4^{\circ}$ & $110.1^{\circ}$ \\
\hline TS rotation (4 -> 4) & $\begin{array}{c}106.6 \\
\circ\end{array}$ & & & & $\begin{array}{c}110.28 \\
\circ\end{array}$ & & $121.4^{\circ}$ & $\begin{array}{c}118 . \\
8^{\circ}\end{array}$ & $113.7^{\circ}$ & & \\
\hline TS rotation a (9 -> 9) & & & $115.6^{\circ}$ & $109.5^{\circ}$ & & & & $122.0^{\circ}$ & $112.6^{\circ}$ & $109.6^{\circ}$ & \\
\hline TS rotation $\mathrm{b}(9->9)$ & & & $116.9^{\circ}$ & $110.9^{\circ}$ & & $\begin{array}{c}110.67 \\
0\end{array}$ & & $122.5^{\circ}$ & & $111.1^{\circ}$ & \\
\hline
\end{tabular}

A.5) Dihedral angles:

\begin{tabular}{lcccccc}
\hline \hline Product & $\mathrm{C}_{\mathrm{a}}-\mathrm{C}_{\mathrm{b}}-\mathrm{F}_{\mathrm{a}}-\mathrm{F}_{\mathrm{b}}$ & $\mathrm{H}_{\mathrm{a}}-\mathrm{C}_{\mathrm{a}}-\mathrm{C}_{\mathrm{b}}-\mathrm{F}_{\mathrm{b}}$ & $\mathrm{H}_{\mathrm{b}}-\mathrm{C}_{\mathrm{a}}-\mathrm{C}_{\mathrm{b}}-\mathrm{F}_{\mathrm{b}}$ & $\mathrm{H}_{\mathrm{c}}-\mathrm{C}_{\mathrm{a}}-\mathrm{C}_{\mathrm{b}}-\mathrm{F}_{\mathrm{a}}$ & $\mathrm{H}_{\mathrm{c}}-\mathrm{C}_{\mathrm{a}}-\mathrm{C}_{\mathrm{b}}-\mathrm{F}_{\mathrm{b}}$ & $\mathrm{H}_{\mathrm{a}}-\mathrm{C}_{\mathrm{a}}-\mathrm{C}_{\mathrm{b}}-\mathrm{H}_{\mathrm{b}}$ \\
\hline 1,1-difluoroethyl radical (0) & $131.50^{\circ}$ & $-64.54^{\circ}$ & $175.43^{\circ}$ & & $55.49^{\circ}$ & \\
1,1-difluoroethyl radical (4) & $121.21^{\circ}$ & & $-155.16^{\circ}$ & & $35.08^{\circ}$ & $84.88^{\circ}$ \\
1,2-difluoroethyl radical a (9) & $81.21^{\circ}$ & $-39.03^{\circ}$ & $-159.13^{\circ}$ & & $-73.67^{\circ}$ & \\
1,2-difluoroethyl radical b (9) & $-81.21^{\circ}$ & $159.12^{\circ}$ & $39.03^{\circ}$ & $73.67^{\circ}$ & & \\
\hline \hline
\end{tabular}

\begin{tabular}{|c|c|c|c|c|c|c|}
\hline Product & $\mathrm{C}_{\mathrm{a}}-\mathrm{C}_{\mathrm{b}}-\mathrm{F}_{\mathrm{a}}-\mathrm{F}_{\mathrm{b}}$ & $\mathrm{H}_{\mathrm{a}}-\mathrm{C}_{\mathrm{a}}-\mathrm{C}_{\mathrm{b}}-\mathrm{F}_{\mathrm{a}}$ & $\mathrm{H}_{\mathrm{a}}-\mathrm{C}_{\mathrm{a}}-\mathrm{C}_{\mathrm{b}}-\mathrm{F}_{\mathrm{b}}$ & $\mathrm{H}_{\mathrm{b}}-\mathrm{C}_{\mathrm{a}}-\mathrm{C}_{\mathrm{b}}-\mathrm{F}_{\mathrm{a}}$ & $\mathrm{H}_{\mathrm{b}}-\mathrm{C}_{\mathrm{a}}-\mathrm{C}_{\mathrm{b}}-\mathrm{F}_{\mathrm{b}}$ & $\mathrm{H}_{\mathrm{c}}-\mathrm{C}_{\mathrm{a}}-\mathrm{C}_{\mathrm{b}}-\mathrm{F}_{\mathrm{a}}$ \\
\hline 1,1-difluoroethene (1) & $180.00^{\circ}$ & & $180.00^{\circ}$ & & $0.00^{\circ}$ & \\
\hline cis-1,2-difluoroethene (10) & $0.00^{\circ}$ & & $180.00^{\circ}$ & $180.00^{\circ}$ & & \\
\hline trans-1,2-difluoroethene (11) & $180.00^{\circ}$ & & $0.00^{\circ}$ & $0.00^{\circ}$ & & \\
\hline Monofluoroethene $(6,14)$ & & $0.00^{\circ}$ & & $180.00^{\circ}$ & & $180.00^{\circ}$ \\
\hline
\end{tabular}

\begin{tabular}{|c|c|c|c|c|c|}
\hline Product & $\mathrm{C}_{\mathrm{a}}-\mathrm{C}_{\mathrm{b}}-\mathrm{F}_{\mathrm{a}}-\mathrm{F}_{\mathrm{b}}$ & $\mathrm{H}_{\mathrm{a}}-\mathrm{C}_{\mathrm{a}}-\mathrm{C}_{\mathrm{b}}-\mathrm{F}_{\mathrm{a}}$ & $\mathrm{H}_{\mathrm{a}}-\mathrm{C}_{\mathrm{a}}-\mathrm{C}_{\mathrm{b}}-\mathrm{F}_{\mathrm{b}}$ & $\mathrm{H}_{\mathrm{b}}-\mathrm{C}_{\mathrm{a}}-\mathrm{C}_{\mathrm{b}}-\mathrm{F}_{\mathrm{a}}$ & $\mathrm{H}_{\mathrm{b}}-\mathrm{C}_{\mathrm{a}}-\mathrm{C}_{\mathrm{b}}-\mathrm{F}_{\mathrm{b}}$ \\
\hline $\mathrm{CF}_{2}(3)$ & $180.00^{\circ}$ & & $180.00^{\circ}$ & & \\
\hline CHF (17) & $0.00^{\circ}$ & $180.00^{\circ}$ & & & \\
\hline $\mathrm{CH}_{2}(8)$ & $180.00^{\circ}$ & & $0.00^{\circ}$ & & \\
\hline Methyl radical (3) & & $180.00^{\circ}$ & & $0.00^{\circ}$ & \\
\hline Monofluoromethyl radical (17) & & $180.00^{\circ}$ & & $180^{\circ}$ & \\
\hline Difluoromethyl radical (8) & & $0.00^{\circ}$ & & & $180.00^{\circ}$ \\
\hline
\end{tabular}

\begin{tabular}{lccc}
\hline \hline Structure & $\mathrm{H}_{\mathrm{a}}-\mathrm{C}_{\mathrm{a}}-\mathrm{H}_{\mathrm{b}}-\mathrm{H}_{\mathrm{c}}$ & $\mathrm{H}_{\mathrm{a}}-\mathrm{C}_{\mathrm{a}}-\mathrm{F}_{\mathrm{a}}-\mathrm{H}_{\mathrm{b}}$ & $\mathrm{H}_{\mathrm{a}}-\mathrm{C}_{\mathrm{a}}-\mathrm{F}_{\mathrm{b}}-\mathrm{F}_{\mathrm{b}}$ \\
\hline Methyl radical (3) & $180.00^{\circ}$ & & \\
Monofluoromethyl radical (17) & & $-140.93^{\circ}$ & \\
Difluoromethyl radical (8) & & & $-144.41^{\circ}$ \\
\hline \hline
\end{tabular}

\begin{tabular}{|c|c|c|c|c|c|c|c|c|c|c|}
\hline Transition state & $\begin{array}{l}\mathrm{C}_{\mathrm{a}-}-\mathrm{C}_{\mathrm{b}^{-}} \\
\mathrm{F}_{\mathrm{a}}-\mathrm{F}_{\mathrm{b}}\end{array}$ & $\begin{array}{c}\mathrm{H}_{\mathrm{a}-}-\mathrm{C}_{\mathrm{a}^{-}} \\
\mathrm{C}_{\mathrm{b}}-\mathrm{F}_{\mathrm{a}}\end{array}$ & $\begin{array}{l}\mathrm{H}_{\mathrm{a}-}-\mathrm{C}_{\mathrm{a}^{-}} \\
\mathrm{C}_{\mathrm{b}}-\mathrm{F}_{\mathrm{b}}\end{array}$ & $\begin{array}{c}\mathrm{H}_{\mathrm{b}-\mathrm{C}_{\mathrm{a}}} \\
\mathrm{C}_{\mathrm{b}}-\mathrm{F}_{\mathrm{a}}\end{array}$ & $\begin{array}{l}\mathrm{H}_{\mathrm{b}^{-}}-\mathrm{C}_{\mathrm{a}^{-}} \\
\mathrm{C}_{\mathrm{b}}-\mathrm{F}_{\mathrm{b}}\end{array}$ & $\begin{array}{c}\mathrm{H}_{\mathrm{c}^{-}} \mathrm{C}_{\mathrm{a}^{-}} \\
\mathrm{C}_{\mathrm{b}}-\mathrm{F}_{\mathrm{a}}\end{array}$ & $\begin{array}{c}\mathrm{H}_{\mathrm{c}^{-}} \mathrm{C}_{\mathrm{a}^{-}} \\
\mathrm{C}_{\mathrm{b}-\mathrm{F}_{\mathrm{b}}}\end{array}$ & $\begin{array}{c}\mathrm{C}_{\mathrm{a}}-\mathrm{F}_{\mathrm{a}}-\mathrm{F}_{\mathrm{b}^{-}} \\
\mathrm{H}_{\mathrm{a}}\end{array}$ & $\begin{array}{c}\mathrm{H}_{\mathrm{a}}-\mathrm{C}_{\mathrm{a}-\mathrm{C}_{\mathrm{b}^{-}}} \\
\mathrm{H}_{\mathrm{b}}\end{array}$ & $\begin{array}{c}\mathrm{H}_{\mathrm{a}}-\mathrm{C}_{\mathrm{a}}-\mathrm{C}_{\mathrm{b}}- \\
\mathrm{H}_{\mathrm{c}}\end{array}$ \\
\hline
\end{tabular}




\begin{tabular}{|c|c|c|c|c|c|c|c|c|c|}
\hline TS H shift $(0->4)$ & $140.71^{\circ}$ & & & $-151.08^{\circ}$ & & $12.72^{\circ}$ & $151.69^{\circ}$ & & \\
\hline TS F shift (4 -> 9) & $97.17^{\circ}$ & $1.44^{\circ}$ & & $-173.65^{\circ}$ & $-86.53^{\circ}$ & & & & \\
\hline $\begin{array}{l}\text { TS H dissociation }(0- \\
>1)\end{array}$ & $-178.88^{\circ}$ & $89.36^{\circ}$ & & $-178.09^{\circ}$ & & $-3.19^{\circ}$ & & & \\
\hline $\begin{array}{l}\text { TS H dissociation (4 - } \\
>5 \text { ) }\end{array}$ & $165.64^{\circ}$ & & & $-175.42^{\circ}$ & & $11.55^{\circ}$ & & $86.51^{\circ}$ & \\
\hline $\begin{array}{l}\text { TS H dissociation (9 - } \\
>10)\end{array}$ & $6.86^{\circ}$ & $-100.25^{\circ}$ & & $174.43^{\circ}$ & $-177.85^{\circ}$ & & & & \\
\hline $\begin{array}{l}\text { TS H dissociation (9 - } \\
>11)\end{array}$ & $176.93^{\circ}$ & $-76.97^{\circ}$ & & $8.27^{\circ}$ & $-6.43^{\circ}$ & & & & \\
\hline $\begin{array}{l}\text { TS H2 elimination ( } 1 \text { - } \\
>2)\end{array}$ & $-180.00^{\circ}$ & & & $0.00^{\circ}$ & & $-180.00^{\circ}$ & & $179.99^{\circ}$ & \\
\hline $\begin{array}{l}\text { TS H2 elimination }(9- \\
>13)\end{array}$ & $180.00^{\circ}$ & & & $0.00^{\circ}$ & $0.00^{\circ}$ & & & $-180.00^{\circ}$ & \\
\hline $\begin{array}{l}\text { TS H2 elimination }(9- \\
>12)\end{array}$ & $0.00^{\circ}$ & & & $180.00^{\circ}$ & $180.00^{\circ}$ & & & $180.00^{\circ}$ & \\
\hline $\begin{array}{l}\text { TS HF elimination }(4- \\
>7)\end{array}$ & $146.68^{\circ}$ & & & $-10.97^{\circ}$ & & $173.80^{\circ}$ & & $169.30^{\circ}$ & \\
\hline $\begin{array}{l}\text { TS HF elimination }(9- \\
>15)\end{array}$ & $-164.89^{\circ}$ & $-15.405^{\circ}$ & & $170.57^{\circ}$ & $18.37^{\circ}$ & & & & \\
\hline $\begin{array}{l}\text { TS HF elimination }(9- \\
>16)\end{array}$ & $23.19^{\circ}$ & $169.81^{\circ}$ & & $-5.35^{\circ}$ & $-161.83^{\circ}$ & & & & \\
\hline TS H shift a (9 -> 9) & $-37.95^{\circ}$ & $178.60^{\circ}$ & & $89.62^{\circ}$ & $116.09^{\circ}$ & & & & \\
\hline TS H shift b (9 -> 9) & $-114.68^{\circ}$ & $34.11^{\circ}$ & $122.66^{\circ}$ & & $34.11^{\circ}$ & & & & \\
\hline TS rotation $(0->0)$ & $132.82^{\circ}$ & $-125.28^{\circ}$ & & $114.93^{\circ}$ & & $-4.86^{\circ}$ & & & \\
\hline TS rotation (4 -> 4) & $119.69^{\circ}$ & & $-121.30^{\circ}$ & & $58.71^{\circ}$ & & & & $-180.00^{\circ}$ \\
\hline TS rotation a (9 -> 9) & $-150.91^{\circ}$ & $89.08^{\circ}$ & & $-30.31^{\circ}$ & $-2.49^{\circ}$ & & & & \\
\hline TS rotation b (9 -> 9) & $0.27^{\circ}$ & $-120.98^{\circ}$ & & $120.84^{\circ}$ & $151.42^{\circ}$ & & & & \\
\hline
\end{tabular}




\section{B) Absolute Energies}

Table 1: Absolute Energies of Products derived at the HCTH147/6-31G** and the CCSD(T)/cc-pVTZ levels of theory

\begin{tabular}{lcc}
\hline \hline Product & HCTH147/6-31G** & CCSD(T)/cc-pVTZ \\
\hline 1,1 -difluoroethyl radical (0) & -277.5539 & -277.2333 \\
1,1 -difluoroethene $(1,5)$ & -276.9846 & -276.6726 \\
1,1 -difluoroethenyl radical (2) & -276.2975 & -275.9889 \\
methyl radical (3) & -39.8169 & -39.7315 \\
$\mathrm{CF}_{2}$ (3) & -237.6419 & -237.4118 \\
1,1 -difluoroethyl radical (4) & -277.5432 & -277.2286 \\
monofluoroethene (6, 14) & -177.7615 & -177.5278 \\
monofluoroethenyl radical (7) & -177.0854 & -176.8527 \\
difluoromethyl radical (8) & -238.2496 & -238.0056 \\
CH 2 (8) & -39.1126 & -39.0451 \\
$1,2-$ difluoroethyl radical (9, rotamer a) & -277.5318 & -277.2145 \\
1,2 -difluoroethyl radical (9, rotamer b) & -277.5318 & -277.2145 \\
cis-1, 2-difluoroethene (10) & -276.9665 & -276.6562 \\
trans-1, 2-difluoroethene (11) & -276.9664 & -276.6556 \\
cis-1, 2-difluoroethenyl (12) & -276.2860 & -275.9758 \\
trans- 1,2 -difluoroethenyl radical (13) & -276.2858 & -275.9757 \\
cis-monofluoroethenyl radical (15) & -177.0777 & -176.8472 \\
trans-monofluoroethenyl radical (16) & -177.0778 & -176.8485 \\
monofluoromethyl radical (17) & -139.0253 & -138.8616 \\
CFH (17) & -138.3676 & -138.2165 \\
hydrogenfluoride (7, 15, 16) & -100.4053 & -100.3291 \\
hydrogen molecule (1, 5, 10,11) & -1.1781 & -1.1623 \\
fluorine atom (6, 14) & -99.6896 & -99.6204 \\
hydrogen atom (1, 5, 10, 11) & -0.5065 & -0.4998 \\
\hline \hline
\end{tabular}

Table 2: Absolute Energies of Transition States derived at the HCTH147/6-31G** and the CCSD(T)/cc-pVTZ levels of theory

\begin{tabular}{lll}
\hline \hline Transition state & HCTH147/6-31G** & CCSD(T)/cc-pVTZ \\
\hline TS H dissociation $(0->1)$ & -277.4865 & -277.1698 \\
TS H shift $(0->$ ) & -277.4783 & -277.1528 \\
TS H elimination $(1->$ 2) & -277.4699 & -277.1395 \\
TS H dissociation $(4->5)$ & -277.4798 & -277.1619 \\
TS HF elimination $(4->7)$ & -277.4790 & -277.1434 \\
TS F shift $(4->9)$ & -277.4940 & -277.1641 \\
TS H dissociation $(9->10)$ & -277.4658 & -277.1491 \\
TS H dissociation $(9->11)$ & -277.4657 & -277.1491 \\
TS HF elimination $(9->15)$ & -277.4771 & -277.1432 \\
TS HF elimination $(9->16)$ & -277.4759 & -277.1421 \\
TS H2 elimination $(10->12)$ & -277.4543 & -277.1233 \\
TS H2 elimination $(10->13)$ & -277.4551 & -277.1244 \\
TS rotation $(0->0)$ & -277.5507 & -277.2304 \\
TS rotation $(4->4)$ & -277.5427 & -277.2275 \\
TS H-shift a $(9->9)$ & -277.4663 & -277.1394 \\
TS H-shift b $(9->9)$ & -277.4576 & -277.1321 \\
TS rotation a $(9->9)$ & -277.5279 & -277.2115 \\
TS rotation b $(9->9)$ & -277.5236 & -277.2066 \\
\hline \hline
\end{tabular}




\section{C) Zero-point Energy (ZPE)}

Table 3: Zero-point Energies of products derived by frequency analysis using the HCTH147/6-31G** level of theory.

\begin{tabular}{ll}
\hline \hline Product & ZPE $[\mathrm{HF}]$ \\
\hline 1,1 -difluoroethyl radical (0) & 0.0462 \\
1,1 -difluoroethene $(1,5)$ & 0.0361 \\
1,1 -difluoroethenyl radical (2) & 0.0227 \\
methyl radical (3) & 0.0294 \\
$\mathrm{CF}_{2}(3)$ & 0.0067 \\
1,1 -difluoroethyl radical (4) & 0.0455 \\
monofluoroethene $(6,14)$ & 0.0430 \\
monofluoroethenyl radical (7) & 0.0300 \\
difluoromethyl radical (8) & 0.0186 \\
CH 2 (8) & 0.0157 \\
1,2 -difluoroethyl radical (9, rotamer a) & 0.0455 \\
1,2 -difluoroethyl radical (9, rotamer b) & 0.0455 \\
cis-1,2-difluoroethene (10) & 0.0360 \\
trans-1, 2-difluoroethene (11) & 0.0358 \\
cis-1,2-difluoroethenyl radical (12) & 0.0236 \\
trans- 1, 2 -difluoroethenyl radical (13) & 0.0232 \\
cis-monofluoroethenyl radical (15) & 0.0297 \\
trans-monofluoroethenyl radical (16) & 0.0294 \\
monofluoromethyl radical (17) & 0.0240 \\
CFH (17) & 0.0118 \\
hydrogenfluoride (7, 15, 16) & 0.0092 \\
hydrogen molecule (1, 5, 10, 11) & 0.0101 \\
\hline \hline
\end{tabular}

\begin{tabular}{lc}
\multicolumn{2}{l}{ Table 4: Zero-point Energies of transi } \\
\hline \hline Transition state & ZPE [HF] \\
\hline TS $(0->1)$ & 0.0366 \\
TS $(0->4)$ & 0.0400 \\
TS $(1->2)$ & 0.0340 \\
TS $(4->5)$ & 0.0371 \\
TS $(4->7)$ & 0.0411 \\
TS $(4->9)$ & 0.0439 \\
TS $(9->10)$ & 0.0373 \\
TS $(9->11)$ & 0.0370 \\
TS $(9->15)$ & 0.0414 \\
TS $(9->16)$ & 0.0413 \\
TS $(10->12)$ & 0.0354 \\
TS $(10->13)$ & 0.0351 \\
TS rotation $(0->0)$ & 0.0455 \\
TS rotation $(4->4)$ & 0.0446 \\
TS H-shift a $(9->9)$ & 0.0412 \\
TS H-shift b $(9->9)$ & 0.0408 \\
TS rotation $(9->9)$ & 0.0443 \\
TS rotation $(9->9)$ & 0.0445 \\
\hline \hline
\end{tabular}




\section{D) CCSD(T) optimized geometries and resulting energies}

Table 5: DFT-optimized structures CCSD(T)/cc-pVTZ single point energies relative to the 1,1-difluoroethyl radical compared to CCSD(T) optimized structures. Energies are in $\mathrm{kcal} / \mathrm{mol}$ and not corrected by zero-point energies.

\begin{tabular}{|c|c|c|c|}
\hline Product/ transition state & DFT-optimized [kcal/mol] & CC-optimized [kcal/mol] & Difference [kcal $/ \mathrm{mol}]$ \\
\hline 1,1-difluoroethyl radical (0) & 0.0000 & 0.0000 & 0.0000 \\
\hline 1,1-difluoroethene (1) & 44.4775 & 44.5844 & 0.1068 \\
\hline 1,1-difluoroethylene radical (2) & 59.9022 & 59.9641 & 0.0619 \\
\hline methyl radical \& CF2 (3) & 62.7805 & 62.5670 & -0.2135 \\
\hline $\mathrm{TS}$ roation $(0->0)$ & 2.2317 & 2.2573 & 0.0255 \\
\hline $\mathrm{TS} \mathrm{H}_{2}$ elimination $(1->2)$ & 21.9904 & 21.9132 & -0.0773 \\
\hline
\end{tabular}

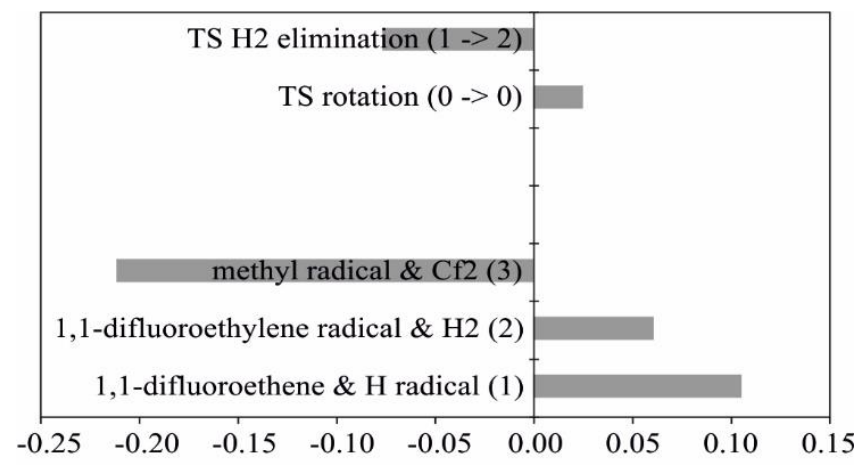

Difference in relative energies and activation energies [ $\mathrm{kcal} / \mathrm{mol}]$

FIG 1: Energy differences between DFT optimized structures CCSD(T)/cc-pVTZ single point energies and CC optimized structures relative to the 1,1-difluoroethyl radical in $\mathrm{kcal} / \mathrm{mol}$. 


\section{E) Excited States}

\section{E.1) Vertical Exciations}

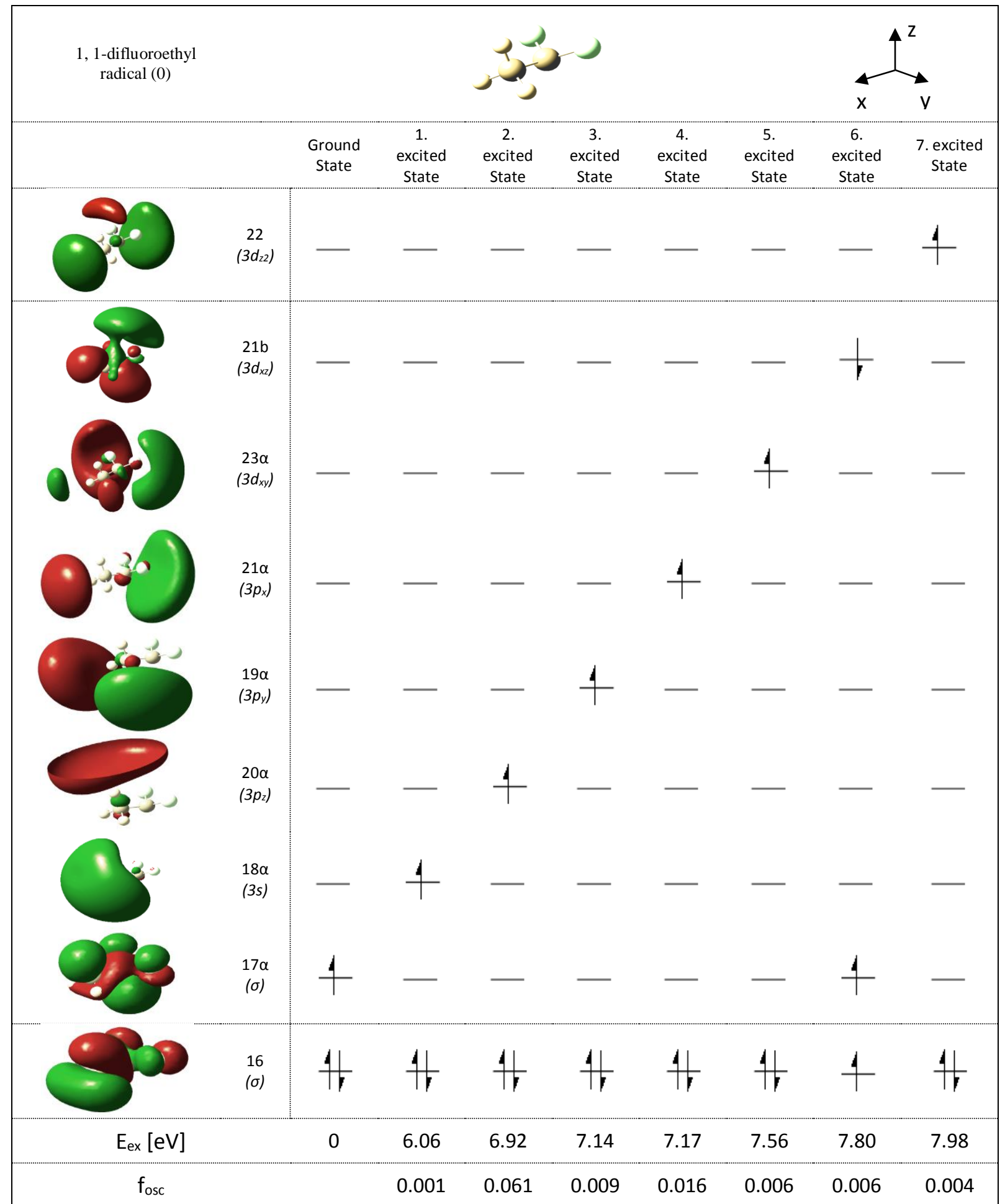

FIG 2: Electronic configurations of the ground state and the first seven excited states of S1. Excitations mainly take place from the $\sigma$-type SOMO to higher lying orbitals, which are Rydberg states at most. Shown are only orbital pictures which have main contributions to the actually mixed excited state. To excited state number four, also the $3 \mathrm{p}_{\mathrm{z}}$ Rydberg state in addition to the $3 \mathrm{p}_{\mathrm{x}}$ state has a large MO-coefficient. Excitation energies in electron volts as well as oscillator strength are given beyond the corresponding electronic configuration. The orbital numbering is arbitrarily chosen and characterization of orbitals is given wherever possible. 


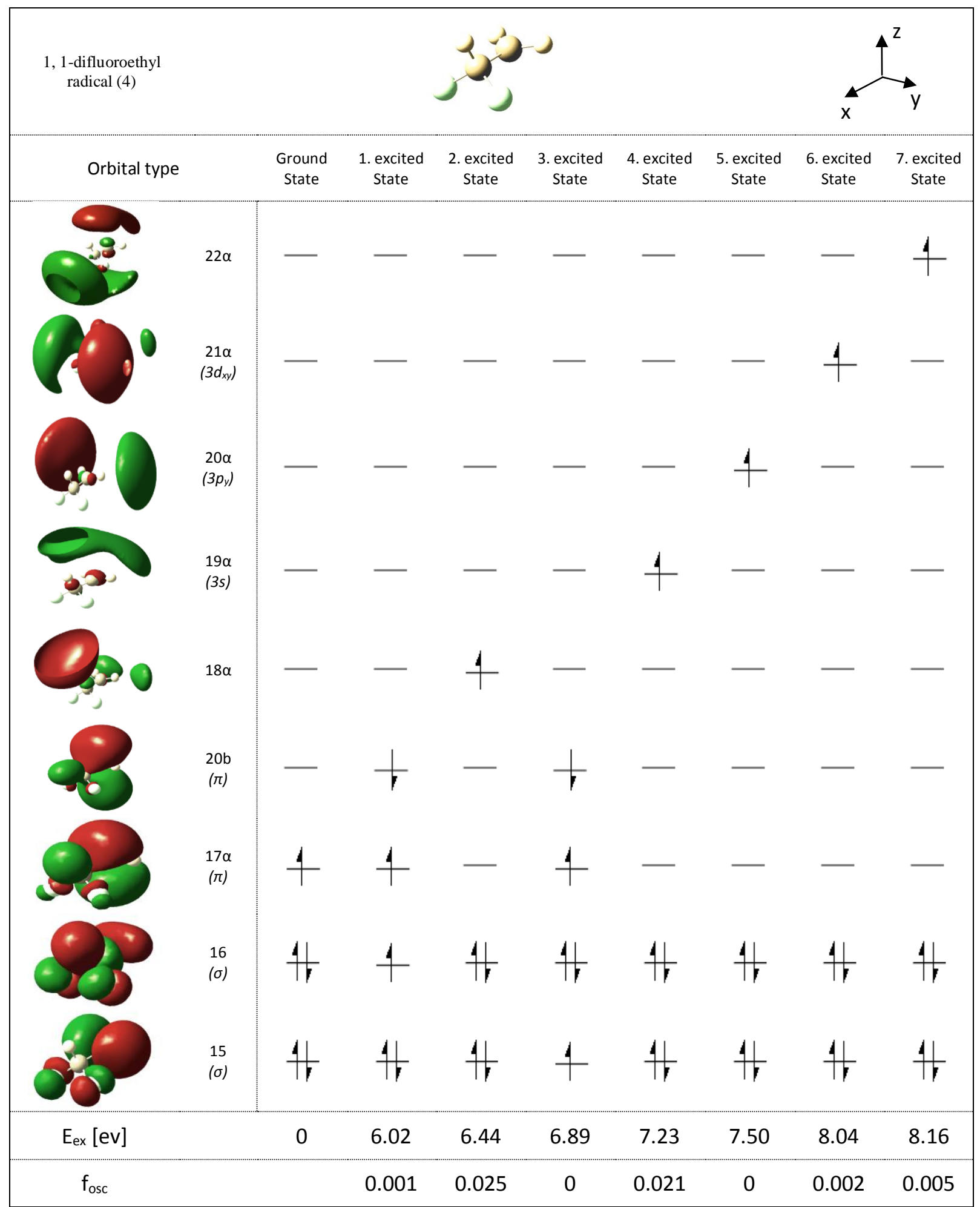

FIG 3: Electronic configurations of the ground state and the first seven excited states of S2. Excitations mainly take place from the $\sigma$-type SOMO to higher lying orbitals, which are Rydberg states at most. Shown are only orbital pictures which have main contributions to the actually mixed excited state. Excitation energies in electron volts as well as oscillator strength are given beyond the corresponding electronic configuration. The orbital numbering is arbitrarily chosen and characterization of orbitals is given wherever possible. 


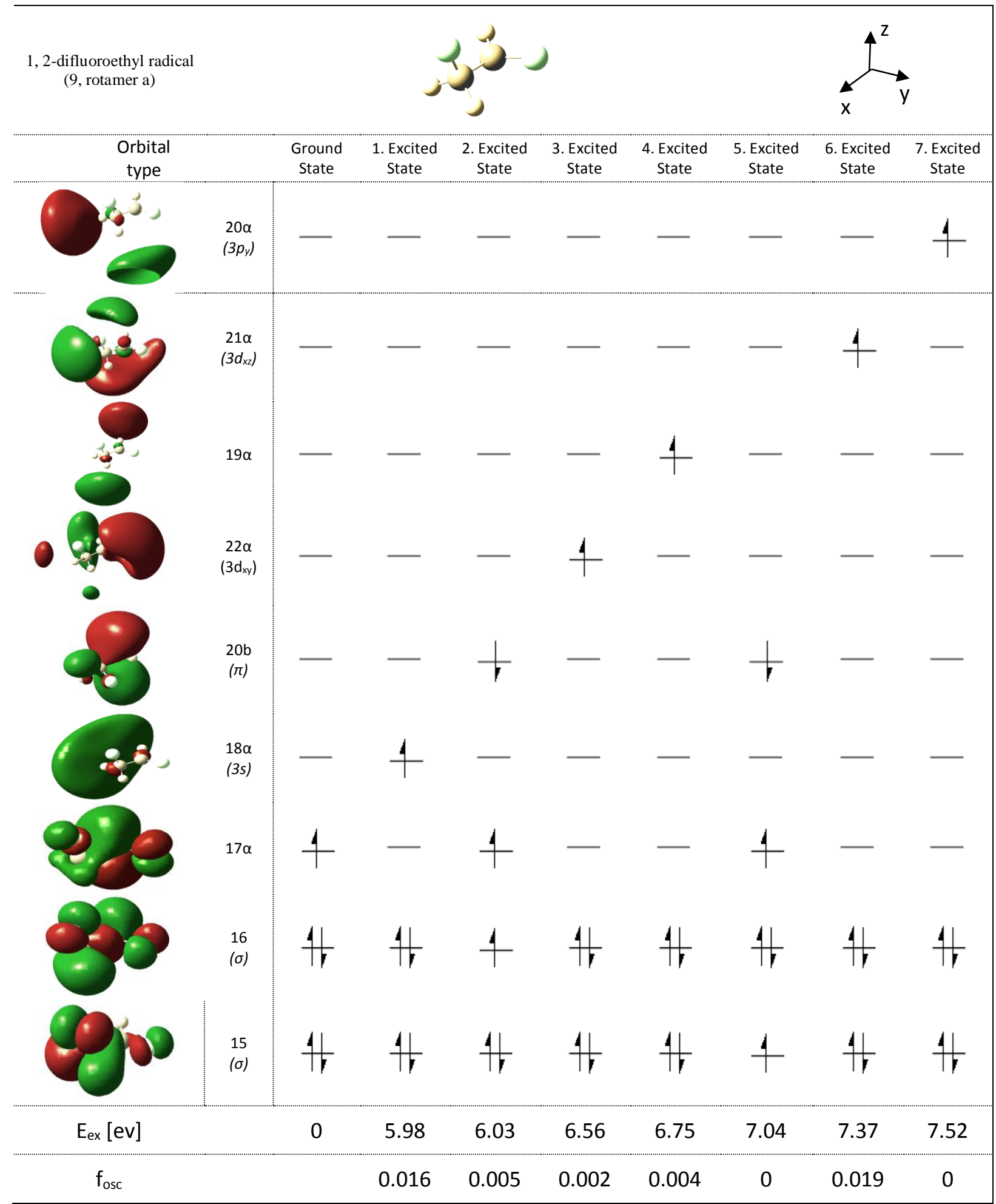

FIG 4: Electronic configurations of the ground state and the first seven excited states of S3a. Excitations mainly take place from the $\sigma$-type SOMO to higher lying orbitals, which are Rydberg states at most. Shown are only orbital pictures which have main contributions to the actually mixed excited state. Excitation energies in electron volts as well as oscillator strength are given beyond the corresponding electronic configuration. The orbital numbering is arbitrarily chosen and characterization of orbitals is given wherever possible. 


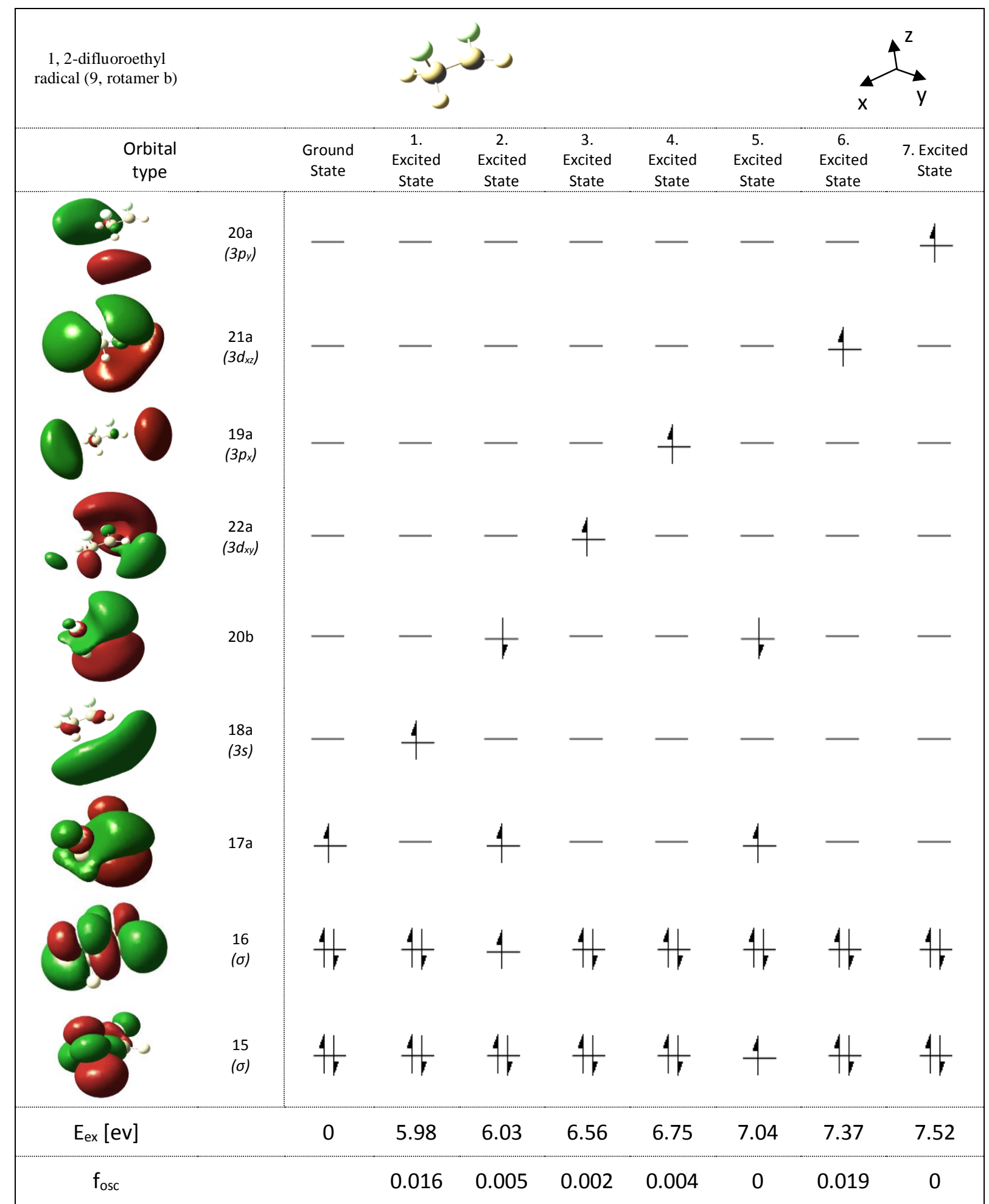

FIG 5: Electronic configurations of the ground state and the first seven excited states of S1. Excitations mainly take place from the $\sigma$-type SOMO to higher lying orbitals, which are Rydberg states at most. Shown are only orbital pictures which have main contributions to the actually mixed excited state. Excitation energies in electron volts as well as oscillator strength are given beyond the corresponding electronic configuration. The orbital numbering is arbitrarily chosen and characterization of orbitals is given wherever possible. 




FIG 6 Electronic configurations of the ground state and the first seven excited states of S1. Excitations mainly take place from the $\sigma$-type SOMO to higher lying orbitals, which are Rydberg states at most. Shown are only orbital pictures which have main contributions to the actually mixed excited state. Excitation energies in electron volts as well as oscillator strength are given beyond the corresponding electronic configuration. The orbital numbering is arbitrarily chosen and characterization of orbitals is given wherever possible. A $t$ indicates that the configuration corresponds to a triplet state. 


\section{E.2) Non-adiabatic excitations:}

Table 6: nonadiabatic extitation energies derived by structure optimization with EOMEE-CCSD/aug-cc-pVDZ

\begin{tabular}{lc}
\hline \hline Product & Excitation energy [eV] \\
\hline 1, 1-difluoroethyl radical (0) & 4.11 \\
1, 1 -difluoroethene (1) & 2.61 \\
1, 1-difluoroethyl radical (4) & 4.01 \\
1, 2-difluoroethyl radical (9, rotamer a) & 5.56 \\
1, 2-difluoroethyl radical (9, rotamer b) & 5.56 \\
\hline \hline
\end{tabular}

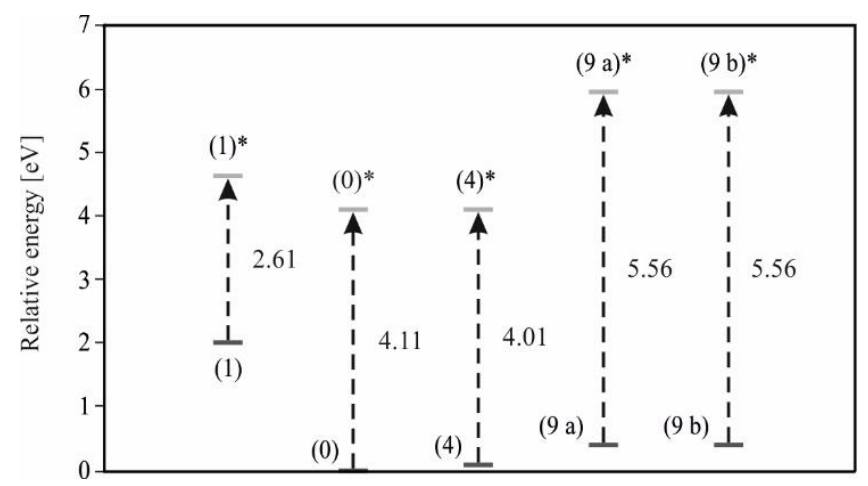

FIG 7: nonadiabatic excitation energy scheme

Geometries optimized in the first electronically excited state resemble much the ones of cationic structures. The following tables contain Cartesian coordinates of cationic and excited state structres.

\begin{tabular}{|c|c|c|c|}
\hline \multicolumn{4}{|c|}{ 1,1-difluoroethyl radical (0) cationic structure } \\
\hline \multirow[t]{2}{*}{ Atom } & \multicolumn{3}{|c|}{ Coordinates $[\AA]$} \\
\hline & $\mathrm{x}$ & $\mathrm{y}$ & $\mathrm{Z}$ \\
\hline $\mathrm{C}$ & -0.003154 & -1.393687 & 0.000000 \\
\hline $\mathrm{C}$ & -0.013344 & 0.052734 & 0.000000 \\
\hline $\mathrm{F}$ & -0.003154 & 0.740191 & 1.061538 \\
\hline $\mathrm{F}$ & -0.003154 & 0.740191 & -1.061538 \\
\hline $\mathrm{H}$ & 1.063134 & -1.702654 & 0.000000 \\
\hline $\mathrm{H}$ & -0.453692 & -1.787535 & 0.917264 \\
\hline $\mathrm{H}$ & -0.453692 & -1.787535 & -0.917264 \\
\hline \multicolumn{4}{|c|}{ 1, 1-difluoroethyl radical (0) excited state structure } \\
\hline \multirow[t]{2}{*}{ Atom } & \multicolumn{3}{|c|}{ Coordinates $[\AA]$} \\
\hline & $\mathrm{x}$ & $\mathrm{y}$ & $\mathrm{z}$ \\
\hline $\mathrm{C}$ & 1.506344 & 0.000055 & 0.008194 \\
\hline $\mathrm{C}$ & 0.046750 & 0.000005 & 0.002811 \\
\hline F & -0.635726 & -1.073292 & 0.000585 \\
\hline $\mathrm{F}$ & -0.635812 & 1.073247 & 0.000585 \\
\hline $\mathrm{H}$ & 1.733455 & -0.000143 & -1.098420 \\
\hline $\mathrm{H}$ & 1.871869 & 0.932755 & 0.472509 \\
\hline $\mathrm{H}$ & 1.871897 & -0.932487 & 0.472825 \\
\hline
\end{tabular}

\begin{tabular}{|c|c|c|c|}
\hline \multicolumn{4}{|c|}{ 1,1-difluoroethyl radical (4) excited state structure } \\
\hline \multirow[t]{2}{*}{ Atom } & \multicolumn{3}{|c|}{ Coordinates $[\AA]$} \\
\hline & $x$ & $\mathrm{y}$ & $\mathrm{Z}$ \\
\hline $\mathrm{C}$ & 0.046750 & -0.000005 & 0.002811 \\
\hline $\mathrm{C}$ & 1.506344 & -0.000054 & 0.008194 \\
\hline $\mathrm{F}$ & -0.635727 & 1.073291 & 0.000585 \\
\hline $\mathrm{F}$ & -0.635812 & -1.073248 & 0.000585 \\
\hline $\mathrm{H}$ & 1.871896 & 0.932488 & 0.472824 \\
\hline $\mathrm{H}$ & 1.871869 & -0.932754 & 0.472824 \\
\hline $\mathrm{H}$ & 1.733455 & 0.000143 & -1.098420 \\
\hline
\end{tabular}




\begin{tabular}{|c|c|c|c|}
\hline \multirow[t]{2}{*}{ Atom } & \multicolumn{3}{|c|}{ Coordinates $[\AA]$} \\
\hline & $\mathrm{x}$ & $\mathrm{y}$ & $\mathrm{z}$ \\
\hline $\mathrm{C}$ & -0.737773 & -0.782314 & 0.162880 \\
\hline $\mathrm{C}$ & 0.453099 & -0.204932 & -0.487253 \\
\hline $\mathrm{F}$ & 1.438124 & 0.168711 & 0.212444 \\
\hline $\mathrm{F}$ & -1.178853 & 0.585216 & 0.033612 \\
\hline $\mathrm{H}$ & -0.636818 & -1.054713 & 1.216196 \\
\hline $\mathrm{H}$ & 0.499151 & 0.045752 & -1.553422 \\
\hline $\mathrm{H}$ & -1.360263 & -1.448269 & -0.438892 \\
\hline \multicolumn{4}{|c|}{ 1, 2-difluoroethyl radical (9 b) cationic structure } \\
\hline \multirow[t]{2}{*}{ Atom } & \multicolumn{3}{|c|}{ Coordinates $[\AA]$} \\
\hline & $\mathrm{x}$ & $\mathrm{y}$ & $\mathrm{z}$ \\
\hline $\mathrm{C}$ & -0.737773 & -0.782313 & -0.162880 \\
\hline $\mathrm{C}$ & 0.453099 & -0.204932 & 0.487253 \\
\hline $\mathrm{F}$ & -1.178852 & 0.585216 & -0.033612 \\
\hline $\mathrm{F}$ & 1.438124 & 0.168710 & -0.212444 \\
\hline $\mathrm{H}$ & -1.360264 & -1.448268 & 0.438892 \\
\hline $\mathrm{H}$ & 0.499151 & 0.045752 & 1.553422 \\
\hline $\mathrm{H}$ & -0.636819 & -1.054712 & -1.216196 \\
\hline \multicolumn{4}{|c|}{ 1, 1-difluoroethene radical (1) triplet state structure } \\
\hline \multirow[t]{2}{*}{ Atom } & \multicolumn{3}{|c|}{ Coordinates $[\AA ̊]$} \\
\hline & $\mathrm{x}$ & $\mathrm{y}$ & $\mathrm{z}$ \\
\hline $\mathrm{C}$ & -0.375760 & -0.269862 & 0.280609 \\
\hline $\mathrm{C}$ & 0.818238 & 0.542735 & 0.065050 \\
\hline $\mathrm{F}$ & -0.297398 & -1.548265 & -0.153187 \\
\hline $\mathrm{F}$ & -1.536258 & 0.272062 & -0.153204 \\
\hline $\mathrm{H}$ & 1.386148 & 0.929225 & 0.906131 \\
\hline $\mathrm{H}$ & 1.161020 & 0.776017 & -0.945380 \\
\hline
\end{tabular}

\section{F) Augmented basis set calculations}

Structures containing fluorine atoms should be treated in calculations with additional polarization functions in the basis set. We do calculations with augmented basis sets and compare the results with the ones of non-augmented basis set calculations.

Table 7: Comparison between relative energies of products based on HCTH147/6-31G** and the augmented basis set method HCTH147/6$31++\mathrm{G}^{* *}$ with 1,1-difluoroethyl radical as reference.

\begin{tabular}{lcc}
\hline \hline Product & $\begin{array}{c}\text { Relative energy }[\mathrm{kcal} / \mathrm{mol}] \\
\text { HCTH147/6-31G** }\end{array}$ & $\begin{array}{c}\text { Relative enery [kcal/mol] } \\
\text { HCTH147/6-31++G** }\end{array}$ \\
\hline (0) & 0 & 0 \\
$(4)$ & 6.67 & 5.08 \\
$(9 \mathrm{a})$ & 13.81 & 10.59 \\
$(9 \mathrm{~b})$ & 13.81 & 10.59 \\
$(1)$ & 39.38 & 39.73 \\
$(5)$ & 39.38 & 39.73 \\
$(10)$ & 50.75 & 48.65 \\
$(11)$ & 50.77 & 49.29 \\
$(2)$ & 49.08 & 49.74 \\
$(12)$ & 56.29 & 56.04 \\
$(13)$ & 56.42 & 56.85 \\
$(6)$ & 64.50 & 59.85 \\
$(14)$ & 64.50 & 59.85 \\
$(7)$ & 39.62 & 30.26 \\
$(15)$ & 44.44 & 34.68 \\
$(16)$ & 44.40 & 34.03 \\
$(3)$ & 59.58 & 58.16 \\
$(8)$ & 120.16 & 119.68 \\
$(17)$ & 100.94 & 98.93 \\
\hline \hline
\end{tabular}

Table 8: Comparison between relative energies of transition states based on HCTH147/6-31G** and the augmented basis set method HCTH147/6-31++G** with 1,1-difluoroethyl radical as reference.

\begin{tabular}{lcc}
\hline \hline Product & $\begin{array}{c}\text { Relative energy [kcal/mol] } \\
\text { HCTH147/6-31G** }\end{array}$ & $\begin{array}{c}\text { Relative enery [kcal/mol] } \\
\text { HCTH147/6-31++G** }\end{array}$ \\
\hline TS $(0->4)$ & 47.39 & 46.10 \\
TS $(4->9$ a) & 37.55 & 30.38 \\
TS $(0->1)$ & 42.23 & 43.17 \\
\hline \hline
\end{tabular}




\begin{tabular}{lcc}
\hline \hline TS $(4->5)$ & 46.46 & 47.28 \\
TS $(9->10)$ & 55.23 & 47.39 \\
TS $(9->11)$ & 55.31 & 56.74 \\
TS $(1->2)$ & 52.64 & 53.76 \\
TS $(10->12)$ & 61.93 & 61.21 \\
TS $(10->13)$ & 62.41 & 62.40 \\
TS $(4->7)$ & 46.92 & 41.60 \\
TS $(9->15)$ & 48.11 & 42.19 \\
TS $(9->16)$ & 48.87 & 43.29 \\
TS H-shift a $(9->9)$ & 60.35 & 52.00 \\
TS H-shift b $(9->9)$ & 54.89 & 57.45 \\
TS rotation $(0->0)$ & 1.96 & 1.68 \\
TS rotation $(4->4)$ & 7.03 & 5.11 \\
TS rotation $(9->9)$ & 16.28 & 13.59 \\
TS rotation $(9->9)$ & 18.99 & 16.91 \\
\hline \hline
\end{tabular}

Table 9: Comparison between relative energies of products based on CCSD(T)/cc-pVTZ and the augmented basis set method CCSD(T)/augcc-pVTZ with 1,1-difluoroethyl radical as reference.

\begin{tabular}{lcc}
\hline Product & $\begin{array}{c}\text { Relative enery [kcal/mol] } \\
\text { CCSD(T)/cc-pVTZ }\end{array}$ & $\begin{array}{c}\text { Relative enery [kcal/mol] } \\
\text { CCSD(T)/aug-cc-pVTZ }\end{array}$ \\
\hline$(0)$ & 0 & 0 \\
$(4)$ & 2.91 & 2.78 \\
$(9 \mathrm{a})$ & 11.74 & 11.06 \\
$(9 \mathrm{~b})$ & 11.74 & 11.06 \\
$(1)$ & 38.16 & 39.51 \\
$(5)$ & 38.16 & 39.51 \\
$(10)$ & 48.45 & 47.02 \\
$(11)$ & 48.80 & 49.57 \\
$(2)$ & 51.43 & 52.66 \\
$(12)$ & 59.67 & 60.61 \\
$(13)$ & 59.71 & 61.16 \\
$(6)$ & 53.40 & 54.94 \\
$(14)$ & 53.40 & 54.94 \\
$(7)$ & 32.30 & 31.95 \\
$(15)$ & 35.74 & 35.08 \\
$(16)$ & 34.96 & 34.13 \\
$(3)$ & 56.43 & 57.72 \\
$(8)$ & 114.43 & 114.69 \\
$(17)$ & 97.35 & 97.75 \\
\hline \hline
\end{tabular}

Table 10: Comparison between relative energies of transition states based on CCSD(T)/cc-pVTZ and the augmented basis set method CCSD(T)/aug-cc-pVTZ with 1,1-difluoroethyl radical as reference.

\begin{tabular}{|c|c|c|}
\hline Product & $\begin{array}{l}\text { Relative enery }[\mathrm{kcal} / \mathrm{mol}] \\
\text { CCSD }(\mathrm{T}) / \mathrm{cc}-\mathrm{pVTZ}\end{array}$ & $\begin{array}{l}\text { Relative enery [kcal/mol] } \\
\text { CCSD(T)/aug-cc-pVTZ }\end{array}$ \\
\hline$(0->4)$ & 50.45 & 50.11 \\
\hline$(4->9 a)$ & 43.34 & 40.42 \\
\hline $\mathrm{TS}(0->1)$ & 39.98 & 40.73 \\
\hline $\mathrm{TS}(4->5)$ & 44.74 & 45.40 \\
\hline TS $(9->10)$ & 52.77 & 45.51 \\
\hline $\mathrm{TS}(9->11)$ & 52.81 & 56.59 \\
\hline $\mathrm{TS}(1->2)$ & 58.77 & 59.74 \\
\hline $\mathrm{TS}(10->12)$ & 68.29 & 68.41 \\
\hline TS $(10->13)$ & 68.96 & 69.57 \\
\hline TS (4 -> 7) & 56.33 & 55.96 \\
\hline TS $(9->15)$ & 56.48 & 55.76 \\
\hline TS $(9->16)$ & 57.16 & 56.56 \\
\hline TS H-shift a (9 -> 9) & 63.41 & 57.99 \\
\hline TS H-shift b (9 -> 9) & 58.89 & 62.60 \\
\hline $\mathrm{TS}$ rotation $(0->0)$ & 1.78 & 1.79 \\
\hline $\mathrm{TS}$ rotation $(4->4)$ & 3.62 & 3.35 \\
\hline TS rotation $(9$-> 9) & 13.67 & 13.15 \\
\hline TS rotation (9 -> 9) & 16.70 & 16.21 \\
\hline
\end{tabular}




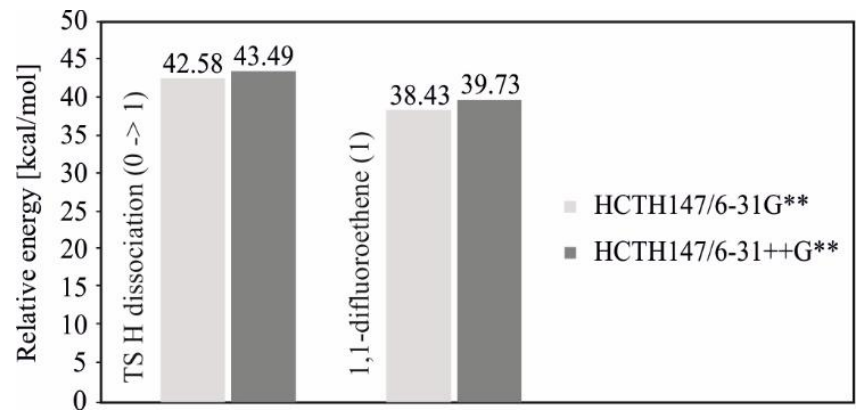

FIG 8: Comparison of energies of transition state and product of the $\mathrm{H}$ dissociation reaction channel outgoing from 1,1-difluoroethyl radical relative to the 1,1-difluoroethyl radical energy based on the HCTH/6-31G** to augmented basis set HCTH/6-31++G**.

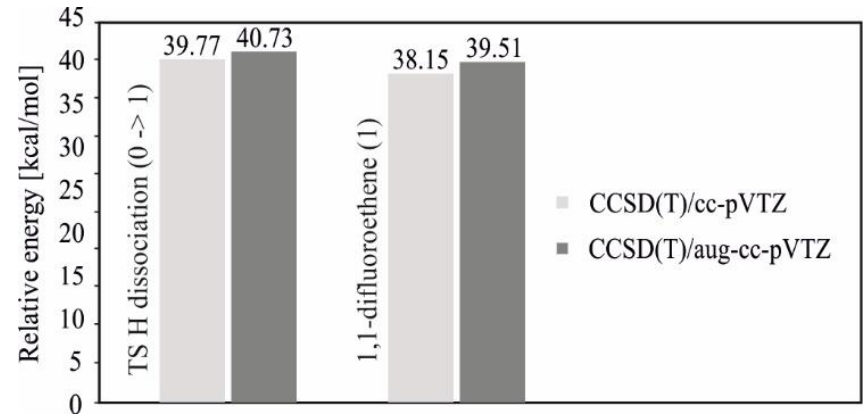

FIG 9: Comparison of energies of transition state and product of the $\mathrm{H}$ dissociation reaction channel outgoing from 1,1-difluoroethyl radical relative to the 1,1-difluoroethyl radical energy based on the $\mathrm{HCTH} / 6-31 \mathrm{G}^{* *}$ to augmented basis set $\mathrm{HCTH} / 6-31++\mathrm{G}^{* * *}$.

\section{G) CCSD(T)/ cc-pVTZ-F12 calculations}

Table 11: Comparison between relative energies of products based on CCSD(T)/cc-pVTZ and CCSD(T)/ cc-pVTZ-F12 with 1,1difluoroethyl radical as reference.

\begin{tabular}{lcc}
\hline \hline Product & $\begin{array}{c}\text { Relative energy }[\mathrm{kcal} / \mathrm{mol}] \\
\text { CCSD(T)/cc-pVTZ }\end{array}$ & $\begin{array}{c}\text { Relative enery }[\mathrm{kcal} / \mathrm{mol}] \\
\text { CCSD(T)/cc-pVTZ-F12 }\end{array}$ \\
\hline$(0)$ & 0 & 0 \\
$(1)$ & 38.2 & 38.9 \\
$(3)$ & 56.4 & 58.2 \\
$(4)$ & 2.9 & 2.9 \\
\hline \hline
\end{tabular}

Table 12: Comparison between relative energies of transition states based on CCSD(T)/cc-pVTZ abd CCSD(T)/ cc-pVTZ-F12 with 1,1difluoroethyl radical as reference.

\begin{tabular}{lcc}
\hline \hline Product & $\begin{array}{c}\text { Relative energy [kcal/mol] } \\
\text { CCSD(T)/cc-pVTZ }\end{array}$ & $\begin{array}{c}\text { Relative enery [kcal/mol] } \\
\text { CCSD(T)/cc-pVTZ-F12 }\end{array}$ \\
\hline TS $(0->1)$ & 39.8 & 40.0 \\
TS $(0->4)$ & 50.4 & 49.8 \\
\hline \hline
\end{tabular}

